Florida International University FIU Digital Commons

$2-10-2017$

\title{
Policymaking in the Gulf Region: The Case of Privatization Policy in the State of Kuwait
}

Shahed Altammar

salta005@fiu.edu

DOI: $10.25148 /$ etd.FIDC001802

Follow this and additional works at: https://digitalcommons.fiu.edu/etd

Part of the Public Affairs Commons

\section{Recommended Citation}

Altammar, Shahed, "Policymaking in the Gulf Region: The Case of Privatization Policy in the State of Kuwait" (2017). FIU Electronic Theses and Dissertations. 3174.

https://digitalcommons.fiu.edu/etd/3174

This work is brought to you for free and open access by the University Graduate School at FIU Digital Commons. It has been accepted for inclusion in FIU Electronic Theses and Dissertations by an authorized administrator of FIU Digital Commons. For more information, please contact dcc@fiu.edu. 


\section{FLORIDA INTERNATIONAL UNIVERSITY}

Miami, Florida

POLICYMAKING IN THE GULF REGION:

THE CASE OF PRIVATIZATION POLICY

IN THE STATE OF KUWAIT

A dissertation submitted in partial fulfillment of

the requirements for the degree of

DOCTOR OF PHILOSOPHY

in

PUBLIC AFFAIRS

by

Shahed J. Altammar

2017 
To: Dean John F. Stack, Jr.

Steven J. Green School of International and Public Affairs

This dissertation, written by Shahed J. Altammar, and entitled Policymaking in the Gulf Region: The Case of Privatization Policy in the State of Kuwait, having been approved in respect to style and intellectual content, is referred to you for judgment.

We have read this dissertation and recommend that it be approved.

Milena Neshkova

Mohamad Alkadry

Michael Maunder

Meredith Newman, Major Professor

Date of Defense: February 10, 2017

The dissertation of Shahed J. Altammar is approved.

Dean John F. Stack, Jr.

Steven J. Green School of International and Public Affairs

Andrés G. Gil

Vice President for Research and Economic Development and Dean of the University Graduate School

Florida International University, 2017 
C) Copyright 2017 by Shahed J. Altammar

All rights reserved. 


\section{DEDICATION}

To my parents, your strength and wisdom in life have instilled within me the value of learning. My siblings, your support is my motivation. To everyone that has dedicated their life to creating peaceful nations through education. To students of the world, the self-thinkers in pursuit of knowledge and social development.

"Education is our passport to the future, for tomorrow belongs to the people who prepare for it today."

- Malcolm X 


\section{ACKNOWLEDGMENTS}

First, I wish to thank my committee members. Dr. Milena Neshkova, Dr. Mohamad Alkadry, and Dr. Mike Maunder. Your guidance has been invaluable to developing the scholars and educators of today. I wish to thank our former and current program directors; your support of our pursuits must be credited. I extend my thanks to each faculty member that I had the honor to work with.

Dr. Mark Rosenberg, our President that is "Worlds Ahead". Thank you for sharing the gift of knowledge. I also wish to thank the deans, administrators, and staff members at the University Graduate School, the School of International and Public Affairs, and the Department of Public Administration. Thank you for creating an academic community that is dynamic, worldly, and authentic - as all education should be.

This research was possible through the support of all sectors and institutions in Kuwait and international organizations in Europe. Thank you to all individuals that have contributed to this research journey during data collection trips and in communications thereafter. The research participants have especially enriched this dissertation.

My final thank you is for my dissertation chair. Dr. Meredith Newman, merci pour tout ce que t'as fais pour moi. 


\begin{abstract}
OF THE DISSERTATION
POLICYMAKING IN THE GULF REGION:

THE CASE OF PRIVATIZATION POLICY
\end{abstract}

IN THE STATE OF KUWAIT

by

Shahed J. Altammar

Florida International University, 2017

Miami, Florida

Professor Meredith Newman, Major Professor

The purpose of this research is to explore the policy processes in Kuwait by examining the recent privatization legislation, which has been adopted but not yet implemented. First, the research reports data from elite interviews, focus groups, and document reviews about policymaking, to illuminate the processes that lead up to the adoption of privatization. Limited data of this nature currently exist. Second, it is anticipated that findings reported in this study will be of theoretical relevance to scholars of comparative politics and particularly to privatization theorists.

The research contributes to a better understanding of the differences in policymaking processes between consolidated democracies of Western countries and transitional democracies of Gulf countries, with a particular focus on Kuwait. Data analyzed depict Kuwait in its struggle to become part of an internationally diversified economy. While the government is still centralized in its operations, there is a push towards greater openness and inclusiveness in the political process. 
The research draws on the interpretivist and social constructivist paradigms, and employs the use of a phenomenological data analysis method. Ministers, directors of public agencies, and private sector executives were interviewed, as well as leaders of nonprofits and representatives of international organizations. Essentially, the study attempted to include all participants in the privatization policy development.

The research shows that Kuwait's economy is the least diversified in the Gulf region, with a great dependency on hydrocarbon revenues. Results indicate that fluctuating oil prices, economic stagnation, and declining citizen satisfaction, drove privatization discussions at different points in time. Although the privatization legislation was enacted in 2010 via Law 37, the government is still struggling with implementation across the public sector. Data analysis of the reasons behind the lack of implementation reveals that limitations in the legal framework, lack of private sector incentives, capacity issues, national workforce concerns, inadequate infrastructure, and the lack of evaluation and management criteria are drastically hindering the policy implementation process in Kuwait. 


\section{TABLE OF CONTENTS}

CHAPTER

PAGE

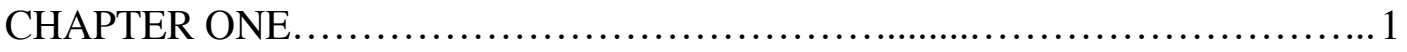

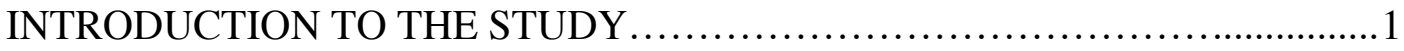

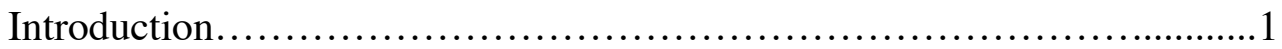

Background to the Study............................................2

Statement of the Problem............................................... 4

Purpose of the Study...................................................... 6

Conceptual Framework.................................................. 8

Research Questions....................................................... 10

Significance of the Study ............................................... 11

Research Design.....................................................13

Research Limitations..................................................... 15

Definition of Key Terms.............................................. 16

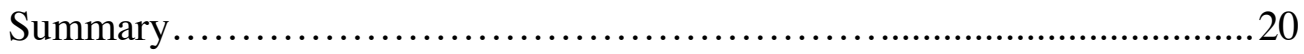

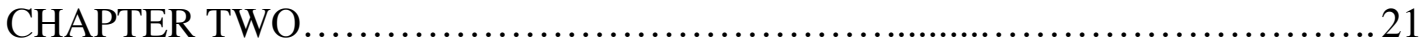

LITERATURE REVIEW ............................................... 21

Introduction...................................................... 21

Policy Development in Theory....................................... 21

The Contexts of Policymaking....................................... 21

Theoretical Frameworks.................................................. 25

Policymaking in the Gulf Region........................................ 35

Case Study: Kuwait..........................................................40

Privatization: Theory and Practice.........................................46

Role of International Organizations .............................................

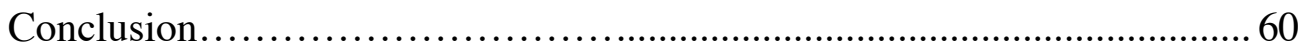

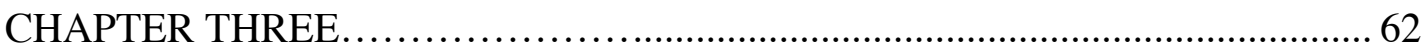

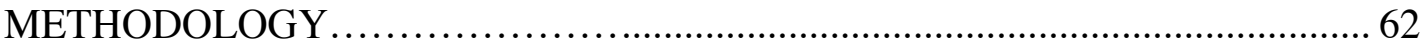

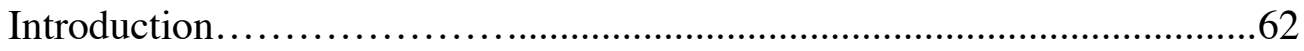

Purpose of the Study ............................................................... 62

The Phenomenological Method.................................................. 64

Research Design......................................................................65

Research Questions...............................................................67

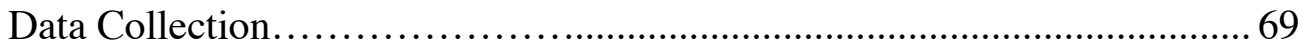

Study Sample..................................................................... 71

Data Analysis and Synthesis....................................... 75 
Ethical Considerations.............................................. 78

Limitations........................................................... 79

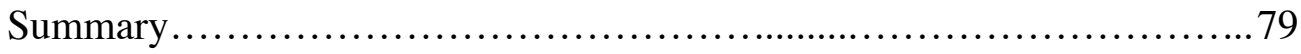

CHAPTER FOUR ....................................................... 80

RESULTS ................................................................. 80

Introduction....................................................... 80

Organization of the Data............................................. 80

Data Results......................................................... 87

Agenda-Setting....................................................... 89

Policy Formulation................................................. 100

Policy Implementation.............................................. 112

Policy Evaluation.................................................... 123

Political Decision-Making.............................................. 127

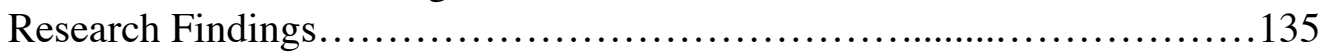

Conclusion........................................................... 144

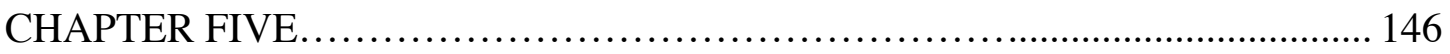

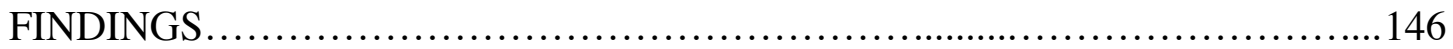

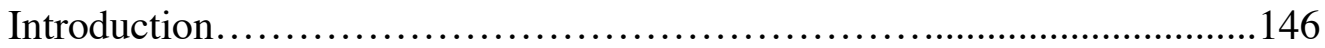

Policy Structures, Participants, and Key Determinants..................... 148

Privatization Policy Development.................................. 152

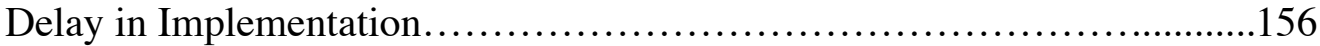

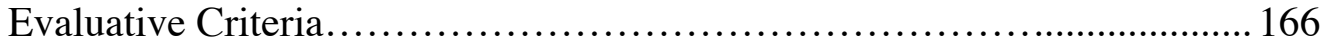

Decision-Making Model.............................................. 168

Summary of Findings.................................................. 170

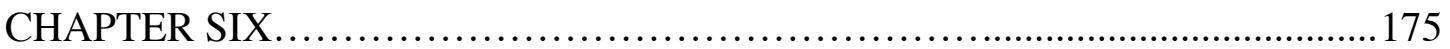

DISCUSSION AND CONCLUSIONS .................................. 175

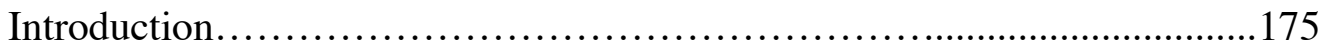

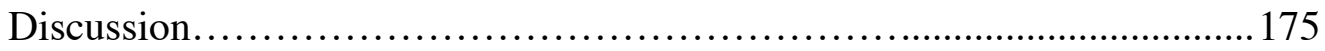

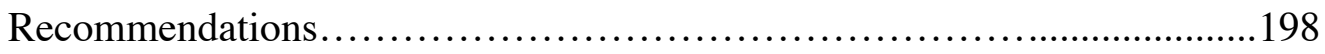

Strategic Policymaking............................................... 209

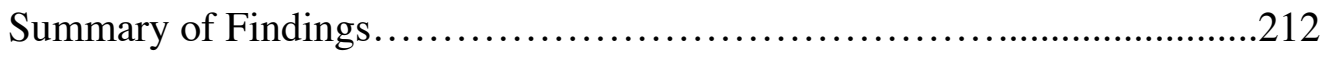

Future Research......................................................... 214

Conclusion............................................................. 215

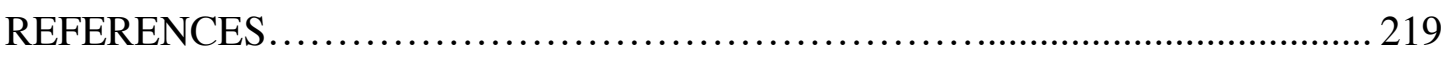

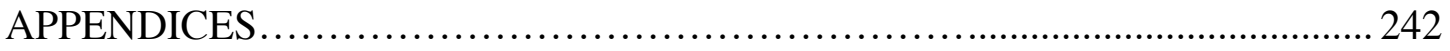

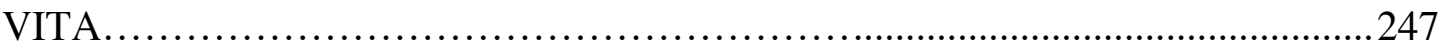




\section{LIST OF TABLES}

TABLE

PAGE

1. Research Questions........................................................... 11

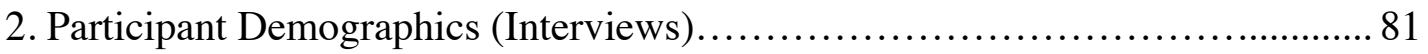

3. Participant Demographics (Focus Groups) ............................. 83

4. Comparison of Law 37/10 and the 1962 Constitution....................... 92

5. Country Rankings: Productivity and Growth............................. 137

6. Global Competitiveness and Human Capital Index Rankings, 2016-2017........ 141 


\section{LIST OF FIGURES}

FIGURE

PAGE

1. Thematic Analysis: Agenda-Setting.......................................... 95

2. Thematic Analysis: Policy Formulation ................................. 101

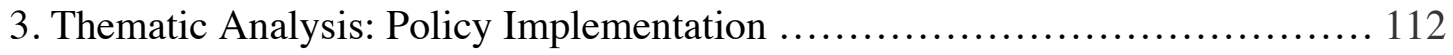

4. Thematic Analysis: Policy Evaluation .................................. 123

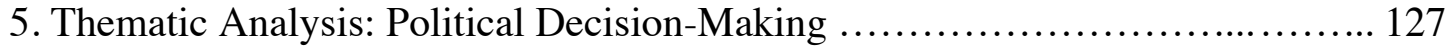

6. Policy Development Conceptual Framework ............................... 212

7. The Global Competitiveness Index Framework ............................... 245 


\section{ABBREVIATIONS AND ACRONYMS}

\begin{tabular}{|c|c|}
\hline API & Arab Planning Institute \\
\hline AUK & American University of Kuwait \\
\hline $\mathrm{CBK}$ & Central Bank of Kuwait \\
\hline CITRA & Communication and Information Technology Regulatory Authority \\
\hline $\mathrm{CSC}$ & Civil Service Commission of Kuwait \\
\hline CSB & Central Statistical Bureau \\
\hline $\mathrm{CSO}$ & Civil Society Organization \\
\hline GCC & Gulf Cooperation Council, referred to herein as the GCC/Gulf region \\
\hline GCI & Global Competitiveness Index \\
\hline GDP & Gross Domestic Product \\
\hline GSSCPD & General Secretariat of the Supreme Council for Planning \& Development \\
\hline ILO & International Labor Organization \\
\hline INGO & International Nongovernmental Organization \\
\hline JSC & Joint Stock Company \\
\hline KFAED & Kuwait Fund for Arab Economic Development \\
\hline KIA & Kuwait Investment Authority \\
\hline KNA & Kuwait National Assembly \\
\hline KNPC & Kuwait National Petroleum Company \\
\hline KOC & Kuwait Oil Company \\
\hline KPI & Key Performance Indicator \\
\hline KU & Kuwait University \\
\hline
\end{tabular}




\begin{tabular}{|c|c|}
\hline LG & Local government \\
\hline$M \& E$ & Monitoring and Evaluation \\
\hline MOF & Ministry of Finance \\
\hline $\mathrm{MOH}$ & Ministry of Health \\
\hline MOP & Ministry of Planning \\
\hline MP & Member of Parliament \\
\hline MSA & Kingdon's Multiple Streams Analysis, used interchangeably with MSF \\
\hline MSF & Kingdon's Multiple Streams Framework, used interchangeably with MSA \\
\hline NGO & Nongovernmental Organization \\
\hline OECD & Organization for Economic Cooperation and Development \\
\hline PACI & Public Authority for Civil Information \\
\hline PPP & Public-Private Partnership \\
\hline $\mathrm{SCP}$ & Supreme Council of Privatization, also referred to as the Council \\
\hline SDG & Sustainable Development Goal \\
\hline SOE & State-owned enterprise \\
\hline $\mathrm{SSN}$ & Social Securities Network \\
\hline $\mathrm{UN}$ & United Nations \\
\hline UNDP & United Nations Development Programme \\
\hline WEF & World Economic Forum \\
\hline
\end{tabular}




\section{CHAPTER ONE}

\section{INTRODUCTION TO THE STUDY}

\section{Introduction}

Public policies often create intense public debate, as unanimous support for a policy seldom exists. This research looks at the way the policy process functions in countries of the Gulf Cooperation Council (GCC), with a particular focus on the State of Kuwait. As the role of ruling families in governments of the GCC region remains strong, there is a consensus among the political elites to advance democratization (Tetreault, 2001; Crystal, 1995). Currently, Kuwait presents the case of a traditional society with multiple democratic elements. Tetreault (2001) discusses that despite some progress made in the political discourse in recent years, economic development has been lagging compared to other GCC countries. This is in spite of the fact that Kuwait's per capita Gross Domestic Product (GDP) surpasses that of several developed countries (World Bank, 2016). During the 1940s, Kuwait was known to be a pioneer in the Gulf region on various fronts, such as education and political development, and served as an example to the United Arab Emirates, Saudi Arabia, Qatar, Bahrain, and Oman (Abu-Hakima, 1983).

With its constitutional monarchy and a partly democratic government, the policymaking process in Kuwait is interesting for many reasons. Some of these reasons include the interplay between the monarch and the elected parliament, and the peculiar situation of international organizations (e.g. World Bank, United Nations Development Programme, International Monetary Fund) seeking to influence policymaking in the 
region but not being able to use financial instruments to advance their policy agendas (Beck, 2014).

Howlett and Ramesh (1995:14) contend that scholars continue to search for, "an improved model of the policy process," that encompasses all relevant factors and components. Amidst the wide array of literature on policymaking, little is known about policy development in the Gulf region. This research utilizes policymaking models and theories to analyze the interplay of political subsystems in the constitutional monarchy setting of Kuwait. The objective of this research is to deconstruct the policy processes in Kuwait by examining the recent privatization policy, which has been approved but not yet implemented, in order to provide recommendations for policymaking in similar sociopolitical contexts.

\section{Background to the Study}

Policymaking is a multi-stage process that involves different sets of actors that vary depending on the particular national context (Smith, 1999; Lasswell, 1958; Dye, 1987). Peters (1999) discusses how a public policy is the sum of government activities, whether acting directly or through agents, as it has an influence on the life of citizens. It is an ongoing and complex process that is comprised of four stages, that is, agenda setting, formulation, implementation, and evaluation (Kingdon, 1984; Sabatier, 2007; Baumgartner and Bryan, 2002). To better understand how this process unravels in Kuwait, the case of the recently approved but not yet implemented privatization policy is studied within the realms of policymaking frameworks and theories in the fields of public administration and public policy. 
Privatization has been a popular reform policy in the developing world. As with various reform approaches, support and opposition exist alongside cases of success and failure (Weimer and Vining, 2004). Kettl (2002) discusses how the Westminster model of privatization was introduced in New Zealand during the late 1970s. This restructuring approach was adopted by the United Kingdom next, followed by the American style reform in the United States, and the new public management approaches that dominated Europe and the rest of the world, thereafter. Public choice theory explains how involving private sectors in public services delivery ultimately decreases the government's burden and establishes a market dominated by competition and public choice (Ostrom, 1973). Theorists such as Osborne and Gaebler (1992) support these new methods for government operations. However, views opposing this new public management approach argue that privatization of public services, instead, expands the multiplayer industry making it too fragmented and bureaucratic to implement policies efficiently (Savas, 1987). In this context, Carolyn and Lynn (2000) agree that cost-effectiveness should not be seen as the only key to better government.

The vision of privatization in Kuwait was first discussed in the 1980s, when the country was experiencing an economic recession (International Monetary Fund, 2003). Important public bodies in the country, such as the National Assembly, Chamber of Commerce and Industry, Kuwait Investment Authority, and the World Bank, explored this vision's implications (Kuwait Alyawm, 2010). The World Bank's study (1993) concluded the potential for this economic development reform; however, further research was required. It was not until 2010 that privatization law 37 was passed, approving the privatization method of re-establishing part of the public sector as joint stock companies. 
While policymakers continue to ponder privatization's implementation in Kuwait, public sector performance has steadily declined along with the citizen satisfaction and trust in government (Altamimi, 2015). Analyzing privatization law 37/2010 provides a better understanding of the political decision-making processes in sociopolitical settings like Kuwait. This research builds on previous privatization literature by applying the policy framework of Kingdon's (1984) multiple streams analysis (MSA) to explain how and why such an issue gained dominance on the government's agenda.

By looking at the privatization policy, this study identifies patterns that can explain how policy issues arrive on the legislative agenda and how solutions to these issues are formulated. As argued by Sabatier (2007), how a problem is defined shapes, if not predicts, the policy proposals and ultimately the outcomes. According to Anderson (2000:5), "there is a need for a more holistic approach of how government works." Given the widespread complaints about the inefficiencies of the administrative system in Kuwait (Alnakib, 2014; Salih, 2013), this research explores the dynamics of the policy process in the understudied context of Kuwait.

\section{Statement of the Problem}

According to Kingdon (1993), policies develop in response to issues that become more pronounced and dominant on the public agenda at certain points in time. This process entails other factors such as the levels of public demand, partisan influences, and the bureaucracy. Weible (2007) explains how an assessment of all factors in a political system is a crucial step to recommending policy alternatives. The social landscape of policymaking in Kuwait is unique to the rest of the Gulf region. Alrumaihi (1994) 
attributes this to the country's representative government system and differentiated civil society. Furthermore, the political system of Kuwait is unique as it is relatively more open, based on a written constitution, comprises a parliamentary electoral system, and a free press (World Bank, 2010). However, there remain widespread complaints about the inefficiency of this political system (Salih, 1992; 2013).

Moreover, Kuwait's economic development process remains lower than some of the other countries in the Gulf Cooperation Council (Central Statistical Bureau, 2016). This is in spite of the fact that Kuwait's per capita Gross Domestic Product surpasses that of several developed countries (World Economic Forum, 2016). Ideas are proposed but seldom does the public witness countrywide accomplishments, including development projects (Alnakib, 2014). Tetreault (2001) discusses how government's funding of public services, as part of the national budget, is exponentially increasing while citizen satisfaction is declining. A recent study of Kuwait conducted by the Bertelsmann Foundation (2014), revealed an increasing turnover rate for politicians and appointees in office, which by proxy impacts the decision-making mechanisms in play. Kuwait's volatile economy, coupled with escalating political tension between the legislative and executive branches of government, as described by Alrumaihi (1994), has placed the country on an economic development path of uncertainty. The Kuwaiti government finds it more difficult to achieve economic development that would position the country on the globalization map (Altamimi, 2015). Furthermore, Sheikh Sabah Al-Ahmad Al-Sabah, the Emir of Kuwait, stressed the need to investigate policy issues that dominate the public sector, such as economic development (Emir's Vision 2035, Ministry of Planning, 2010). 
In an attempt to overcome these obstacles and in line with the Emir's vision, the Kuwaiti parliament enacted privatization law (37/10) in 2010. This law applies to the whole public sector of the country. A review of recent reports published by the Ministry of Finance (2016), concludes that six years into passage of the law no implementation efforts have been witnessed. Barrett (2006) and Selvik (2011) discuss the frequent lack of agreement between the parliament and the executive branch of government often results in an unsystematic pace of policymaking. While plans of economic expansions are underway with funds being spent, many projects including the establishment of publicprivate partnerships have still not materialized (Elbadawi and Kubursi, 2014). This fact raises the question of whether privatization is the cure for what some observers claim to be an ill-performing government (Alkoumi, 2010; Alnakib, 2014). To better understand why the privatization policy was pursued in the first place, this research investigates perceptions of individual policymakers about policy issues faced in the country and how such perceptions led to the adoption of the 2010 privatization legislation. In doing so, policymaking frameworks and decision theories are applied to the case of Kuwait to analyze the interplay of the political subsystems.

\section{Purpose of the Study}

This research seeks to provide a framework for understanding the policy processes in the GCC region, particularly with respect to privatization in Kuwait. It applies multiple theoretical lenses and validates them against the perspectives of various actors involved in the policy process. It is expected that these shared perspectives will inform practitioners of possible ways to improve the efficacy of government policies, and 
assist academics when conducting scholarly comparative work and advancing development literature of transitional economies in Gulf countries. The goals of this research are to analyze the structure of policymaking in Kuwait - takeaways of which can apply to similar political contexts in the Gulf - and to analyze a policy issue from a theoretical standpoint, which has not been applied in Kuwait. Olshfski and Cunningham (2008:10) discuss how, "agenda-setting in policymaking literature has not received much attention in the administrative arenas." Stone (2002) explains how the vague understanding of policymaking has resulted in public dissatisfaction in the way the government is run. Thus, little is known about how political agendas are set and how decisions are made, despite the growing body of literature discussing policy development processes. The linkages between different components of the policy subsystems are analyzed in the case of privatization policy in Kuwait.

As explained by Patton (1990:71), a phenomenological study focuses on, "descriptions of what people experience and how it is that they experience." Thus, the purpose of this phenomenological study is twofold: 1) to describe the policymaking process in the region, more specifically in Kuwait, and, 2) to explore how policymakers directly involved with formulating and implementing policies experienced this process with the privatization policy. Knowledge generated from this study is expected to inform policymakers and administrators of how to achieve a more effective policy implementation. By assessing the policy issues from various theoretical perspectives, this study suggests areas for improvement. 


\section{Conceptual Framework}

Kingdon (1984) posits that the policy process consists of four main phases: 1) agenda setting, 2) policy formulation, 3) public policy implementation, and 4) evaluation. This research applies Kingdon's framework to privatization policy in Kuwait and explains the government's failure to launch the adopted reinventing program. The interactions between different government bodies are articulated from the perspectives of major stakeholders in the process.

Kingdon (1984:9) defines the policymaking process as an "organized anarchy" that is composed of influential actors. Regardless of the motives for how policy choices are made, the first stage of the policy process, agenda setting, determines the problem definition and decision outcome (Baumgartner and Jones, 2002). The political arena is comprised of networks of organizations that share similar goals but act independently of each other (Katz and Kahn, 1966). Problems reach the policymaker's agenda by one of three portals: position, politics, or perspective (Olshfski and Cunningham, 2008). There is a need to first understand the dynamics of how a political agenda is set in order to better understand the policymaking process (Kingdon, 1984). Therefore, the first research question that guides this study is: What factors and elements drove the agenda-setting process in the case of privatization policy in Kuwait?

Birkland (2010) explains how policymaking is about problem solving. Policy formulation depends largely on problem definition, after which "the development of pertinent and acceptable proposed courses of actions for dealing with a public problem" (Anderson, 2000:7) would be required. Since there can be various interpretations of the same problem, an assessment of all factors in a political system is a crucial step to 
recommending policy alternatives (Jones, 1994). Therefore, the second research question is: What problems does the privatization policy address?

According to Weible (2014), a successful policy process is one in which the policy's development during primary stages was effective and responsive. Similarly, Stone (2002) argues that the policy action must lead to desired outcomes and agreement between the bureaucracy's decisions and the broader public preferences. The privatization policy in Kuwait presents the case of a policy that has been approved but not yet implemented. As such, the third research question is: What are the obstacles facing implementation of the privatization policy in the case of Kuwait? Furthermore, to what extent did the policymakers consider evaluation criteria when adopting the privatization policy? This serves as the fourth research question directing this study.

Decision theory suggests that in order to understand the various decision-making mechanisms, one must consider the actors involved, the discretion granted to them, and their motives (e.g., Lindblom, 1979; Simon, 1946; Stone, 2002). Frederickson and Smith (2011) discuss how the type of politics exercised largely depends on the environmental context. Theories of public management are applied to explain how policies are made in the constitutional monarchy setting of Kuwait. In doing so, the final research question states: To what extent does decision-making in Kuwait follow any of the theoretical frameworks?

Components of the decision theory are applied to the case of Kuwait, with respect to the privatization policy, to understand the public policy process in the context of constitutional monarchies. Zahariadis (2014) explains how Kingdon's policy development cycle is especially useful for understanding ambiguous conditions of 
policymaking. Feldman (1989:5) defines ambiguity as, "a state of having many ways of thinking about the same circumstances or phenomena." Therefore, understanding how the privatization policy was formulated in Kuwait requires explanations of this phenomenon from various policymakers' perspectives.

While the topic of policymaking is significant, existing literature does not address the relevance of this topic to governments in the Gulf region. The case of Kuwait is particularly understudied. To understand the general dynamics of policymaking in Kuwait, the policy development frameworks of Sabatier (2007), Kingdon (1984), and Jones (1994) will be applied in conjunction with theories of political decision-making. The research adopts an interpretivist and social constructivist approach to illuminate the case of how a broad-ranging policy change has been attempted in the Kuwaiti political context, but failed in the implementation stage.

\section{Research Questions}

This research aims to better understand the policymaking system in Kuwait, in addition to the factors and elements that comprise the policy development cycle. The interview questions and hypotheses in Table 1 were drawn from a review of the literature and theoretical frameworks. This research attempts to deconstruct the policy process in Kuwait by looking at the privatization policy as a case study. 
Table 1

Research Questions

\section{Research Questions}

\section{Guiding Hypotheses}

Agenda-setting

What factors and elements drove the agenda-setting process in the case of privatization policy in Kuwait?

Formulation

What problems does the privatization policy address?

Implementation

What are the obstacles facing implementation of the privatization policy in the case of Kuwait?

Evaluation

To what extent did the policymakers consider evaluation criteria when adopting the privatization policy?

Decision-Making

To what extent does decision-making in Kuwait follow any of the theoretical frameworks?

* Stone (2002) explains this decision-making model in which the decision is made first and the means are determined later. This process is neither sequential, nor consequential.

\section{Significance of the Study}

This is the first study to analyze the policy debates that led to the adoption of privatization law in Kuwait and the factors that explain the failure of the government to carry out these policies. The study contributes to a better understanding of policymaking in the Gulf region, which has largely been understudied. Although there are numerous studies on policymaking and implementation in developed and developing countries, the 
literature that explores these processes in the context of constitutional monarchies in the GCC region has been rather limited. Through the means of primary data collection effort, this study is amongst the first to conduct an in-depth analysis of the policy processes in Kuwait and provide recommendations about the most effective practices in constitutional monarchy settings.

This research contributes to the understanding of differences in the policy process between the consolidated democracies of Western countries and the transitional democracies of Gulf countries. It is thus anticipated that richness of the contextual and textural descriptions provide for a better understanding of the policymaking processes in countries of the GCC, with a focus on Kuwait. Policymakers and administrators from different sectors of Kuwait comprise the research sample. As such, this research intends to provide practitioners with insights of the existing conditions, opportunities for improvement, and the dynamics to consider when building support for public sector restructuring initiatives. The research intends to provide academics with a comprehensive understanding of how governing systems in Kuwait function as they formulate and implement policies.

Research findings from this study should prove useful to both privatization policy scholars and policymakers. They speak to broader issues of democratization, public management, and strategic planning. Research findings are intended for use in scholarly comparative work and for advancing development literature of constitutional monarchies. Moreover, the research contributes knowledge of issue areas critical when studying third world countries and comparative politics, as Crystal (1995:xi) explains, "notably statesociety relations, democratization, and regime stability." Insights gained from this 
research will better inform the broader policy discourse. Findings from this study are useful to both practitioners and academics from various disciplines including political, legal, economic, business, and administration.

\section{Research Design}

To answer the research questions, this study uses qualitative research methods. Qualitative methods are useful when the study aims to explore and describe complex issue areas, such as perceptions, worries, and feelings (Lincoln and Guba, 1985). This methodology helps achieve a deeper understanding of the phenomenon addressed, and is particularly appropriate for analyzing the privatization policy, as it has been relatively new in the region and not yet implemented in Kuwait. The study is designed as a phenomenological study and draws heavily on content analysis.

Phenomenology is an approach widely used in social sciences (Moustakas, 1994). By applying this method, qualitative researchers "study things in their natural settings, attempting to make sense of, or interpret phenomena in terms of the meanings people bring to them" (Denzin and Lincoln 2005:3). Through the process of self-reflection, researchers are able to understand the social and historical contexts within which social decisions and policies are made. The phenomenological components of this study explore the lived experiences of key decision-makers directly involved in making and/or implementing policies in Kuwait, to have a better understanding of the process of agenda setting, policy formulation, implementation, and evaluation. Experiences are explored in terms of meaning, structure, and essence (Patton, 2002). 
Data were collected through in-depth interviews, focus groups, and document reviews. Interviews and focus groups were conducted in a semi-structured format. Document reviews helped provide the knowledge of past and current policy actions. Both inductive and deductive data analysis approaches are followed, where data are analyzed based on emerging themes and patterns, in addition to categorical classifications from extant literature.

The research employed three primary sampling methods. Participants from key industries were selected based on criterion sampling, followed by snowball sampling. These sampling approaches are especially appropriate for phenomenological studies as participants must be closely familiar with the phenomenon (Creswell, 2007). Interviewees had to be in an executive decision-making position in the country, directly involved in formulating and/or implementing policies, and in the position for at least three years according to the standard four-year time frame of public posts in the country (Civil Service Commission, 2008). The selection of focus group participants was also based on predefined criteria. The groups include university graduate students active in student governments, and employed community members above the age of thirty years. Sabatier and Jenkins-Smith (1999:124) explained how policymaking involves participants from, "all levels of government, multiple interest groups, research institutions, and the media."

The phenomenological process of epoché was the first step in which researcher interviewed oneself to acknowledge personal perspectives of the research topic. This is a necessary verification measure to eliminate all pre-judgments and suppositions (Moustakas, 1994). Thereafter, the study participants were interviewed in terms of their 
experiences with political decision-making in the case of privatization. Data collected from the three data collection methods of interviews, focus group, and document reviews, were analyzed using Creswell's (2007) version of Moustaka's modified Stevick-ColaizziKeen phenomenological data analysis method.

\section{Research Limitations}

As with all research designs, there were some limitations to account for. Participants' responses can be inconclusive. To counteract the likelihood of this occurring, measures such as cross-validation, triangulation, and use of multiple data sources were taken during the data collection stages. With regards to the research design, Bernard (1994:173) stated that, "objectivity does not mean value neutrality", rather, "the idea is whether or not scientists conduct research in an unbiased way" (Kuznar, 2008:132). Harris (1994:64) further elaborated on how, "science makes no claim to being value free (...) it proposes to overcome the inevitable biases of all forms of knowledge by methodological rules that insist upon opening to public scrutiny the operations by which particular facts and theories come to be constructed." One of the rules the phenomenological methodology requires is epoché. In this context, measures of epoché and member checking were taken to eliminate the likelihood of researcher subjectivity during data analyses.

Research findings, although limited to a one-country case study, are intended for use in scholarly comparative work and to advance policy literature of constitutional monarchies. Howlett and Ramesh (1995:14) contend that scholars continue to struggle in search of, "an improved model of the policy process," that encompasses all related 
factors and components. This is one of few studies that evaluate policy processes in one of the economically and politically leading countries of the Gulf region (Schwab and Sala-i-Martin, 2016). It is expected that findings from this study benefit policymakers and practitioners across the country, while contributing to the greater policy discourse internationally.

\section{Definition of Key Terms}

Theorists defined the key concepts in policymaking literature in various ways. The following definition of key terms will be applied throughout this research.

Public policy. A public policy is the sum of government activities, whether acting directly or through agents, as it has an influence on the life of citizens (Peters, 1999). It is a purposive course of action or inaction followed by an actor or set of actors in dealing with a problem or matter of concerns (Anderson, 2000). It what governments choose to do or not to do (Dye, 1987). Solutions are policies; they are answers to questions that may not be produced only when needed.

Politics. Politics is the struggle over ideas as seen from multiple perspectives, rather than objective facts (Stone, 2002). It is the process by which society determines who gets what, when they get it, and how they get it (Lasswell, 1958). It is the broader political discourse within which policy is made (Zahariadis, 2014).

Policymaking. Policymaking is the process of making political decisions, which is also referred to as political decision-making. It is the process of deciding who gets what, when, and how (Smith, 1999). 
Theories. Theories are a range of approaches that specify the scope of inquiry, lay out assumptions, provide a shared vocabulary among members of a research team, and clearly define and relate concepts in the form of principles and testable hypotheses and propositions (Weible, 2014; McCool, 1995).

Problem. Problems are the concerns that individuals inside and outside the policy system have (Zahariadis, 2014). They can also be 'policy issues'; this research uses the two terms interchangeably.

Policy Entrepreneurs. They are actors who use their knowledge of the process to further their own policy ends (Kingdon, 1984). Entrepreneurs can try out one idea or a combination of ideas (Cairney, 2012). They are individuals or corporate actors who attempt to couple Kingdon's (1984) three streams of policy, politics, and problem (Zahariadis, 2014).

Elements. This refers to the environment within which policies are made. It is the social, economic, and demographic trends that influence policymaking (Birkland, 2010).

Factors. Factors are the indirect and direct policy actors that influence different stages of the policy process (Kingdon, 1984; Jones, 1994).

Policy windows are opportunities for advocates of proposals to push solutions as they perceive them, or to bring attention to problems as they define them (Kingdon, 1984).

Government. It is a collection of institutions that act with authority to create formal obligations (Kettl, 2002). In this research, 'government' refers to the executive branch of authority in Kuwait. 
Bureaucracy. They are organizations designed with tall hierarchies and narrow spans of control (Weber, 1922).

National Assembly. This term is used interchangeably with 'parliament'. This is the legislative body in the State of Kuwait (Constitution, 1962).

Majles Alommah is the Parliament of Kuwait, also referred to as the National Assembly.

Supreme Council of Privatization (SCP). The SCP is, "chaired by the Prime Minister and consists of five ministers and three experts from different sectors of the society" (Article 5, law 37/10). This council is charged with developing a strategic plan for privatization in Kuwait, a plan that must undergo approval stages from the legislative, executive, and judicial bodies (law 28/2014).

Emir is the term used to refer to the President of the State of Kuwait, who currently is His Highness Sheikh Sabah Al-Ahmad Al-Jaber Al-Sabah.

Kuwait Alyawm is the Official Gazette of the Government of the State of Kuwait. The three main branches of government -executive, judicial, and legislative - support the gazette. It is not a commercial newspaper. Rather, it is the public's primary source of information of laws, policies, and procedures as approved immediately by the Emir.

The Public. The 'public' in this research refers to all Kuwait citizens, excluding the interviewee sample of policymakers that directly contributed to the formulation of the privatization policy in Kuwait.

State. In this research, the country of Kuwait is referred to as both 'state' and 'country', as Kuwait is considered a city-state. A city-state as explained by Sinclair and Hakansson (2000) is a city and its surrounding villages that together share the same 
government and form an independent state. Moreover, the country is internationally recognized as the State of Kuwait.

Democracy is an active, peaceful engagement of debate through channels safeguarded by a constitution that is accepted and adhered to by all (Alrumaihi, 1994). Democratic order is based on freedom, justice, and equality (Waldo, 1948).

Constitutional monarchy is a form of government in which the monarch acts as head of state, exercising their authorities in accordance with a written or unwritten constitution; sometimes referred to as a parliamentary monarchy. It is also known as a government that is lead by a monarch in the existence of democratic institutions such as a parliament (Blum, Cameron, and Barnes, 1970). Countries that are governed by constitutional monarchies include Sweden, Morocco, Japan, and all members of the Gulf Cooperation Council.

Gulf Cooperation Council (GCC) includes the six countries that comprise the Gulf region. This includes Kuwait, Bahrain, Saudi Arabia, United Arab Emirates, Oman, and Qatar (GCC Charter, 1981)

Reinvention is the process of transforming government systems to create (dramatic) increases in efficiency, effectiveness, and the capacity to innovate (Osborne and Gaebler, 1992).

Privatization is the devolution of government property and assets, involving certain governmental services and responsibilities, to the private sector (Mahmoud, 1992). It is the transfer of enterprise ownership, whole or part, from the state to private hands. This is also called denationalization and "destatization" (Savas, 2000). 


\section{Summary}

This dissertation is comprised of five chapters. Chapter two reviews literature in the fields of policy development and privatization. The first part of the literature review focuses on the dynamics of policymaking in the GCC region in general and in Kuwait in particular. The second part reviews the theoretical underpinnings of the new public management reform movement through history, along with discussions of privatization as a policy response in Kuwait. Chapter three outlines the research questions that guide this study, in addition to the phenomenological methodology that was applied to analyze the primary field data gathered. How the data were collected, managed, and analyzed is discussed. Chapter four presents the results of data analyzed, while chapter five discusses the findings in relation to the research questions. The qualitative data gathered were consolidated, analyzed, and interpreted. Chapter six presents a discussion of the results within the context of policymaking frameworks and theories covered in the literature review. It is anticipated that findings from this study address the research questions raised, provide conclusions for the study, and implications for research and practice. 


\section{CHAPTER TWO}

\section{LITERATURE REVIEW}

\section{Introduction}

Literature on policymaking and privatization presents various findings. Policy research helps, "mitigate the effects of (cognitive) presuppositions by highlighting the most important items for study and specifying the relationships between them" (Weible, 2014:12). In this context, the first section of this chapter provides a theoretical overview of the policy development process. A historical background of policymaking in the GCC in provided, with a closer look at privatization policy development in the State of Kuwait. Findings from the literature reviewed inform the data analysis.

\section{Policy Development in Theory \\ The Contexts of Policymaking}

When understanding the theoretical underpinnings of the policy process, it is important to first introduce some key concepts in policy research. Policymaking, or what Smith (1999) refers to as political decision-making, is deciding who gets what, when, and how. Politics, however, is the process by which society determines this distribution (Lasswell and Kaplan, 1950). Although theorists defined public policy in more than one way, Peters (1999) combined aspects of the various definitions and explained that a public policy is the sum of government activities, whether acting directly or through agents, as it has an influence on the life of citizens. From these definitions, we can infer that policymaking is a continuous process that involves various factors and elements. 


\section{Factors}

Policymaking is a lengthy and complex process. Kingdon (1984) explains it to be an organized anarchy composed of influential actors. There are different factors to consider in the policy development process. Actors contribute directly to the policy's agenda setting and formulation stages. Elected politicians are the first and foremost of this impact group; thus, motives and decision-making behavior become critical. Downs (1967) and Niskanen (1971) acknowledge the concept of corruption in policymaking, when discussing rational choice institutionalism. They explain that corruption exists in policy processes around the world when self-interested politicians behave in ways that maximize their personal gains. There are two positions that result from this argument. Some theorists advocate the need to improve government accountability by making the bureaucracy more democratic and having a representative government (e.g. Kingsley, 1944; Allison, 1971). From their perspective, this helps maintain an accountable, democratic government. Other theorists believe in restricting discretion; instead, they advocate for external controls that restrict bureaucrats' freedom to act autonomously (e.g. Lowi, 1979; Finer, 1941).

Citizens, the second group of actors, also play an important role in the policymaking process. Coleman, Brudney, and Kellough (1998) discuss the critical need for the public's involvement in political decision-making. Public sector reforms in Britain and the United States created new worlds of governance that Bevir (2010) explains reflect less faith in the State. His view of participatory democracy, rather than a representative one, signifies the role the public plays in a country's policymaking process. Other theorists in favor of citizens participation note the importance of social 
inclusion and value pluralism in a society. Naturally, people differ in their conceptions of the good, efficient, performance, as well as in their professional values (Spicer, 2010). Kingsley (1944) adds that having representative bureaucracies help achieve more equitable policymaking processes.

In contrast, theorists such as Weber (1922), Wilson (1887), and Fayol (1916) favor centralized authority, which contributes to more efficient political processes. The role of the bureaucrat and the citizen is further distinguished in the newer public management and public service approaches. These theorists defined the concept of public interest as politically expressed in laws, whereas scholars of the new public management and public service movements defined public interest to be an aggregation of individual self-interests that results from policy discourses in networks (Catlaw, 2007; Fox and Miller, 2007). Denhardt and Denhardt (2000) explain how there was no role for a public servant in old public administration. This role, however, evolved and became active through time as governments became more decentralized in response to economic, political, and social changes.

Moreover, in any process of policymaking, Howlett and Ramesh (1995:14) explain that institutions, certain instruments, and policy actors will be involved. Zahariadis (2014) confirms such factors that comprise political decision-making, while signifying the role of legislators and parties acting within the national mood. Policy entrepreneurs, especially, can assume the role of direct or indirect policy influencers depending on whether they act personally or on behalf of a larger group (Kingdon, 1984:104). Jones (1994) explains how these policy entrepreneurs use their knowledge of the policy processes to build enough attention in order to seize a window of opportunity 
that places a policy problem on the agenda. It is quite often the case that particular organizations, not just their individual representatives, are behind the push for certain policies (Roberts and King, 1991). Policy entrepreneurs can be leaders of interest groups, bureaucrats, elected politicians, or congressional staff members. Indirect actors include unofficial spokespeople in media outlets or communal gatherings that work to gather attention for problematic conditions. This also includes nongovernmental organizations (NGOs) and think tanks. There are other players in the policy process that do not act for political benefits, rather are contributors of knowledge or experience. Nevertheless, these actors such as consultants, academics, and researchers can influence the process directly with their paid or unpaid work products.

\section{Elements}

Sabatier (2007) devotes the complex policy process to the large number of people seeking political influence, in addition to elements that include the occurrence of unexpected events, the mix of programs and other policies that span the government levels, and the geographic and socioeconomic contextual settings. Early literature on policymaking deduces the process to determinants of policy adoption (Blomquist, 1999). Shortly after, theorists such as Dye (1965) and Hofferbert (1966) acknowledged the influence of contextual elements in the process, such as the environment and organizational structure. Birkland (2010:2) defines policymaking as essentially problem solving. Social, economic, and demographic trends influence policymaking, as well as the environment in which policies are made. He explains politics as, "a process by which societies help figure out how to organize and regulate themselves; that is, how to govern 
themselves" (3). Literature reveals that citizens' dissatisfaction in government's performance is a determining factor for state governments when devising policies (Jennings, 1998). As such, culture is an element as is the organization/sector that develops the policy. Olshfski and Cunninham (2008:21) demonstrate how the level of centralization in the political decision-making process within an organization can impact idea generation. The scientific management reform movement, dating back to Taylor (1912) and Gulick's (1937), helped shape the welfare/administrative state in the 1950s. The notion of deregulating internal administration empowered policymakers across different levels of government to contribute to policy development, within their knowledge and expertise. These approaches continued through the liberation management movement in the 1990s (Light, 1997). In this context, structure, institutions, and roles are elements that collectively contribute to the policy development process.

\section{Theoretical Frameworks}

In line with the abovementioned discussion, that there is not one single, wellorganized policymaking method with explicit elements and factors. Interpretivists share the view that reality is constructed through understandings that are developed from social interactions and experiences (Berger and Luckmann, 1967). Internal and external elements help shape these meanings and understandings. In studying human group life and human conduct, Blumer (1969) introduces the concept of symbolic interactionism within the interpretivist paradigm. This approach, he defines, rests on the premises that human beings act on the basis of meanings that things have for them, meanings of which arise out of social interactions (Blumer, 1969:2). 
Theorists discuss how the methods in which policy decisions are made vary amongst people and contexts. Some legislatures focus on making policies that improve the quality of living. Others base policy alternatives by weighing costs against benefits (Sharpe, 1998). Self-interested politicians would make policies that benefit their constituencies (Buchanan and Tullock, 1962; Downs, 1967; Niskanen, 1971). In discussing the differences between Kingdon's MSA and rational choice, Weible (2014:39) mentions how the assumption is often made that policymakers, "have problematic preferences and are subject to manipulation." However, Simon (1946) refutes this argument with his theory of bounded rationality. He claims that human beings do not seek to maximize their personal benefits. Instead, the individual is bounded by cognitive limits and insufficient information, leading to individuals' satisficing decisionmaking behaviors as they choose the best option given the situation (Jones, 2001). This is especially common in high density situations, where policy issues, "challenge cultural norms, attract many participants attempting to influence the policy decision, and are situated structurally so that multiple authorizations are needed before a decision can be made or implemented" (Olshfki and Cunningham, 2008:28). As such, policy types are a result of the interplay between policy preferences and processes, both of which largely depend on the influencing elements and factors.

\section{Stages of a Policy Cycle}

Easton's (1953) system theory contributes to the foundation of public policymaking literature, highlighting that policymaking is a never-ending cycle. In this theory of functions and stages, Easton explains how the process begins with inputs to the 
government in the form of demands and supports. The inputs undergo a conversion process that results in outputs in the form of public policies. These decision outputs yield feedback, further demand, and support that eventually lead to yet another input process. This systems theory, reiterated in Katz and Kahn's (1978) work, helped in understanding work processes, organizational purpose, and the power structure contained within political environments. Since Easton's systems analysis of political life, theorists continue with attempts to better understand the policy process. The political arena is comprised of networks, where organizations share similar goals but act independently of each other. The interplay of influence, power, and authority determines how bureaucrats manage policy formulation and implementation stages. Nevertheless, this network theory explains how some bureaucrats manage policies for self-interests, while others for organizational survival (Compston, 2009).

Various interpretations of what the policy cycle is have been developed over time. Sabatier (2007) discusses how the process was rather simplistic in the 1970s and 1980s. For example, the Stages Heuristic approach deduces policymaking into five main stages of agenda setting, formulation, legitimizing, implementing, and evaluating. As time advanced and political issues became more complex, other approaches were developed as an attempt of understanding policymaking. Kingdon's (1984) multiple-streams framework views policies as comprised of three main streams - problem, policy, and politics streams - that intersect to create a policy change. The problem stream involves recognition; the policy stream focuses on formulation, while the politics stream involves refining the policy proposals. Kingdon explains how each stream is independent of the other, with a window of opportunity appearing mostly during major events or annual 
reviews. Birkland (2010:5) reiterates this viewpoint stating that, "the policy process must avoid the tendency to arrange policymaking into neat, orderly steps." In the Stages model, he defines the policy cycle consisting of the stages for issue emergence, agenda setting, alternative selection, enactment, implementation, and evaluation. Olshfski and Cunningham's (2008) decision-making models refer to identifying the problem, proposing alternative solutions, implementing the policy, and evaluating the effectiveness of decisions made.

As seen, these theoretical policymaking frameworks, among various others, overlap in the major phases of policymaking. Meijerink (2005) demonstrates the commonality shared in that all frameworks offer complementary explanations for longterm policymaking. However, these policymaking frameworks have been designed with western democracies in mind. As such, they fail to capture critical elements that are specific to the nature and structure of politics in the Gulf region. In order to investigate the policy development process with regards to the privatization policy in Kuwait, Kingdon's policymaking model is applied to guide this research.

March and Olsen (1983) discuss how Kingdon's policymaking cycle continues to lead policy research when understanding the stages of policymaking and agenda setting. Although Kingdon's MSA has been criticized for being ahistorical and not paying due attention to the way previous solutions affect contemporary debates and policy choices (Weir, 1993), his framework for analyzing policy processes still dominates the field of applied research. Zahariadis (2014:34) expresses support of this model by discussing how it is, "a lens or framework that explains how policies are made by government under conditions of ambiguity, (...), it has proven useful in explaining national, supranational, 
and subnational policies in a variety of cross-national settings." In a study of MSA's application to the national education policy in Hong Kong, Chow (2014) demonstrates the usefulness of this policymaking analytical framework to studying a single-case application. Furthermore, an application of Kingdon's model to the case of privatization policy in Kuwait helps identify the congruencies and divergences between western policy processes and policymaking in Kuwait.

\section{Agenda-Setting}

The key component of problem definition and policy outcomes is agenda setting (Barry et al., 1997; Anderson, 2006; Durant, 1998; Lester and Stewart, 2000; Rochefort and Cobb, 1994). Baumgartner and Jones (2002:77) argue that, "given the finiteness of agenda space in the policy process, no single issue can dominate the public agenda indefinitely.” Alternatively, Stone (2002) discusses how certain issues can gain more attention at certain points in time. To understand this, we can consider issues that concern the country's safety or public health to rank high on the government agenda. If issues are defined as problems, as Rochefort and Cobb (1994) discuss, they will receive more attention. Additionally, focusing events divert the attention of media and policy entrepreneurs to problem areas that eventually are added to the agenda (Jones, 1994). However, policies are not only proposed as a result of changes in the elements that comprise the surrounding environment. They can also be ideas generated from factors related to the particular issue. If policies are ideas that compete to win acceptance in policy networks, then specialists, as well, can propose reform policies to interest areas that may not be timely issue areas. However, since these ideas are not in response to a 
social or political need of the time in which they are proposed, Durant and Diehl (1989) explain how their policy proposals risk being overlooked during the agenda setting stage.

\section{Formulation}

Lindblom and Cohen (1979) explain how policymaking is about problem solving. Formulating a policy depends largely on defining the problem, after which, "the development of pertinent and acceptable proposed courses of actions for dealing with a public problem" (Anderson, 2000:7) would be required. Since there can be various interpretations of the same problem, an assessment of all factors in a political system is a crucial step to recommending policy alternatives (Weible, 2007).

According to Olshfski and Cunningham (2008:9), problems reach a policymaker's agenda by one of three portals: position - what the policymaker is experiencing given his current position, politics - what is 'pushed on the desk' flowing in from the politics stream, or perspective - what the policymaker's idea is when framing the situation. As seen, perspective is an undeniable element of problem definition that contributes towards agenda setting and eventually policy outcomes. Rationalist theorists interpret perspective as political manipulation (Williamson, 1985; March, 1997). However, Baumgartner and Jones (1991) discuss how all information is not value-neutral. As such, decision-making mistakes, or frame blindness (Russo and Schoemaker, 1989), can occur as policymakers attempt to solve a problem that has been wrongly defined. Mitroff (1998:9) elaborates on the existence of various understandings for a singular situation. This is especially critical when politicians and interest groups begin to frame issues based on their conceptions using labels and symbols that strategically stir attention to certain policy choices. 
Moynihan (2006) explains the ambiguity of such situations is what allows policymakers to use their discretionary power to engage in the interpretation process. This is especially common in political systems where power is centralized, which may or may not be the case in government structures of the Gulf region that are run under a constitutional monarchy rule. In these centralized bureaucracies, Weber (1922) introduces elected politicians as being positioned at the apex of the pyramid, which by proxy grants them discretionary power.

\section{Implementation}

Howlett (1991) presents how middle and front-line policy contributors do not always relegate implementation processes, which results in ineffective and unfeasible policy outcomes. Hill and Lynn (2004) describe the implementation of a policy is internally based on the organization's structure, the design of its programs, and the managerial methods followed. Externally, however, theorists agree that networks facilitate the implementation stage (Lynn et al., 2000; Carpenter, 2001). Network, in this regard, refers to the role of multiple social actors in implementing and delivering the desired policy outcomes (O’Toole, 1987; O'Leary, 1994). Implementing a public policy can happen in one of two ways - either top-down or bottom-up. While the top-down model is associated with clear objectives and implementation chains (Van Horn, 1975; Mazmanian and Sabatier, 1983), the bottom-up approach entails ambiguous goals and conflicting norms and interests (Elmore, 1982).

As Sabatier (2007) contends, there is not one single 'correct' method for policy implementation. While the former assumes that all factors and elements can be pre- 
determined and, as such, a clear implementation process can be drawn, the latter is built on assumptions from the perspective of the lowest-level policy implementers. Moreover, policy failures are inevitable and naturally occur, which justifies why, "policy development is an ongoing process with no discernible beginning and no obvious end, but with plenty of opportunities for refinement and fine tuning” (Birkland, 2010:275). In the end, however, Smith (1973) explains how effective implementation of any policy requires the participation of knowledgeable policymakers, support of decision-making authorities, and favorable demands in the society. Margaret Thatcher (Marsh, 1991) assessed this need during her term in office by focusing on mobilizing social efforts and building support prior to embarking on the implementation stage of the privatization policy in the United Kingdom.

\section{Evaluation}

The topic of evaluation was mostly discussed in management and organizational behavior literature, rather than policymaking literature. Parsons (1995) describes this final stage of the policymaking process as a critical step to test the problem definition during the agenda setting stage. It helps strengthen the policy processes and document accomplishments. Olshfski and Cunninham (2008:22) discuss how policymakers sometimes assess alternative policy solutions by, "checking with peers in other states or a professional association for suggestions." Consequently, documenting outcomes of public policies through the use of evaluative measures becomes essential.

A study conducted by the Organisation for Economic Co-operation and Development (OECD) evaluated the impact of regulation and regulatory policies. In the 
study, Coglianese (2012) demonstrates how policy evaluation is widely based on measuring the level of effectiveness, which is the degree to which policy actions lead to the desired outcomes. He claims the need for indicators to measure a policy's outcomes (i.e. impact, cost-effectiveness, and net benefits), as well as the policy's design in order to assess the degrees of change post-implementation for the target policy. Furthermore, performance management tools such as the balanced scorecard (Kaplan and Norton, 1992), SMART ${ }^{1}$ measures (Ammons, 2002), and results-based management (United Nations Development Group, 2011), provide government authorities with information of the success of policies implemented and the avenues for public participation.

\section{Political Decision-Making}

Political decision-making, as defined by Smith (1999), is deciding who gets what, when, and how. Dye (1987:1) defines public policy as, "whatever governments choose to do and not to do." The way decisions are made determines the anticipated level of support for policy proposals. Optimal policymaking, therefore, would result from communications between the political structure and well-informed participants (Jones, 1994). Jones continues to explain how, "policy outcomes (are) dependent either on the manipulation of the rules by leaders (agenda-setters) or by the establishment of structureinduced equilibria" (2). In democratic decision-making processes, he presents three models: the populist, the pluralist, and the elite-competition. In the populist, politicians would, "enact mass preferences and then control the bureaucracy during the

\footnotetext{
${ }^{1}$ SMART is an abbreviation for strategic, measurable, attainable, realistic, and timely measures (Ammons, 2002).
} 
implementation stage." Democracy is achieved in the pluralist model through the complex process of organizing interests. Lastly, democracy in the elite-competition model is all about competition between parties of elite figures, rather than individual constituents. According to Jones, policy choices are made as a result of a politician's preferences paired with an interpretation of the political context.

Further decision-making approaches include that of March's (1978), in which he highlights the rational approach where decisions made are essentially the most optimal ones considering all alternatives of the time. This deductive approach focuses on maximizing gains. Simon (1946) presents another decision-making approach, bounded rationality. He explains how cognition, time, resources, and environmental factors bind a policymaker's decision-making behavior. The policymaking process can also be comprised of influential actors that portray irrational or incremental decision-making behaviors. Irrational theorists discuss some motives that guide irrational policy decisions. Vroom (1964) presents the expectancy theory in terms of how political behavior is chosen based on the outcomes and credits one wishes to achieve. Downs (1967) reiterates how most bureaucrats make decisions based on convenience and prestige, rather than public service ethos as Niskanen (1971) discusses. Alternatively, incremental decisionmaking is a successive limited comparisons approach, where policy choices are made based on a comparison of past events (Lindblom, 1979). Simon's satisficing man behaves incrementally, in that rational (reasonable) decisions are made after considering possible alternatives. Although this can help preserve institutional equilibrium, Dahl (1947) advocates for the need to expand the view of a rational man to include the aspect of 
human behavior. Human relations theorists, as a result, call for transformational behavior where all policy actors are included in the decision-making process (Selznick, 1948).

Frederickson and Smith (2011) consider the type of politics exercised as largely dependent on the environmental context. They refer to how motives behind bureaucrats' political behaviors impact the agenda-setting process. Theories of public management and the bureaucracy are investigated in-depth, for a better understanding of how policies are made in the constitutional monarchy setting of Kuwait. Components of the decision theory are applied to the case of Kuwait, with respect to the privatization policy in order to understand the decision-making contexts of the public sector. Although theoretical literature that discusses policy analysis continues to grow, this research contributes new approaches to the interpretivist and social constructivist paradigms through the topics studied. Lindblom (1968:4) reiterates that there is "no beginning or end" to the policy process. In this context, there is a need to first understand the process of policymaking in the GCC, in order to better understand the dynamics of the privatization policy in Kuwait.

\section{Policymaking in the Gulf Region}

The institutional design of a country's government determines how policies are made (Issacharoff et al., 2002). In a comparison of public policies across countries and governments, Blake and Adolino (2001) introduce the interplay of policy procedures and outcomes. While the policy procedures applied impact the policy's outcomes, concurrently, the nature of the policy itself can also determine which policymaking procedures to apply. 
The Gulf Cooperation Council was established in 1981 to unify the social, political, and economic policymaking structures of its member countries (Al-Saud, 1997). The six member countries include Saudi Arabia, Kuwait, United Arab Emirates, Oman, Bahrain, and Qatar. Although the distribution of internal power varies amongst the countries, given the different geographies and population sizes, the constitutional monarchy method of ruling is shared. A review of the GCC Charter (1981) shows that a significant role the council possesses is overseeing the political arena in individual countries to ensure the existence of democratic grounds for public participation. Frederickson (1996) explains how an active and participative citizenry is crucial to having an effective policy process and administrative grounds. One of the main objectives agreed amongst the member states is encouraging the cooperation of private sectors and setting up joint ventures in order to foster development of the economy, legislations, and scientific progress (GCC Charter, 1981).

When comparing western frameworks to structures of the GCC region, one finds variations in the processes, politics, and participants (Khuri, 1990). The interplay of politics and power in the GCC impacts the development of policies regionally. Khodr (2014) attributes this to two main reasons: tribalism and rentierism. Tribalism refers to the system of cultural ties and power founded in the premonarchical Arab societies that still exists in present day (Peterson 2001; Zahlan 1998). Rentierism occurs when states adopt similar policies due the likelihood for regional policies diffusion to occur (Berry and Berry, 2007). The dependence on natural resources and the impact of oil on politics of the country fuels the rentierism debate (Ross, 2001; Gray, 2011). Khuri highlights how 
tribes and monarchies characterize political structures of the GCC region just like power hierarchies and graded authorities characterize the Western countries.

Nevertheless, a comparison of countries within the GCC region can be helpful in understanding how the level of integration and the pace of local governments (LGs) develop on various fronts. Kelly (1968) describes Gulf countries having a similar pace of human settlements and establishments, in addition to external policies and trade relations. All countries have strong bureaucracies where policymaking emerges from, "opaque intergovernmental processes rather than from empowered regional institutions" (World Bank, 2010:2). However, Herb (2002) discusses how the increasing government bureaucracy and intervention is a factor that impacts public sector development.

Simultaneously, there are key differences between local governments of the six countries in terms of local constitutions, roles of politicians, electoral systems, and the degrees of financial autonomy (Nakhleh, 1986). In a study of economic integration within the GCC, the Middle East research unit of the United Nations describes how distributions of each country's hydrocarbon wealth is shared by the public sector of the respective country, which impacts economic reform initiatives such as privatization (United Nations, 1999).

The political processes in Kuwait partly relates to the processes followed in the remaining GCC countries. This is largely based on the commonalities in the historical backgrounds, cultural affiliations, religious ties, and economic resources (Elbadawi and Kubursi, 2014). Essentially, the GCC council was established based on, "an institutional embodiment of a historical, social and cultural reality (...) deep religious and cultural ties link the six states, and strong kin relations prevail among their citizens" (GCC Charter, 1981). The main difference between the six countries lies in the geography, political 
structure, and economic autonomy. Thus, policy adoption in the Gulf countries can be deduced to two main drivers: 1) characteristics of the system, and 2) diffusion processes. Walker (1969) discusses how some states simply adopt policies that are deemed successful in nearby states sharing similar contexts. In their policy diffusion framework, Berry and Berry (2007) relate regional diffusion of policies to the geographic proximity of countries that share similar standards. They discuss the "bandwagon" effect, which Ehteshami (2003) explains to be existent in the GCC, whereby certain policy actions are taken mainly because neighboring countries have adopted similar action plans.

To better understand the policy development process in Kuwait, it is helpful to consider how policymaking generally unravels in the GCC region. Crystal (1995) explains how the concept of tribes and royal families ruling flows through the Gulf, making countries within this region an interesting case to study. Most policies of the GCC focus on similar issue areas in general, however, agenda setting varies in each country.

A review of World Bank reports (2010) on integration in the GCC region provides the some insights. The UAE and Oman are more focused on developing their paths towards globalization and economic development, by increasing private sector involvement. Qatar heavily invests in infrastructure, with an economic policy of increasing private investment in non-energy sectors (General Secretariat for Development Planning, 2011). Bahrain continues to struggle with labor policy issues and economic diversification, however its record of foreign direct investments continues to grow. This is especially after passage of the Free Trade Agreement with the United States in 2006. Policymaking in Saudi Arabia involves the health and education sectors to a great degree 
(Chamber of Commerce and Industry, 1990). Although the Saudi government exercises strong control over economic activities, the country supports private sector growth as an attempt to diversify the economy.

Kostiner (2009) explains how countries within the same region, especially if they share somewhat of a similar sociocultural context, tend to stay within the policy structure of the region. Various reasons support this case, such as the goals of enhancing tourism, advancing economic development initiatives, and maintaining the cultural identity of the region. Berry and Berry (2007) discuss how the geographic proximity between countries is an important factor for policy diffusion within the region. Simmons and Elkins (2004:171) further elaborate how, "Policy transitions are influenced by [...] the policies of a country's sociocultural peers." Furthermore, they are influenced by the social landscape of the country. This refers to policies generated locally, for the purposes of developing and organizing the society. Such policies are specific to the country, as they are based on the capacity of resources and the longer-term vision. The policymaking process in Kuwait, alternatively, does not seem to be focused on a particular area. As Tetreault (2001) discusses, the country strives towards inclusion by focusing on an array of policy issues in its path towards economic development. The Emir's Vision for 2035 reiterates this point, by stressing the need for public sector restructuring, enhancement of work and production processes, business development, consolidation of citizenship and democratization, and strengthening the justice system (Ministry of Planning, 2010; National Assembly, 2010). How effective the policy process is in achieving target goals is investigated through this research. 


\section{Case Study: Kuwait}

\section{Historical Background}

The history of Kuwait began in the early $17^{\text {th }}$ century, as the Utub tribe migrated away from Najd (in Saudi Arabia) and into Qatar, to escape the drought and wars that were widespread in Central Arabia (Alrumaihi, 1986). In Qatar, they learned the fundamentals of fishing, shipbuilding, and pearl diving. After being forced to relocate a number of years later, the families spread across the Arabian Gulf and eventually settled in Kuwait (Abu-Hakima, 1983). The Al-Sabah family, known today as the ruling family in Kuwait, is one of the families in the Utub tribe. The Utub tribe was essentially made up of three families: Al-Sabah, Al-Khalifa, and Jalahima. Al-Khalifa are the ruling family of Bahrain. Alsalamah (2004) continues to explain how Utub's roots date back to the Aniza tribe. The Utub moved again in the year of 1716 to Grane, on the southern coast of Kuwait, and settled next to a small fort called Kut (Al-Hatim, 1980; Kelly, 1968). This officially marked their entry to Kuwait. Modernization of the country began around this fort, as Kuwait was completely a desert land before Utub's entry (Alrashid, 1960). Signs of Kuwait's political identity began appearing in 1752, as Sheikh Sabah Bin Jabir AlSabah was elected by members of the tribes at that time to be the country's first ruler (Casey, 2000). From that date onwards, the country began to establish its sovereign governing system and its economy to withstand the incoming waves of Najd migrants.

As the case in every country, policy development in Kuwait went through different time periods. When the Kuwaiti economy was based on fishing and shipbuilding in the $18^{\text {th }}$ and $19^{\text {th }}$ centuries, policies of that time were centered on housing and infrastructure as the country was establishing its human settlements (Alsalamah, 
2004). During most of the $18^{\text {th }}$ century, Kuwait's economy was more commercial based; the country was known for its natural trade ports (Alrashid, 1960). This economic status however, declined in the rise of wars worldwide and trade blockades that impacted the country's trading abilities. After oil was discovered in the 1930s, the country's political focus shifted to trade and development policies of imports and exports (Crystal, 1992).

According to Alyahya (1993), education began to occupy a strong role in Kuwait in 1955. Between 1955 and present day 2016, Kuwait has developed in various sectors including the economy, education, and health (Schwab and Sala-i-Martin, 2016). Alsalamah (2004) discusses how changes in the government's political agenda were especially apparent after the country gained its independence from the Gulf War. The Gulf War in the 1990s greatly impacted the development process. Kuwait was struggling to define itself economically and politically (Alrumaihi, 1986). Since then, there has been minimal diversity in the economy. As a result, the country's economic development plan (2035) was released after almost a twenty-five year lag. Part of this plan focused on privatization as an attempt to achieving economic development.

Kuwait's political structure is described as a multiplayer network fueled by constituencies and dominating powers in the country (Alessa, 1981). When comparing Kuwait's development process to the remaining Gulf countries, Salih (2013) discusses how reform ideas are proposed but large-scale achievements are scarce. Public expenditures continue to increase exponentially, alongside a declining citizen satisfaction of government's performance (MOF, 2016). When noting problem areas within the current political structures of the country, Trofimov (2009) explains how Kuwait's volatile economy paired with increasing political tensions between the legislative and 
executive branches paved the way for an economic development path of uncertainty. This introduces questions regarding agenda setting and the policymaking process in the country. As the case with most countries in history, the policymaking process is impacted by the political and economic transitions a country experiences over time (Simmons and Elkins, 2004).

\section{Political Environment in Kuwait}

According to Tetreault (2001:203), an early movement in 1938 attempted to establish a constitution and parliament to counteract the growing state autocracy during the reign of Emir Ahmad Al-Jabir (1921-1950). This movement, which deemed unsuccessful, strengthened the role of the ruling family in the country's governance process. When Emir Abdullah Al-Salim Al-Sabah came to power in 1950, the country experienced a wave of modernization that transformed the society (Al-Hatim, 1980). Policies that strengthened the society were developed, education and health services were improved, and income support was ensured to all families. It was not until 1962 that the Kuwaiti constitution was ratified during Sheikh Abdullah Al-Salim's rule. This reform placed the citizen - women, man, and youth - at the heart of the constitution. The constitution defines the system of laws and principles in the country (Ulrichsen, 2014). In doing so, Mernissi (1992) explains how it outlines the parameters of state-society relations, highlighting fundamental components such as the structure of government, its different functions, and power limitations.

As outlined in the Kuwait Constitution (1962), power is distributed in the country amongst 3 authorities: 1) the Executive body, the Government; 3) the Legislative body, 
the Parliament; and 3) the Judicial body, the Supreme Court. The President is the Head of State, overseeing these 3 power structures that run the country. A review of the Parliament's bylaws states that there are fifty parliament members elected by the public during an open, democratic elections process. An additional eleven to sixteen other members are from the Cabinet of Ministers in the Executive Branch of Government.

Moreover, according to the Parliamentary Bylaws (National Assembly, 2009), new policies can be proposed in one of three methods - by the government, by a parliamentary congressional committee, or by an individual member of parliament. The parliament of Kuwait, as per the constitution, is a popularly mandated body that has substantive power in the policy development process. If the government were to propose a policy, this policy is raised to the relevant congressional committee in the Parliament. The committee studies the policy jointly with Ministers and external consultants. The final version of the policy is then released by the committee and placed on the Parliament's agenda items to be discussed. The policy is then voted for approval or debated and returned to the government for further amendments. In the second case, the congressional committee at the parliament directly proposes the policy in the presence of relevant government officials during the committee meetings. The policy is then placed on the government's agenda for voting. There are two terms to the floor's voting cycle. Term 1 is when the policy is returned to the government or relevant congressional committee for amendment. Term 2 is when the policy has a majority vote and proceeds to the level of enactment. Regardless of which body proposes a new policy, voting must take place at the parliament. The policy cannot be enacted without a two-thirds majority vote. The Kuwait National Assembly is comprised of sixty-five members in total, fifty of 
which are legislative members (Members of Parliament) and fifteen of which are executive representatives (Government officials).

Based on the theory that policies begin as ideas (Downs, 1957), the third policy method is a proposal made directly by a member of parliament (MP). Members of the public cannot make a direct law proposal to the government. Instead, they could voice their concerns to their representative MP who would propose the law on their behalf, if agreeable. The MP's proposal can be a new law or an amendment to an already existing one. The MP would raise this proposal to the Head of the Parliament (Majles Alommah), who would then direct the bill to the relevant parliamentary congressional committee for discussion and voting. When any bill, law, or policy obtains the majority vote in Term 2 voting cycle, the policy is then raised to the Emir, the President of Kuwait. The Emir determines whether the policy will be approved or rejected. Once the Emir signs a bill, the country's official gazette (Kuwait Alyawm) prints the final version of the revised bill, after which the treaty has force of law (Article 70, Constitution 1962). From the publication date, the government is granted one hundred days to enact the bill/policy. During this time period, the government develops the policy's bylaws, provisions, and guidelines.

The Kuwaiti population is approximately 4.3 million, which is relatively small when compared to other countries with similar GDP per capita (Public Authority for Civil Information, 2016). This population is comprised of layers of subpopulations, including tribal, family, religious, and political interest groups (Tawfic, 1979). Recognizing the dynamics of the society is a crucial step to understanding the policy processes, especially in a country that represents a transitional society with multiple 
democratic elements. These democratic elements reflect the country's attempt to improve equality, individual rights, and freedoms (Assaad, 2207). Alrumaihi (1994:2) contends that, "there is no single path to democracy." He also notes that democracy in Kuwait is infused by the traditions and culture of the society.

Khuri (1990) discusses how power hierarchies and the way in which the country is politically organized impacts the decision-making processes in Arab societies. The Kuwaiti public sector follows a centralized government system (Barakat, 1993). In relative comparison to the world, one would question how policies are made yet development remains on the lower margin. According to World Bank data (2016), Kuwait's GDP levels surpass those of developed countries, yet economic development lags behind. The Gulf region, including Kuwait, has been understudied. Minimal literature investigates the country's policy processes. The interplay between the monarch's rule, the elected parliament's rule, and how this impacts the policy development process provides for an interesting case study (Crystal, 1995).

The political systems of Kuwait and Bahrain are more open, given their written constitutions, parliamentary electoral systems, and free press, when compared to systems of the remaining GCC countries (World Bank, 2010). Compared to Bahrain, Kuwait is more developed in its infrastructure, economy, and various other public sectors of the country (Central Statistical Bureau, 2014). During the 1940s, Kuwait was known to be a pioneer in the Gulf region, leading the United Arab Emirates, Saudi Arabia, Qatar, Bahrain, and Oman. Alrumaihi (1994:3) explains that, "Kuwait has taken the lead among the Arabic-speaking states toward civil society and representative government.” Tetreault (2001:205) elaborates that the, "urban Kuwaiti society (of the $20^{\text {th }}$ century) is arguably 
the most modern in the Gulf region." Although economic development lags behind when compared to the United Arab Emirates, for example, the political structure of Kuwait had early on incorporated democratic features by establishing a parliament three years postindependence (Alrumaihi, 1986). The constitution itself has liberalized the political system granting people privileges and rights, such as the freedom of speech, more so than the remaining GCC countries (Ulrichsen, 2014). Moreover, the existence of a popularly mandated parliament that is elected by the public in an open elections process, distinguishes Kuwait from the remaining GCC countries.

Overall, public policies in Kuwait have evolved through different time periods, all developed within constitutional grounds. The privatization policy was officially enacted as Law 2010/37 in May 2010 (Kuwait Alyawm, 2010). Six years into passage of this law and no implementation has happened (MOF, 2016). This research builds on previous privatization literature by applying Kingdon's (1984) policy framework model that combines elements of theories and policy frameworks through history, to better explain the dynamics of policymaking in Kuwait. The 'how and why' of privatization policy is investigated further. Subsequent sections of this chapter provide a literature review of privatization through history of the Gulf region and particularly in Kuwait.

\section{Privatization: Theory and Practice}

\section{Historical Overview}

Privatization, as Mahmoud (1992:33) defines it, is the devolution of government property and assets, involving certain governmental services and responsibilities, to the private sector. It is a popular reform strategy in the developing world. As with various 
reform approaches, support and opposition exist alongside cases of success and failure. The Westminster model of privatization was introduced in New Zealand during the late 1970s. This approach was then adopted by the United Kingdom to restructure public organizations (Kettl, 2005). The second form of privatization was that of the United States, known as the American style reform. The focus of this approach shifted towards the operational aspects of public organizations. Thereafter, the reform strategy was introduced in Europe and the rest of the world, as a movement towards new public management (Osborne and Gaebler, 1992). The managerial reforms of the 1970s and 1980s were directed at reforming organizations by developing new techniques and business-like values. The movement towards New Public Management embraces the idea that governments should 'steer and not row' (Osborne and Gaebler, 1992). This new approach of having third-party organizations deliver public services was adopted not only in the United Kingdom and United States, but also in developing countries worldwide. Kuwait is one of the countries that strongly considered its role in this movement.

The past two decades have witnessed more attention devoted to the business side of government, precisely efficient and effective organizational performance. White (1954) explains that administration of a public entity is further strengthened throught he cooperation of more than one sector. In theory, private ventures exist to aid public entities large-scale programs. Literature discusses the various forms of privatization. According to Savn (1992:573), there are four common methods:

1. Divestiture - privatizing management of the public asset using leases and contracts, also referred to as contracting out;

2. Stock sharing; 
3. Sale of public assets - privatizing ownership;

4. Spinning-off public assets to private sectors.

The worldwide movements towards offering quality services at lower costs, presented privatization as a reform strategy that decreases the government's burden. Privatization was initially proposed to enhance the role of private sectors in the public services' delivery process. Capitalist theorists, such as Adam Smith (1776), view private sectors as more efficient bodies in ensuring the most optimal outcomes for service delivery. Smith (1776) called for a government structure that supports a free economy, in which an "invisible hand" brings about market equilibrium. His laissez-faire capitalism emphasized the positive impacts private intervention can have in the public sphere. Proponents argue that inclusion of private sectors in service delivery expands the multiplayer industry, raising concerns for accountability and efficiency due to the resulting fragmented government structure (Sullivan, 1987).

Privatization theory discusses the different ways in which the private sectors can contribute to the policymaking process. Lindblom (1977) introduces the concept of 'politico-econ processes.' He explains how politics and markets cannot be separated from each other, as they possess joint values of efficiency, liberty, equality, and popular control. Weimer, Vining, and Lowery (1998) further acknowledge that a perfect market is one that is moderated by both the private and public sectors, rather than having one sector control the market. From their perspectives, the market fluctuates and having healthy, competitive grounds can improve a country's development process. Weimer and Vining (2004) define an ideal economy as one that is perfectly competitive, consisting of utility maximizing firms and self-maximizing consumers. In their explanation of a market-based 
economy, the private sector can fail in the existence of externalities, rise of natural monopolies, and information asymmetry. At the same time, the public sector fails when systems are structured as democracies and representative bureaucracies, in the way that minority groups are neglected and self-interested politicians dominate the decisionmaking arena. As such, the government intervenes to distribute the functions of private and public sectors via public policies that moderate the economy, political structures, and morality of actions. To avoid failures from both sectors, Le Grand and Bartlett (1993) discuss policymaking that supports the development of quasi-markets, in which market approaches like privatization are injected in the public sector.

As a policy response, privatization also yielded controversial opinions. Theorists such as Osborne and Gaebler (1992) expressed their agreement of exploring alternative venues as new methods for government operations. However, opposing views such as that of Savas (1987) argued that cost-effectiveness should not be seen as the only key to better government. Indeed the viability of government need not be measured solely by its cost burden and quality outputs. The level of policy inclusivity and the steps leading up to policy formulation and successful implementation, are factors that must be considered prior to suggesting privatization as a solution to government performance. Even with the public's support and successful implementation initiatives, Rosenbloom (2007) argues the need for continuous evaluation of current conditions in order to strengthen performance levels. In the United States, it has been considered that political decisionmaking should focus more on democratic-constitutional values. This is especially important in the modern multiplayer government structures, globally. 
Scholars, such as Terry (1998) and Light (1997), support the privatization claims of cost-effectiveness, healthy competition, and decreased government burden. The aforementioned arguments are most compelling for this research. However, it is important to acknowledge the relatedness of contrasting viewpoints. By contrast, studies by Carolyn and Lynn (2000) conclude that privatization introduces the issues of market failures, monopolies, and inequalities.

Public choice theory explains how involving private sectors in public services delivery ultimately decreases the government's burden and establishes a market dominated by competition and public choice. Ostrom (1973) explains that these market forces help in increasing responsiveness and efficiency, while decreasing costs. However, views opposing this new public management approach argue that privatization of public services instead expands the multiplayer industry making it too fragmented and bureaucratic to implement policies effectively (O'Toole, 1987; Bevir, 2010). This raises concerns of accountability and efficiency given the resulting fragmented government structure (Kettl, 2002). Nevertheless, in a welfare market, there are circumstances where the market sometimes fails to distribute goods equitably (Weimer and Vining, 2004). This is when the government would intervene to reinstate stability. Howlett and Ramesh (1995) discuss the need to regulate distribution during these times. As seen, there are two views to the privatization spectrum. In the end, a situational analysis and consensus must be conducted prior to proposing such a reform strategy. This research looks further into the dynamics the privatization policy in the case of Kuwait. 


\section{Objectives of Privatization}

Various reasons contribute to the government's consideration of privatization as a method of improving performance. Some of these most prominent reasons include increasing budgetary expenses, lack of citizens' trust in the government, and the inability of public enterprises to contribute to the government's overall policy. Due to the relatively weak performance of state-owned enterprises (SOEs) in industrial countries, privatization helps improve efficiency and competition (Ray, 1980). In this context, privatization was proposed early in the developing world to fulfill various objectives. Mainly, Savn (1992) explains that it is a reform strategy that public enterprises incorporate to overcome development problems. From a power perspective, privatization serves to enhance the governance structure. Kettl (2002) explains governance to be the link between the government and the political, social, and administrative environments in the country. In adopting this reform, governments acknowledges the need for the devolution of authority as an attempt for social inclusion.

Kay and Thompson (1986) list the objectives of privatization to be the reduction

of the state sector, revenue generation for the government, enhancement of competition, and increasing the speed of decision making. Privatization in Brazil, Pakistan, and Jamaica successfully managed to equalize outputs with costs and prices (Jones and Wortzel, 1982). However, the growing number of private sectors participating in public services delivery has resulted in deficits of the management structure overall as various public posts remained vacant (Nellis, 1986).

The objectives of privatization, as Bishop and Kay (1989:643) explain, are "to reconstruct (public) enterprises so as to create conditions that make private sector 
operations effective and efficient." Ostrom (1973) discusses some of the benefits of decentralizing authority is that the government becomes more responsive to public demand for quality services. Some of the most common challenges faced when privatizing public services include mismanagement, corruption, capacity issues, and expanding networks. A study conducted by the World Bank (1983) highlights the main objective of decentralizing government. It involves transferring the responsibility of public functions from central government to local governments, quasi-market institutions, NGOs, and/or private organizations. The government's structure shifts from the common Weberian centralized bureaucracies, to more corporate governance structures of flatter hierarchies, a wider span of control, and bottom-up policymaking processes. Ray (1980) discusses how integrating the country's private and public sectors, distributes oversight and disrupts the formation of monopolies due to the growth of health market competition that distributes power and authority. As seen, there are multiple objectives that privatization can fulfill based on the privatization method implemented and the mix of goals that a country's respective government pre-determines.

\section{Privatization a Policy Response}

\section{GCC Experience}

Although the United Kingdom is generally considered to be a pioneer in privatization practice (Kay and Thompson, 1986), other countries in the Gulf region have followed this course of action as well. The private sector's economic growth in the Gulf region has attracted substantive attention, however their political contribution is still limited. 
As discussed in previous sections, policymaking processes in GCC countries are similar in many aspects due to the similar social, economic, and political structures in the region. Although the needs supporting privatization proposals are also similar, Alomar (1996) highlights the main differences in institutional capacity and the economic and regulatory conditions of each country. The privatization method commonly implemented in the GCC region is divestiture/contracting out. Prager and Desai (1996) explain this as a form of collaborative governance that is based on "steering, not rowing." Steering, in this context, refers to unleashing the market forces. Alomar (1996) explains how it was not until the 1990s that countries of the Gulf region began to implement privatization. The Kingdom of Saudi Arabia first approached privatization in some of its state industries in an attempt to attract private sector investment in government-run infrastructure projects (Ramady, 2010). Oman's initial approach was public floatation of some governmentowned entities, after which the United Arab Emirates, Qatar, and Bahrain began to revert to this reform strategy as well (Ahmad, 1990). During that time, however, Kuwait was still studying how to go about this public restructuring method.

The private and public sectors collaborating in these initiatives share similar goals, but different authority relationships. By allowing the private sector to manage the publicly owned enterprises, the government is able to benefit from the private sector's expertise, reduce the internal bureaucracy and burden, and overcome the constitutional constraints due to the separation of powers (Marsh, 1991). Although this method has just recently been considered in the Gulf region, the cases of prisons in New Jersey and welfare administration in Indiana present examples of how contracting out can be problematic when service quality is reduced for the sake of cost-cutting (Epstein, 2012). 
This results in political issues of citizens' distrust in government. Furthermore, the case of the World Bank's water utility privatization program presents an example of failed privatization initiatives due to weak market competition (Perkins, 2016). In this context, statutes help identify the activities that are inherently government and those that can be privatized so as to avoid the occurrence of such problematic issues.

Zahariadis (2014) explains how privatization gained prominence in the United Kingdom, more so than in Germany, due to the degree of integration in the policy communities. Compston (2009) defines networks to be interdependent as they share goals, interests, and values. Zahariadis claims that more integrated networks follow an emergent and convergent policy development process, while less integrated networks posses policy processes that are quantum and gradualists. These terms are best defined by Durant and Diehl (1989), where quantum is the rapid propulsion of new ideas, emergent is the gradual gestation of new ideas, convergent is the rapid gestation of old ideas, and gradualist is the slow gestation of marginal extensions of existing policies. In the case of privatization's policymaking in the GCC, literature reviewed indicates that Saudi Arabia and the United Arab Emirates are leading the preliminary implementation stages for this policy in the Arab Gulf region.

The Kuwaiti government sectors are centralized and bureaucratic (Selvik, 2011). With increasing dissatisfaction in government's performance, one questions how policies continue to be made yet development is minimally witnessed. To understand the processes of policy and decision-making in developing countries like Kuwait, this research helps analyze the recent privatization policy. Conducting a historical research provides a solid background for the current situation in the policy arena. This research 
builds on previous privatization literature, by applying policy frameworks such as Kingdon's (1984) streams model and Sabatier's (2007) policy cycle, to better explain how such an issue gained dominance on the government's agenda.

\section{Privatization's Human Capacity Issues in the GCC}

Alomar (1996) discusses how the privatization in the form of divestiture is the most common approach in the GCC region. However, this policy response has raised human capacity issues over the past recent years. Achoui (2009) discusses some of the most common human capacity issues in the Gulf, which include the large expatriate labor force, the low rates of female employment, and the weak link between the education systems and needs of job sectors. This results in an unskillful national workforce.

Additionally, Abed and Davoodi (2003) contends the growing unemployment rate as negatively impacting economic growth in the Middle East. As a result, Budhwar and Mellahi (2007) discuss how oil-dependent countries of the Gulf began to emphasize development of their human resources. According to the World Banks's (2010) study of social integration in the GCC, a labor market strategy is needed to both assess human capacity issues of immigration and revisit fiscal policies at the regional levels. The World Bank advocates for diversification of revenue sources and, "service sector liberalization, which would expand the size of markets and promote the efficient allocation of resources for the GCC as a whole" (21).

\section{Privatization in Kuwait}

The vision of privatization in Kuwait was first discussed in a Ministerial committee in the 1980s, as the country was going through an economic recession 
(Alkoumi, 2010). The committee was formed to develop solutions to the economic and administrative problems in Kuwait at that time. The result of those meetings was a preliminary proposal of privatization as a solution, however further information was needed as this reform was only known to the Western institutionalized democracies at that time (Alsaigh and Buera, 1990). As such, the Ministries Council tasked Kuwait Investment Authority - the country's sovereign wealth fund that manages all assets in the country - to convene a high-level committee to investigate this reform's feasibility (Kuwait Alyawm, 2010). The committee included representatives of important public bodies in the country, such as the Ministry of Finance and the Chamber of Commerce and Industry. The members agreed to commission the World Bank to explore this vision's implications in Kuwait. This was the first study to be conducted, however it was too inconclusive and merely a consultancy overview. The World Bank concluded, in their 1993 study, the potential for privatization in developing the economy, however further market research was required (World Bank, 1993).

Alomar (1996) explains how discussions and lobbying efforts continued to escalate since the World Bank's study. However, this research explores further reasons of the time gap between the late 1990s and early 2000. It was not until 2009 that the government proposed to the parliament, of that time, an official privatization policy proposal (Alrayih, 2011). The proposed law then passed through the normal legislative process where it was first studied in the economic, financial, and legislative parliamentary committees (Kuwait Alyawm, 2010). Thereafter, a final draft of the privatization bill 2010/37 was released to the parliament for voting. In agreement with the 
new realities of delivering public services, the parliament approved the Privatization Law 2010/37 as a means for economic and social development.

In the Emir's vision for Kuwait 2035, Sheikh Sabah Al-Ahmad calls on all sectors of the country to work collectively on making Kuwait a financial and commercial center that is attractive for investments (Ministry of Planning, 2010). The Emir explicitly mentions how he envisions the private sector to lead this economic activity, in the spirit of healthy competition. The objective is to increase production levels and the efficiency of services, in light of a supportive government and strong values that maintain the country's social identity. The goal is to achieve human development and a balanced economy that is possible with supportive legislation, a healthy environment, and strong infrastructure that facilitates business activities.

According to the Kuwaiti constitution (1962) in which ownership of some public services and assets, such as health, education, and oil production, belongs to the government (Constitution, 1962), the privatization bill only approves the establishment of joint stock companies. Weible (2014) defines public policy to be a decision of the government, irrespective of whether action is actually taken. Birkland (2010:7) explains how policies can take many forms. He states that, “A policy might be a law, or a regulation, or the set of all the laws and regulations that govern a particular issue area or problem". It can be a statute, an executive decision, or even a government program. In the case of Kuwait, the privatization policy was passed as a law.

Privatization Law 37/2010 was still not official until the Emiri decree was issued on the 30th of May 2010 (Ministry of Planning, 2010). Soon after, the Ministry of Information published it in the national gazette. The law was in effect once published in 
the country's official government gazette, Kuwait Alyawm, on the 13th of June 2010. Since the law's enactment, privatization efforts are yet to be witnessed across the country's public sector (MOF, 2016). This situation, to an observer, raises questions regarding the policymakers' motives when approving the policy and whether the policy's eventual implementation is truly the solution to what the government perceives the public problem(s) to be. While policymakers continue to ponder privatization's implementation in Kuwait, public sector performance is continuing its steady decline with low satisfaction and distrust in government (Altamimi, 2015). Analyzing Privatization Law $37 / 2010$ as a case study for this research, provides a better understanding of the political decision making process in a sociopolitical setting like Kuwait.

\section{Role of International Organizations}

As worldly governments evolve in their approaches to policymaking and agenda setting, politicians are expected to work even harder to preserve the democraticconstitutional values. In this context, the role of international organizations in maintaining democratic grounds and equality for all has strengthened accordingly (Mansfield and Pevehouse, 2006). This is especially important in the globalized, multiplayer government structures that dominate most countries today. Of the focal points included in Al Gore's National Performance Review are the decision-making processes used at state and national governments (Kamensky, 1996). Kamensky discusses how these processes determine a policy's level of efficiency and the anticipated level of support for policy proposals. 
Reviews of countries' policy processes reflects that public policies are usually formulated with two perspectives in mind - the legislations, as outlined in the country's constitution, and the international law, as enforced by international organizations of which the country is a member (United Nations, 2016). The situation of international organizations in the GCC region is a peculiar one, as they attempt to influence policymaking in the region but are not able to use financial instruments to advance their policy agendas (e.g. World Bank, United Nations Development Programme - UNDP, International Monetary Fund - IMF). Countries of the Gulf region perceive these international organizations as peacekeeping bodies that provide support for the national pursuit of sustainable development goals (UNDP, 2016). According to Wainhouse (1973), most of the international organizational influences are in the areas of security, the economy, environment, and human rights. Political and administrative assistance is limited to consultations and strategic proposals. This relationship is unique considering the political frameworks of monarchical rulings in the Arab states. As such, even with security matters, these organizations can be limited in their contributions as there is considerable controversy as to whether or not resolutions reached are legally binding (Schwartz, 1977).

Consequently, the most prominent roles played are those that involved economic development, in which IMF and World Bank are leaders. One of the most recognized roles international organizations played in the Gulf region includes that of the IMF during the plunge of oil prices in the 1980s (Shah, 2007). Most Arab states, except the Gulf states, turned to the IMF during their budgetary crises. However, within the Gulf region, the IMF pursued a consultative role with the respective governments. 
International organizations can contribute in one of three ways in the GCC countries -1 ) through long-term beneficiary partnerships with the government, 2) project-based external consultative status, or 3) through a field office/presence in the country (Baker, 1994; Russett and Sutterlin, 1991). Regardless of their role, Nakhleh (1986) explains how all contributions are in the form of consultancies due to the political structures of the countries being constitutional monarchies. However, the global recognition and reputation of such international actors, allows them to impact the policy processes on a larger scale in the relatively less institutionalized contexts of the GCC countries (Dolowitz and Marsh, 2000:10).

The role of international organizations in the policy development process of privatization in Kuwait was mostly consultative. There were two preliminary initiatives from the World Bank and IMF reporting on privatization and economic development in Kuwait. The World Bank (1993) expressed support for privatization initiatives, in terms of reforming public enterprises. Acting as a supranational institution, the World Bank pursued the role of an international policy entrepreneur. The IMF (2013) discussed the economic gains the country would benefit from post-privatization implementation. However, other aspects such as the labor market would be affected in the process as most of the public sector in Kuwait has a large expatriate labor force (Central Statistical Bureau, 2014). As such, the privatization law attempted to address these consultations received from international organizations.

\section{Conclusion}

Most of the policymaking models reviewed are oriented towards Western democratic systems and thus fail to capture country-specific elements. The nature of 
policymaking in the Gulf region, especially in Kuwait, is unique with the constitutional monarchy setting and the partly democratic rule. As such, subsequent sections of this research explore the case of the privatization policy in Kuwait from the perspective of Kingdon's policymaking model. The research questions that guided this study are developed based on Kingdon's model. Thus, each stage of the policy making was investigated for the case of the privatization policy. Chapter 4 provides an analysis of the data collected from the in-depth interviews, focus groups, and documents reviewed. 


\section{CHAPTER THREE}

\section{METHODOLOGY}

\section{Introduction}

A thorough review of the literature and policymaking frameworks reflects four main stages to the policy process: agenda setting, formulation, implementation, and evaluation (Kingdon, 1984; Sabatier, 2007; Olshfski and Cunningham, 2008). As such, the research questions were devised to reflect each stage of the public policy process. The fifth research question moves beyond the policy stages to incorporate the aspect of decision making. Dye (1987) explains how decision-making is a crucial component of the policy development process. In this context, interview and focus group questions were developed based on literature in the field. Data collected from the three methods employed, provided answers to Kingdon's Multiple Streams Analysis - problem, policy, and politics - in addition to each stage of the policy development process.

\section{Purpose of the Study}

This research seeks to provide a framework for understanding the nature of policymaking in the GCC region in general, and in Kuwait in particular with respect to the privatization policy. Through means of data gathering, the study provided community members a platform to voice their thoughts of policymaking and implementation in the country. It is expected that these shared perspectives will inform practitioners of possible ways to improve the efficacy of government policies, and assist academics when

conducting scholarly comparative work and advancing development literature of 
relatively less institutionalized countries. The goals of this research are to communicate the fundamental structure of policymaking in Kuwait - takeaways of which can apply to similar political contexts in the Gulf - and to analyze a policy issue from a theoretical standpoint, which has not been applied in Kuwait. Olshfski and Cunningham (2008:10) discuss how, "agenda-setting in policymaking literature has not received much attention in the administrative arenas." Stone (2002) explains how this vague understanding of policymaking has resulted in public dissatisfaction in the way the government is run. Thus, little is known about how political agendas are set and how decisions are made, despite the growing body of literature discussing policy development processes. The linkages between different components of the policy subsystems are analyzed in the case of privatization policy in Kuwait.

As explained by Patton (1990:71), a phenomenological study focuses on, "descriptions of what people experience and how it is that they experience." Thus, the purpose of this phenomenological study is twofold: 1) to describe the policymaking process in the region, more specifically in Kuwait, and, 2) to explore how policymakers directly involved with formulating and implementing policies experienced this process with the privatization policy. Knowledge generated from this study is expected to guide policymakers and administrators of more effective and responsive methods when making or implementing countrywide policies. It is anticipated that key stakeholders will be informed of dominating issue areas, so as to increase the efficacy of privatization initiatives. Application of the theoretical policymaking models helped assess policymaking problems from various angles, in order to provide recommendations for policymakers and administrators of the existing opportunities for improvement. 


\section{The Phenomenological Method}

Phenomenology is commonly studied in the disciplines of psychology, social sciences, political science, and social work (Van Manen, 1990; Moustakas, 1994). As an approach in social sciences, it dates back to Husserl in the early twentieth century. Husserl looked at the problem from within, interpreting reality from aggregate perspectives. The overarching idea is that reality is composed of various interpretations that collectively relate to a larger meaning (Husserl, 1931). Through the process of selfreflection, researchers are able to understand the social and historical contexts within which social decisions and policies are made. Phenomenology, as an interpretivist approach, views humans as active agents rather than passive respondents (Holstein and Gubrium, 1994). Schwandt (2000) explains how such discourse facilitates actions. Through the process of self-reflection, researchers are able to understand the social and historical contexts within which social decisions and policies are made. As such, the method of phenomenology was used to explore this research topic further.

Qualitative researchers, "study things in their natural settings, attempting to make sense of, or interpret phenomena in terms of the meanings people bring to them" (Denzin and Lincoln, 2005:3). Phenomenology, as a qualitative research method, is an approach widely used in social sciences to understand concepts and worldly events from the perspectives of individuals directly experiencing it. Social science literature recognizes this methodology as an effective approach of looking at the problem from within, interpreting reality from aggregate perspectives (Van Manen, 1990). Phenomenological research questions do not, "seek to predict or to determine causal relationships," instead 
they are, “.... illuminated through careful, comprehensive descriptions, vivid and accurate renderings of the experience rather than measurements, ratings, or scores" (Moustakas, 1994:105). It is an understanding of how the everyday, inter-subjective world is constituted (Schwandt, 2000). The underlying assumption is that, "we can only know what we experience" (Husserl, 1970). The phenomenological components of this research explore the lived experiences of key decision makers directly involved in formulating and/or implementing policies in Kuwait, to provide for a better understanding of the policymaking processes. Experiences are explored in terms of meaning, structure, and essence (Patton, 1990).

Patton elaborates on how interviews are the major datum source for phenomenological studies, as they convey perceptions of lived experiences. Researchers generate "a composite textual-structural description of the meanings and essences of the experience" (Moustakas, 1994:121). Coding is mostly used to develop common categories and themes for the data collected.

\section{Research Design}

This research builds on the interpretivist and social constructivist paradigms. Guba and Lincoln (1994) explain how the naturalistic methods of interviewing and text analysis are most suitable for interpretive approaches. Qualitative methods are typically used, in which meanings and understandings emerge during the data collection and analyses stages. As such, this research is designed qualitatively with a holistic approach. According to Creswell (2007), this methodology provides a complex, detailed understanding of the issue and helps achieve greater breadth and depth to the data. 
Bernard (1994) explains how a qualitative approach is most applicable to research that involves describing the contexts and settings that study participants are engaged in. Patton (2002:432) expands on this view, stating that, "in this complex and multi-faceted analytical integration of disciplined science, creative artistry, and personal reflexivity, we mold interviews, observations, and field notes into findings."

The scope of this study generally revolves around political decision-making. Thus, it is important to acknowledge what Stone (2002:8) defines politics as, "the struggle over ideas seen from multiple perspectives, rather than objective facts." In this context, the use of the phenomenological method for data collection and analysis is most fitting, as this method involves the, "study (of) things in their natural settings, attempting to make sense of, or interpret phenomena in terms of the meanings people bring to them" (Denzin and Lincoln, 2005:3). Rossman and Rallis (1998) describe phenomenology as a tradition in German philosophy that focuses on the essence of lived experiences. Through dialogue and reflection, the quintessential meaning of the experience is reviewed and language becomes the primary symbol system through which such meanings are conveyed (Holstein and Gubrium, 1994). The purposes of phenomenological inquiry are description, interpretation, and critical self-reflection into the world as world (Van Manen, 1990:72).

To respond to the research questions guiding this study, research participants had to be engaged in the processes of reflecting on their experiences as active or passive participants in the policymaking process and sharing their perceptions of this experience with regards to the privatization policy. This method of inquiry aligns with the phenomenological research method. Creswell (2007) explained how interviews are a key 
means to obtaining data in phenomenological studies. As such, this study was designed as a qualitative research. Data were collected in the form of in-depth interviews, focus groups, and document reviews of secondary sources to analyze existing data.

\section{Research Questions}

The research questions guiding this study are exploratory, employing mostly an inductive approach complemented by a deductive approach. Creswell (2007) best explains the inductive approach as patterns, categories, and themes built, "from the bottom-up, by organizing the data into increasingly more abstract units of information." The deductive approach, where questions are asked based on a guiding hypothesis, was primarily used for the first research question. Each research question refers to a particular stage of the policy process as per Kingdon's (1984) theoretical framework discussed in the literature review. Additionally, each stage of the policymaking process was investigated through a series of probing questions. This part focused on the following research questions:

(1) What factors and elements drove the agenda-setting process in the case of privatization policy in Kuwait?

(2) What problems does the privatization policy address?

(3) What are the obstacles facing implementation of the privatization policy in the case of Kuwait?

(4) To what extent did the policymakers consider evaluation criteria when adopting the privatization policy? 
(5) To what extent does decision-making in Kuwait follow any of the theoretical frameworks?

The following guiding hypotheses to the above mentioned research questions were drawn from a review of the literature.

H1: Four sets of factors and elements drove the agenda-setting process in the case of privatization policy in Kuwait: Perceived problems, actual problems, political preferences, and economic benefits.

H2: Privatization of the public sector is generally viewed as an enhancement of the country’s economic development process.

H3: Obstacles facing implementation of the privatization policy in Kuwait include: policymakers' problem definition, capacity issues, and lack of legislative support. H4: There is a lack of evaluative criteria for public policies in Kuwait.

H5: Policymaking in Kuwait resembles a 'garbage can' decision-making model. Stone (2002) explains this to be situations in which the decisions are made first and the means are determined thereafter.

Data gathered not only elicit information regarding privatization as a policy case study, to better understand the policy actors, determinants, and processes. The data also elucidate information of the overall dynamics of policymaking and political decisionmaking in Kuwait. All interviews and focus group sessions were conducted in a semistructured format, so as to guide the discussion yet allow participants to diverge as per their perceptions and experiences. 


\section{Data Collection}

Primary data were collected in the form of interviews and focus groups, constituting the larger portion of the analysis. Secondary data, in the form of document reviews, comprised the remaining part of this research.

Thirty interviews were conducted with policymakers that are in an executive decision-making position of a public, private, or nongovernmental sector in Kuwait, plus international organizations. Initially, thirty-eight interview requests were sent. Of those invites, thirty confirmed their participation. There is no consensus among phenomenological researchers of the target size for study samples. Since the main data collection method for phenomenological studies is interviews (Holstein and Gubrium, 1994; Giorgi, 1985), Guest et al. (2006) explain how sample sizes range from a minimum of six interview participants to a maximum of twenty-five. Englander (2012) elaborates on how a sample greater than twenty interviewees falls on the higher end of target sample sizes for phenomenological researches in general. Phenomenological researchers are not focused on the number of participants to include, rather the deep insight that participants can relay given their intimate experiences with the phenomenon studied (Van Manen, 1990). Nevertheless, the interviewees' sample included in this research is a universe sample. The in-depth interviews lasted between sixty to ninety minutes each, face-toface, conducted in a semi-structured format. Interviewees were recruited via email, where a letter was shared explaining the research's purpose and significance of their participation in the study. A mutually convenient time was scheduled, during which the interview was conducted at the participant's office location. 
There were four focus groups in total, composed of seven to eight participants in each group. Participants were either university graduate students or members of the society, at large. As Morgan (1997) explains, focus groups help the researcher obtain several perspectives of the same topic. The perspectives of study participants provided an opportunity to observe group dynamics and interactional processes. Kreuger (1988) discusses the features that distinguish focus groups are the insights shared and the data that result from the interactions of participants. Participants felt empowered as a result of participating (Goss and Leinbach, 1996). Kitzinger (1994) agrees that the interaction between focus group participants enables them to ask each other questions while reevaluating their own understandings of their personal experiences. Focus group discussions were conducted in a semi-structured format and the duration of each session was sixty minutes.

Secondary data, in the form of document reviews, constituted the final data collection method for this research. Sources included news outlets, government publications, parliamentary hearings, ministerial reports, and reports from international organizations. Reviewing data from these sources provided knowledge of past and current policy actions.

Data were collected through the process of note taking and transcription after each data collection session. The researcher maintained a reflective journal of the public agencies visited during the interviewing process. The purpose was to better understand the contextual structure and the sequence of events that lead up to policymaking, implementation, and evaluation. The reflective journal was also an additional step to eliminate any possible subjectivity. The researcher documented thoughts and 
interpretations as side notes to self, in order to eliminate all inferences during data analysis. Nvivo data analysis software was used to analyze all data collected from the interviews, focus groups, and document reviews, using the phenomenological method. Data were transcribed and coded into themes and categorical descriptions.

\section{Study Sample}

There were two methods of data collection that involved research subjects, interviews and focus groups. The study sample included representatives of different population subgroups that are relevant to the research questions studied.

\section{Interviews}

The purpose of this research is to describe the policymaking process in Kuwait by exploring policymakers' experience with the recent privatization policy. As such, the first sampling method applied to select interviewees was criterion sampling. First, an initial literature review of Privatization Law 2010/37 indicated that the Ministries Council and

the Kuwait Parliament were the official authorities that approved the law. However, these two authorities also deal with other policy issues that are beyond this research's scope. As such, criterion sampling within those two sectors was applied. Patton (2002:238) explains criterion sampling as, "selecting cases that meet some predetermined criterion of importance.” Interviewees at the Ministries Council and the Parliament were selected based on their executive decision-making position in the country, direct involvement in formulating the privatization policy, and employed in the position for at least three years given the standard four-year time frame of most public posts in Kuwait (CSC, 2012). Thereafter, snowball sampling was employed as the second recruitment method. In 
snowball sampling, interviewees were asked, towards the end of the interview session, to identify further study participants that were executively involved in formulating and/or implementing the privatization policy. In the end, the interviewees' sample included in this research is a universe sample.

Guest et al. (2006) explain how this process provides for a sample of interview participants familiar with the work processes and experienced enough to share perspectives that will enrich the study. It was important to make sure that the sample of interviewees was a representative one, where all of the country's sectors that actively contributed to developing the privatization policy were represented. Creswell (2007) elaborates on how this method is most fitting for phenomenological studies as participants must be closely familiar with the phenomenon. Ultimately, the interviewee research sample included representatives from public agencies, private sectors, government sectors, academic settings, and international and nongovernmental organizations. More precisely, the sectors included:

- Public Agencies: Arab Planning Institute (API), Communication and Information Technology Regulatory Authority (CITRA), Kuwait Fund for Arab Economic Development (KFAED), Kuwait Investment Authority (KIA), Central Bank of Kuwait (CBK), General Secretariat of the Supreme Council for Planning and Development (GSSCPD), Kuwait National Petroleum Company (KNPC), Supreme Council of Privatization (SCP)

- Private Sectors: Boubyan Bank (BB), Global Investment House (GIH);

- Government Sectors: Kuwait National Assembly (KNA), Ministry of Health (MOH), Ministry of Planning (MOP), and Ministry of Finance (MOF); 
- Research and Academic Sector: Kuwait University (KU);

- Nongovernmental Organizations (NGOs) in Kuwait: The Lawyers Association (LA), Citizenship and Development Association (CDA);

- International Organizations: United Nations Development Program (UNDP), United Nations Office for Human Rights in the Middle East and North Africa (UN MENA), and the World Bank.

Sabatier and Jenkins-Smith (1999:124) explained how policymaking involves participants from, "all levels of government, multiple interest groups, and research institutions." To avoid sample bias, the researcher asked every interviewee to confirm the sectors/executive personnel that participated in developing this policy. The researcher repeated this process until the interviewees' responses were consistent, in order to be certain that all sectors relevant to the research questions were included in this sample.

\section{Focus Groups}

According to Stone (2002), a policy action serves as an agreement between the bureaucracy's decisions and the greater public's preferences. Literature acknowledges the role the public contributes to a country's policy development process. Although the interviewee sample comprised members of NGOs in Kuwait that equally represent the public's voice, additional focus groups were included as part of the research sample.

There were two categories of focus groups. The first category was graduate university students. Almughamis (2016) explains how students in the student government of Kuwait University play an active role as the voice of youth in the society. Approximately forty percent of the Kuwaiti population comprises the age group of 
twenty to thirty-five years old (Central Statistical Bureau, 2014). UNDP (2009)

documents the increasing number of graduate students, eligible to vote, participating in campaigns of parliamentary candidates full-time during the recent elections cycles in the country. Moreover, these graduate Kuwait University students have the eligibility to become members of local NGOs and registered employees at the Civil Society Commission. In addition to a variety of public services, the Civil Service Commission is mainly involved in employing Kuwaiti nationals across the country's public sector (CSC, 2016). Within the context of this research, the criteria for the first category of focus group participants included students in pursuit of a graduate degree at Kuwait University, that are also members of the student government. The researcher controlled for the effect of gender impacting participants' contributions, by conducting two focus groups - all males and all females. Further, to enhance diversity, each of these two groups consisted of a minimum representation of four colleges at the university. As such, a criterion sampling approach was applied along with volunteer sampling.

The second category of focus groups includes members of the society. Diwaniyas and Istiqbals are important elements of the Kuwaiti culture (Tawfic, 1979). A Diwaniya is an open space, where men of the society convene to discuss issues of the day. In history, a Diwaniya is a gathering place where one or a few related men would receive other male guests of different profiles and backgrounds (Miller, 1984). Today, the diwaniya is an integral part of Kuwaiti society and an indispensable feature of a Kuwaiti man's social life (Fattahova, 2011). Alfuzai (2016) explains how this salon concept of a male domain has transformed through history, appealing to females of the society that wanted a similar themed venue. Istiqbals became known as the traditional gatherings for 
women of the society. These gender-specific, informal salon gatherings are part of the everyday culture; members, regardless of profession, background, or social/familial affiliation, convene to discuss a range of issues (Clawson, 1997). In a study assessing the Kuwaiti reaction to the Iran-Iraq war, Miller (1984) explained how most of the topics discussed at the diwaniyas she attended centered on politics and the economy. She explains how this is because a majority of the attendees are entrepreneurs and politicians, sometimes members of the Kuwaiti parliament if the host is from a prominent family in the society. In relevance the study's research questions, the criteria for selecting this second category of focus group participants was that the participant had to be a working employee, a Kuwaiti national, and above the age of thirty. According to the Constitution's Judicial Chapter (1962), thirty is the age in which a Kuwaiti citizen can run for public office. The sample was diverse in that community members from both private and public sectors of the country were included. Similarly, a criterion sampling approach was applied along with volunteer sampling.

\section{Data Analysis and Synthesis}

\section{Epoché}

When analyzing data from a phenomenological study, Moustakas (1994:3) explains how important it is to differentiate between interpretation and judgment. In phenomenological data, there are two main perspectives to account for. The first is the perspective of the researcher studying the phenomena. Husserl (1970) stressed the need for the researcher to acknowledge the subjective self when conducting a

phenomenological study. Peshkin (1988:547) reinforced that it is important to be aware 
of our subjective selves and the role the subjective self plays in research. Consequently, the first step of data analysis was epoché, in which the researcher interviewed oneself to elucidate personal experiences of the phenomenon and set aside potential biases in data inferences. Thereafter, the study participants were interviewed and the focus groups were conducted. According to Patton (1990), epoché is a phase in which the researcher eliminates or clarifies preconceptions. Researchers need to be aware of "prejudices, viewpoints or assumptions regarding the phenomenon under investigation" (Maykut and Morehouse, 1994). The second perspective to account for is descriptions from the people directly experiencing the phenomena. As such, the process of phenomenological reduction was used in addition to epoché. This process, as described by Van Manen (1990), involves the researcher bracketing out the world and presuppositions to identify the data in pure form, uncontaminated by extraneous intrusions. Bracketing involves a separation of the phenomena in question from the rest of the world. Creswell (1998) explained how epoché paired with phenomenological reduction helps the researcher bracket personal experiences in order to set aside all possible prejudgments.

\section{Document Reviews}

Secondary sources such as newspapers, congressional reports, and annual reports of public agencies were analyzed using content analysis. Data were first examined for patterns, themes, and categorical classifications. Thereafter, Kingdon's (1984) coding scheme was applied to rate the topics for frequency and breadth. This process helped develop a knowledge base of current issues and participants' experiences as they relate to policymaking and the privatization policy in Kuwait. Publicly accessible databases of the 
Central Statistical Bureau (CSB), Public Authority for Civil Information (PACI), United Nations (UN), World Bank, and the World Economic Forum (WEF) were accessed for country data and rankings.

\section{Interview and Focus Group Data}

Interview and focus group data were collected, analyzed, and synthesized using Creswell's (2007) version of Moustaka's modified Stevick-Colaizzi-Keen phenomenological data analysis method. Study participants were interviewed in terms of their general experiences with policymaking in general and with the privatization policy in particular. An emergent strategy was applied to synthesize the data collected from both these research methods. References made to the literature findings and policymaking frameworks, tested the emerging themes and ideas. Qualitative data collected from all three methods were analyzed using NVivo software.

\section{Verification Measures}

Four techniques were applied to ensure soundness of the qualitative research design: credibility, transferability, dependability, and confirmability (Lincoln and Guba, 1985). First to test for credibility, four strategies were employed as internal validity measures. These include conducting informant reviews, member checks, engaging in epoché, and maintaining accurate reflections. Second, a rich contextual description coupled with a demographic and situational description, was used as transferability measures. Data collected underwent a thorough transcription process, to identify points of convergence and divergence. This helped account for the research design's external validity. Third, dependability (i.e. reliability) of the research design was measured via 
external checking. As Creswell (1998) explains, this refers to conducting a thorough audit by an external person to verify the data results and interpretations reached. Finally, for the measures of confirmability or objectivity, two strategies were used to help ensure objectivity of the research design. As Mathison (1988) suggests, a strategy of triangulation and use of multiple data sources helps increase the validity of the research findings. Patton (1990:331) reaffirms that to strengthen the data analysis phase of the phenomenological process a researcher should, "cross validate, triangulate, and select key informants." Additionally, an audit trail and a reflective journal were maintained during the process of the interviews, to ensure accuracy and avoid the interference of any research biases (Berg and Lune, 2012). Ethical considerations were also taken to protect the anonymity of the study's participants.

\section{Ethical Considerations}

All participants were asked some demographic questions related to their name, gender, age, employment status, and/or years of residency, to verify their participation in line with the sampling criteria. However, protective measures were taken to ensure the participants' complete anonymity. Every participant was informed of the research subject beforehand, along with the benefits of his/her contributions to the larger field of social sciences. Participants had the opportunity to refrain from answering any question and also opt out of the entire study at any time. Further, identifiers were used in place of names to protect the participants' identities. Denzin and Lincoln (2005) explained how confidential data are protected via the use of pseudonyms, or identifiers, to protect the anonymity of research participants. 


\section{Limitations}

Advantages of the research approach, as defined in this chapter, are that findings provide greater breadth to the data collected. However, there is a disadvantage that the design may not be transferable to other contexts. To counteract this, a detailed description of the research design was provided. Conducting the interviews and the focus groups required logistical planning that was time consuming. Nevertheless, these data collection methods provided greater depth to the questions raised and the topic addressed and an opportunity to study the groups' dynamics. Furthermore, there can be a likelihood of the researcher's personal research interests and prior knowledge of the phenomena infusing the data analysis, if not accounted for in advance. As such, the process of epoché and a series of data verification measures were employed to make the phenomenological results researcher-independent.

\section{Summary}

Data collected from all methods employed was studied collectively to identify points of convergence and divergence, which informs analyses of the findings. It is expected that data findings address the research questions raised and provide conclusions for the study. 


\section{CHAPTER FOUR}

\section{RESULTS}

\section{Introduction}

Data collected from interviews, focus groups, and document reviews, were analyzed using the phenomenological method. According to Creswell (2007), this methodology provides a complex, detailed understanding of the issue and helps achieve greater breadth and depth to the data. Patton (2002:432) expands on this view, stating that, "we mold interviews, observations, and field notes into findings." The idea is to better understand the contextual structure and sequence of events that lead up to policymaking, implementation, and evaluation. Data were transcribed and coded until saturation was reached (Charmaz, 2006). An emergent strategy was employed to identify themes and meaning units for each research question.

An exploration of how policymakers in Kuwait experience a policy's development stages is studied in relation to the privatization policy. How the society, at large, conceives this policy's formulation and implementation is also explored. Themes and subthemes emerged during the data analysis; clusters of meanings are highlighted for further discussion in the proceeding chapters. The use of participants' verbatim quotes is anonymously incorporated in the text below to support the findings.

\section{Organization of the Data}

Kingdon (1995) identifies two factors that determine the agenda-setting stage -

the participants and the processes. Each interviewee represents a different sector of the 
country that was involved in formulating the privatization policy. All sectors involved in the privatization policy's formulation were included; this research presents a universe sample. Each focus group participant represents a different region of the country, at which public services are received. The final focus group sample encompasses all voting districts in Kuwait. The level of each research subject's engagement with the policy, and the relative impact of their contributions, varies. As such, the responses to the same set of questions reflect similarities and differences. To better understand the level of diversity among research subjects, Tables 2 and 3 list the demographics of research participants. Pseudonyms are used to protect respondents' anonymity as an ethical research measure (Homan, 1991).

Table 2

Participant Demographics (Interviews, $n=30$ )

\begin{tabular}{cllll}
\hline Participant & $\begin{array}{l}\text { Age } \\
\text { Group }\end{array}$ & Gender & Education & Sector \\
\hline 1 & $60+$ & Male & Bachelors & Government Sector \\
2 & $35-49$ & Male & PhD & Public Sector \\
3 & $35-49$ & Male & PhD & International NGO \\
4 & $50-59$ & Male & Masters & Public Authority \\
5 & $60+$ & Male & Bachelors & Public Authority \\
6 & $50-59$ & Male & Bachelors & Government Sector \\
7 & $60+$ & Male & Masters & Government Sector \\
8 & $35-49$ & Male & Masters & Public Sector \\
9 & $60+$ & Male & PhD & Public Authority \\
10 & $35-49$ & Female & Bachelors & Government Sector
\end{tabular}




$\begin{array}{lllll}11 & 50-59 & \text { Male } & \text { Bachelors } & \text { Public Authority } \\ 12 & 35-49 & \text { Male } & \text { Bachelors } & \text { Public Authority } \\ 13 & 35-49 & \text { Male } & \text { Masters } & \text { International NGO } \\ 14 & 60+ & \text { Male } & \text { Bachelors } & \text { Government Sector } \\ 15 & 50-59 & \text { Male } & \text { PhD } & \text { Pubic Authority } \\ 16 & 50-59 & \text { Male } & \text { PhD } & \text { Public Sector } \\ 17 & 35-49 & \text { Female } & \text { Masters } & \text { Government Sector } \\ 18 & 35-49 & \text { Male } & \text { Bachelors } & \text { Public Authority } \\ 19 & 50-59 & \text { Male } & \text { Bachelors } & \text { Public Authority } \\ 20 & 60+ & \text { Male } & \text { Bachelors } & \text { Public Authority } \\ 21 & 35-49 & \text { Female } & \text { PhD } & \text { Academic Sector } \\ 22 & 50-59 & \text { Female } & \text { Masters } & \text { Local NGO } \\ 23 & 35-49 & \text { Female } & \text { Masters } & \text { Local NGO } \\ 24 & 50-59 & \text { Female } & \text { Bachelors } & \text { International NGO } \\ 25 & 50-59 & \text { Female } & \text { Bachelors } & \text { International NGO } \\ 26 & 35-49 & \text { Female } & \text { Bachelors } & \text { Government Sector } \\ 27 & 50-59 & \text { Male } & \text { PhD } & \text { Public Authority } \\ 28 & 50-59 & \text { Male } & \text { Bachelors } & \text { Public Authority } \\ 29 & 35-49 & \text { Male } & \text { Bachelors } & \text { Government Sector } \\ 30 & 35-49 & \text { Male } & \text { Masters } & \text { International NGO }\end{array}$

\footnotetext{
Notes:

i. Participant: Identifiers are used to protect the participants' anonymity.

ii. Age group: This refers to the profile of interviewees - adults (35-59 years) or seniors (60+ years).

iii. Sector: A detailed list of sectors can be found in Chapter 3. This research requires interviewees to have been in the position for at least three years, considering the standard four-year time frame of executive public posts in the country (Civil Service Commission, 2008).
} 
At the onset of each focus group discussion, time was spent at the beginning to briefly connect with the participants to enhance their feelings of comfort when sharing personal experiences with other participants and the researcher. Focus group participants were either university graduate students or members of the society, at large. Diversity of these participants was met by ensuring that the research sample represented all five voting districts in the country. Voting districts in Kuwait are arranged based on a constituent's area of residence. Each district of the country has a different composition of tribal families, established geographically based on cultural ties that have defined the country and elements of a patriarchal society that remain strong (Ghabra, 1993). These families vary in social values and political priorities, which Kapiszewski (2006) discusses directly impacts the level of political support for policy choices. Ghabra (1993) explains how the tribal families' power in numbers also determines the composition of MPs in parliament, considering the country's open elections process. Therefore, ensuring a diverse sample of participants that are within the minimum age of 30 years and are employed, produced mixed responses. Table 3 is composed of demographics for the focus group participants.

Table 3

Participant Demographics (Focus Groups)

\begin{tabular}{lllll}
\hline Group & $\begin{array}{l}\text { Age } \\
\text { Category }\end{array}$ & $\begin{array}{l}\text { Marital } \\
\text { Status }\end{array}$ & $\begin{array}{l}\text { Voting } \\
\text { District }\end{array}$ & Occupation and Sector \\
\hline Group 1: & Adult & M & 3 & Graduate, School of Education \\
Female & Adult & M & 1 & $\begin{array}{l}\text { Graduate, School of Admin. } \\
\text { Sciences }\end{array}$
\end{tabular}




\begin{tabular}{|c|c|c|c|c|}
\hline University & Student & $\mathrm{S}$ & 5 & $\begin{array}{l}\text { Graduate, School of Social } \\
\text { Sciences }\end{array}$ \\
\hline Graduate & Student & S & 4 & $\begin{array}{l}\text { Graduate, School of Business } \\
\text { Admin. }\end{array}$ \\
\hline \multirow[t]{4}{*}{ Students } & Adult & M & 4 & Graduate, School of Education \\
\hline & Student & $S$ & 2 & $\begin{array}{l}\text { Graduate, School of Social } \\
\text { Sciences }\end{array}$ \\
\hline & Student & $\mathrm{S}$ & 3 & $\begin{array}{l}\text { Graduate, School of Political } \\
\text { Science }\end{array}$ \\
\hline & Student & $\mathrm{S}$ & 3 & $\begin{array}{l}\text { Graduate, School of Business } \\
\text { Admin. }\end{array}$ \\
\hline Group 2: & Student & $\mathrm{M}$ & 1 & Graduate, School of Engineering \\
\hline Male & Adult & $\mathrm{S}$ & 4 & $\begin{array}{l}\text { Graduate, School of Social } \\
\text { Sciences }\end{array}$ \\
\hline University & Student & M & 5 & Graduate, School of Medicine \\
\hline Graduate & Student & $\mathrm{S}$ & 3 & Graduate, School of Education \\
\hline \multirow[t]{4}{*}{ Students } & Adult & $\mathrm{S}$ & 2 & Graduate, School of Engineering \\
\hline & Student & $\mathrm{S}$ & 3 & $\begin{array}{l}\text { Graduate, School of Political } \\
\text { Science }\end{array}$ \\
\hline & Adult & $\mathrm{M}$ & 2 & $\begin{array}{l}\text { Graduate, School of Political } \\
\text { Science }\end{array}$ \\
\hline & Student & $\mathrm{S}$ & 5 & Graduate, School of Engineering \\
\hline Group 3: & Adult & $\mathrm{M}$ & 2 & Teacher - Government Sector \\
\hline Istiqbal & Adult & $\mathrm{S}$ & 3 & Designer - Private Sector \\
\hline Community & Senior & M & 4 & $\begin{array}{l}\text { Administrator - Government } \\
\text { Sector }\end{array}$ \\
\hline Group & Adult & $\mathrm{M}$ & 2 & Banker - Private Sector \\
\hline \multirow[t]{4}{*}{ (Females) } & Adult & M & 3 & Engineer - Government Sector \\
\hline & Adult & M & 1 & Accountant - Government Sector \\
\hline & Senior & $\mathrm{S}$ & 2 & Entrepreneur - Private Sector \\
\hline & Adult & $\mathrm{M}$ & 2 & Entrepreneur - Private Sector \\
\hline
\end{tabular}




\begin{tabular}{lllll}
\hline Group 4: & Senior & M & 2 & Engineer - Government Sector \\
Diwaniya & Adult & M & 3 & Politician - Government Sector \\
Community & Adult & M & 4 & Banker - Government Sector \\
Group & Adult & M & 2 & Entrepreneur - Private Sector \\
(Males) & Adult & M & 5 & Engineer - Government Sector \\
& Adult & $\mathrm{S}$ & 3 & Architect - Private Sector \\
& Senior & $\mathrm{S}$ & 2 & Entrepreneur - Private Sector \\
& Senior & $\mathrm{M}$ & 4 & Consultant - Government Sector \\
\hline
\end{tabular}

Notes:

i. Group: This refers to the population subgroup that the respondent participated in - Graduate university student group (male and female) or Community group (male and female).

ii. Participant: Identifiers are used to protect the participants' anonymity.

iii. Age category: This refers to the profile of focus group participants - students (18-24 years), adults (2559 years), or seniors of the society $(60+$ years $)$.

iv. Marital Status: The status is either single (S), or married (M).

v. Voting district: There are five electoral districts in Kuwait, each representing a different region of the country (National Assembly, 2010). These voting districts are legislatively distributed based on the country's six governorates. The five districts, together, encompass all residential areas in the country.

Interviewing is the primary data collection method for phenomenological studies

(Marshall and Rossman, 2011). Reference was made to previous literature of

policymaking and theories in the field when developing the research questions and

hypotheses. The semi-standardized interviews were conducted from a predetermined set

of questions that allowed some flexibility and openness in the conversations (Berg and

Lune, 2012). As a result, the discussions' semi-structured format resulted in some themes

that were more elaborative than others. Additionally, conducting focus groups in the

traditional diwaniya and istiqbal settings highlighted some elements of a democratic

policymaking process in Kuwait. Alnajjar (2000) explains how these traditional

gatherings have a tendency to become political meetings where critical policy issues are 
raised such as women's political rights, economic development, and more recently privatization, as this research has identified. Individual members of the society, in their diwaniyas and istiqbals, are found to be open and confident in articulating their critical views of government and the policymaking process. Kapiszewski (2000) explains how political discourse in these traditional gatherings increases political awareness for the activities of social groups, thereby empowering parliament members to criticize the government, as they exercise their roles of representing constituents.

Each stage of the policymaking process was investigated through the following set of research questions and guiding assumptions:

(1) What factors and elements drove the agenda-setting process in the case of privatization policy in Kuwait?

H1: Four sets of factors and elements drove the agenda-setting process in the case of privatization policy in Kuwait: perceived problems, actual problems, political preferences, and economic benefits.

(2) What problems does the privatization policy address?

H2: Privatization of the public sector is generally viewed as an enhancement of the country's economic development process.

(3) What are the obstacles facing implementation of the privatization policy in the case of Kuwait?

H3: Obstacles facing implementation of the privatization policy in Kuwait include: policymakers' problem definition, capacity issues, and lack of legislative support. 
(4) To what extent did the policymakers consider evaluation criteria when adopting the privatization policy?

H4: There is a lack of evaluative criteria for public policies in Kuwait.

(5) To what extent does decision-making in Kuwait follow any of the theoretical frameworks?

H5: Policymaking in Kuwait resembles a 'garbage can' decision-making model. Stone (2002) explains this to be situations in which the decisions are made first and the means are determined thereafter.

\section{Data Results}

The method of epoché was the first step in the phenomenological data reduction process. According to Moustakas (1994), this is the step in which the researcher interviews him/herself to acknowledge and set aside personal views and experiences. Thereafter, interviews, focus groups, and document reviews were conducted. To analyze the data, both deductive and inductive approaches were applied. Selection of the approach was based on extant literature and the nature of the research question.

The inductive approach involved data analysis with no predetermined framework.

Pope et al. (1999) discuss how clusters of meanings are identified from the raw data collected and analyzed. The inductive approach was applied for research questions two (policy formulation) and three (policy implementation). First, all raw data for these research questions were uploaded to NVivo qualitative data analysis software. Respondent validation, or member checking, was then conducted to ensure the research's validity (Long and Johnson, 2000). Third, transcripts were analyzed into an initial coding 
framework on NVivo that identified categories for the words and phrases. In the third stage, these categories were collapsed into themes and subthemes, also referred to as nodes and sub-nodes in NVivo. All nodes were reviewed in an aggregative manner, to develop a hierarchical data coding. The inductive codes identified for the second and third research questions are displayed in Figures 2 and 3 (view Policy Formulation and Policy Implementation sections of this chapter), respectively.

In the phenomenological deductive approach, Moustakas (1994) discusses the use of literature not only helps frame the inquiries, but also informs the analyses process. Spencer et al. (2004) explain how guiding literature and document reviews help identify a preliminary structure to analyze data. First, nodes were developed on NVivo from the literature reviewed for research question one (agenda-setting). For this research, privatization literature and Kingdon's (1984) policy process framework identified the deductive codes in Figure 1 (view Agenda-Setting section of this chapter). Second, raw data was uploaded to populate these nodes and sub-nodes. Third, emerging themes were identified from the deductive data analysis approach.

Research questions four (policy evaluation) and five (political decision-making) applied both an inductive and a deductive data analysis approach. Emerging themes when analyzing both these questions were found to be overlapping. In the final stage, the categories of responses from both approaches employed were organized into the main themes as depicted in Figures 4 and 5 (view Policy Evaluation and Political DecisionMaking sections of this chapter). Burnard (2006) notes the importance of collapsing categories to eliminate overlapping responses and similar data points. 
All qualitative data were further organized into meaning units to inform the discussion and recommendations sections of this research. The following meaning units were developed based on the themes and subthemes depicted in Figure 1 through Figure 5 in this chapter: systematic policymaking; legal framework; economic development; infrastructure and capacity issues; national workforce; and political decision-making. Documents were also reviewed for semantic and thematic analysis. Ritchie et al. (2004) explain how the thematic content analysis is the most common method used in qualitative work. In phenomenology, this thematic content analysis involves analyzing transcripts and identifying themes by using examples of responses (Burnard, 2006; Pope et al., 1999).

Consistent with Creswell's (2007) phenomenological analysis method, data were horizontalized for each research question to develop a list of non-repetitive, nonoverlapping significant statements for each research question. This process of horizontalization involves the identification of specific statements to further explore participants' perspectives and experiences. Verbatim quotes are used to identify textural and structural descriptions that are embedded within the themes and subthemes that emerged through the data analysis (Seale, 2000).

\section{Agenda-Setting}

Interviewees shared the different sources of data that were considered when approving this law, which includes the constitution, the country's economic development plan, and reports of public authorities. Participant 15 considered further data that he personally worked on during policy formulation. These include KIA studies, World Bank 
reports, reports of the GSSCPD, reports of the economic and finance parliamentary committees, market studies of private sectors and local banks, studies conducted by the State Audit Bureau, reports of the Ministry of Trade and Commerce, and the Chamber of Commerce and Industry reports. Participant 9 discussed how the constitution played a major role in proposing this law in its primary stages. Content analysis of the provisions that refer to private sectors' involvement in the national economy provided some key takeaways.

Article 20 of the constitution signifies the role private sectors play in the national economy. It stresses the need for cooperation between public and private sectors, however it does not specify the type of cooperation. The article states, "National economy is based upon social justice; its mainstay is a balanced and fair cooperation between public and private enterprise; its aims are the realization of economic development, the increase of production, the raising of the standard of living, and the substantiation of the citizens' prosperity, all within the limits of the Law." Participant 9 explained how the legal memorundums do not elaborate on the understanding of what a 'balanced and fair cooperation' is. He shared his colleagues' feelings of frustration as they try to determine what method(s) of cooperation would be considered fair and just.

Article 16 stipulates, "Ownership, capital and labor are the mainstays of the State's social entity and of national wealth; they all are individual rights with social functions regulated by Law." Article 17 explains that, "Public property (and funds) are inviolable and its protection is the duty of every citizen", while Article 21 defines, "All of the natural wealth and resources are the property of the State; the State shall preserve and properly exploit those resources, heedful of its own security and national economy 
requisites." Participants 4, 5, 11, and 12 all felt puzzled at the concept of 'national wealth' and how these distinctions will be made when private sectors are given the control of privatized assets that build these public reserves. In Article 48, "Payment of taxes and contribution to public expenditure are a duty in conformity with the Law; the Law shall exempt small incomes from taxation in order to guarantee a minimum income for living." Participant 26, speaking on behalf of the lower income groups in his community, discussed his concerns for the privatization law's implications on this population subgroup. Article 152 states that, "Exploitation of any natural resource, wealth generated from natural resources, or any of the country's public services, must be within limits of the law and for a specified duration." Article 153 further elaborates how, "Any monopoly shall only be granted by law and for a specific period of time." Participants 22 and 23, representing the local NGO population in Kuwait, felt strongly against the law approving the rise of monopolies. Participant 21 explained how monopolies are dominating the market and, in fact, exploiting these natural resources with their abundant capital.

Participant 30 explained that, "although there are constitutional provisions that relate to the privatization bill that was passed, not all policymakers referred to these provisions during the time of policy formulation." Participant 25 reiterated that approval of the bill by policymakers was made from a political, rather than an economic standpoint. In spite of these arguments, existence of these constitutional provisions can strengthen the legislative aspects of the bill, if revisited. Table 4 lists articles from the 1962 Constitution and corresponding provisions from privatization law 37/10. 
Table 4

Comparison of Law 37/10 and the 1962 Constitution

\begin{tabular}{|c|c|}
\hline Privatization Law, 37/2010 & Constitution, 1962 \\
\hline $\begin{array}{l}\text { Article } 1 \\
\text { A public enterprise is an enterprise that is } \\
\text { wholly owned by the State. Privatization } \\
\text { is approved in the form of transferring } \\
\text { ownership of a public enterprise, wholly } \\
\text { or partly, in accordance with the } \\
\text { provisions of law } 37 / 10 \text {. }\end{array}$ & $\begin{array}{l}\text { Article } 21 \\
\text { All natural wealth and all resources are } \\
\text { the property of the State. The State shall } \\
\text { ensure their preservation and proper use, } \\
\text { with due consideration given to the } \\
\text { requirements of State security and the } \\
\text { national economy. } \\
\text { Article } 26 \\
\text { Public functions are a national service } \\
\text { entrusted to those holding positions of } \\
\text { responsibility and the aim of State } \\
\text { functionaries in the performance of their } \\
\text { duties shall be the public interest. } \\
\text { Save in the cases defined by Law aliens } \\
\text { shall not be entrusted with public } \\
\text { functions. }\end{array}$ \\
\hline $\begin{array}{l}\text { Article } 4 \\
\text { Privatization of oil and natural gas } \\
\text { production, oil refineries, health, and } \\
\text { education utilities may not be privatized. } \\
\text { This includes natural wealth and utilities. }\end{array}$ & $\begin{array}{l}\text { Article } 11 \\
\text { The State shall guarantee assistance to } \\
\text { citizens in their old age, in sickness or in } \\
\text { disability. It shall also provide them with } \\
\text { social insurance services, social help and } \\
\text { medical care. } \\
\text { Article } 13 \\
\text { Education is a cornerstone in social } \\
\text { advancement. The State shall guarantee } \\
\text { and tend it. } \\
\text { Article } 14 \\
\text { The State shall supervise education, } \\
\text { literature and the arts, and shall } \\
\text { encourage scientific research. } \\
\text { Article } 40 \\
\text { In conformity with the Law and with in } \\
\text { the limits of public order and morals, } \\
\text { education for Kuwaitis is a right } \\
\text { guaranteed by the State. In compliance }\end{array}$ \\
\hline
\end{tabular}




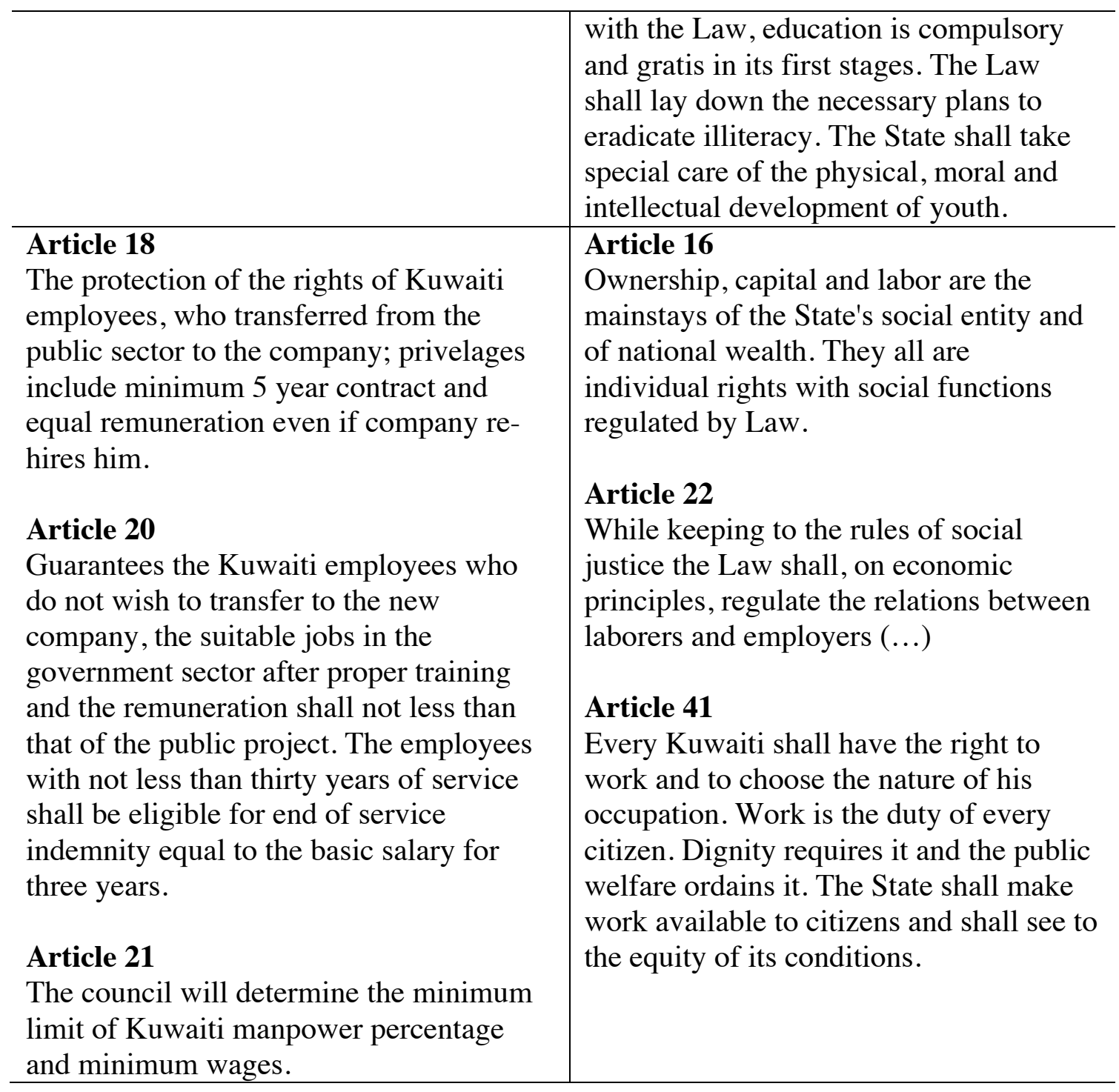

It can be inferred from this comparison that, (1) the state owns all natural wealth and resources, and (2) public functions of security, healthcare, education, oil and natural gas production, are owned by the state. The law indicates the privatization method approved of transferring partial and full ownership of a public enterprise to the private sector. Within the context of the constitution, participant 19 noted that education, health, and oil industries are not possible to privatize because they are controlled and owned by the government. However, privatizing the administration and management of these 
industries is possible. Participant 19 neither expressed support for this reform, nor opposition. He feels that privatization is a very particular situation, since it relates to assets that have always been owned and controlled by the government. In line with this reasoning, participant 20 suggested that a strategy plan is needed to determine how to legally and effectively implement this privatization reform.

In reference to other sources of data that were considered when devising this policy, participant 5 discussed his experience at the public authority when tasked with the duty of reporting on citizens' satisfaction with government services.

If you look at the Global governance indicators of public authorities' reports, you will find a low citizen satisfaction of public services in the country. This refers to the quality and processes during which citizens receive public services, including factors of the law, bureaucracy, and corruption. In formulating the privatization law, legislators should have paid attention to how this reform initiative would increase citizen satisfaction in the quality of services received.

Participant 13 valued the contributions of international nongovernmental organizations to the privatization policy in Kuwait. He expressed his support for the current economic development plan in Kuwait.

It is good in theory, however it lacks practicality of application. There were strong efforts in collaborating this plan; it would be a shame to see it not implemented. From our experience in the region, it seems that some public sectors are more advanced than others. It would be beneficial to see how these stronger sectors can facilitate the weaker ones. This helps create the feeling of a collective contribution to the economic development and growth process.

Howlett and Ramesh (1995:14) explain that institutions, certain instruments, and policy actors are involved in the agenda-setting stage. Weible (2007) defines the policy process to include actors, events, and contexts. In addition to the data sources that participants shared from their experiences facilitating the policy's development process, respondents made references to further elements and factors that determined the agenda- 
setting stage for the privatization policy. The factors and elements that drove the agendasetting process, in the case of privatization policy in Kuwait, are organized into the themes and subthemes in Figure 1 that emerged from participants' responses.

Figure 1

Thematic Analysis: Agenda-Setting

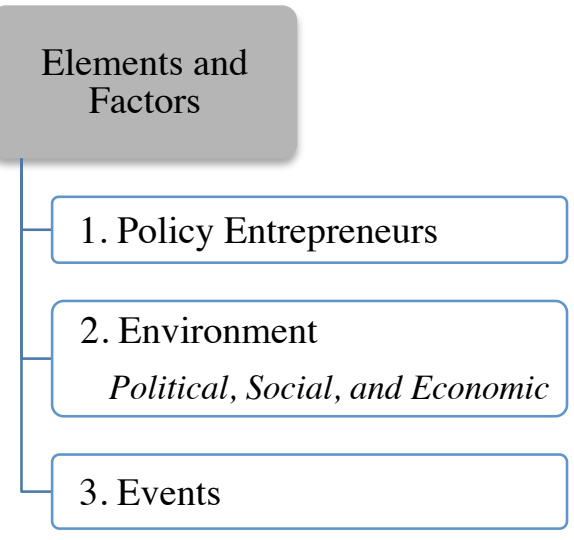

The first research question refers to the factors and elements that drove privatization policy's agenda-setting process. Responses mainly revolved around the existence policy actors and certain facilitating instruments, the mix of programs and government policies, the geographic and socioeconomic contextual settings of the country, and the occurrence of unexpected events. Significant statements shared below, from interviewees and focus group participants, were categorized into these clusters of meanings.

\section{Policy Entrepreneurs}

When asked who mainly participates in the policymaking process in Kuwait, MPs and Ministers in the interview sample identified a process that includes the Emir and the three branches of government - legislative, executive, and judicial. Local NGO 
representatives added to this group of contributors the civil society and non-state actors. Participants of focus groups referred to the strong tribal influence and elite circles in the society, as additional policy actors.

Participants 23,27 , and 28 referred to members of their workforce as primary policy actors that were involved in proposing privatization as a timely policy issue. This group includes former members of parliament that still have strong ties with their constituents and government networks, and parliamentary staff that pursued the role of policy entrepreneurs lobbying for the policy's approval. Participant 28 explained how, in the case of Kuwait, there were a large number of citizens and government employees that directed privatization discussions in their individual capacities. Participant 23 discussed how public and private institutions were also involved - each demonstrating a different level of support for the policy based on their particular development agendas.

Participants 2, 8, and Nourin represented the private sectors in the research sample. The experiences they shared indicate how private sectors contribute more to the policy's implementation stage, rather than the formulation stage. Participant 8 explained how his company reports to two main authoritative bodies in Kuwait: the Central Bank of Kuwait (CBK) and the Ministry of Finance (MOF). As a private finance company, Nourin discussed how they operate within CBK's financial regulations. This includes the allocation of loan ceilings and interest rates, for example. CBK aims to establish consistent policies between the private and public sectors (Hussain et al., 2007). Nourin explained this as the country's attempt to harmonize the operations of both sectors within the law. 
Participant 2 expressed his discontent with how policymaking for economic and financial development is a political process.

The good thing about our investment company is that we do not need the government to support us with capital. We generate our money from international markets. We educate our investors during advisory sessions to gain their trust and support, especially during the company's expansion strategies. However, we do need the government for licensing purposes. Generally speaking though, our company is part of an international market association, and so the rules that we follow are the association's rules.

As such, matters of bureaucracy and centralization at the government level do not impact established and internationally recognized private sectors. However, they do impact smaller businesses and starting entrepreneurs, as community members discussed in the focus groups. Nourin explained from her experience working with some of the privatized markets in the GCC region, how Bahrain is the number one financial market with the highest wealth status. The second is Saudi Arabia and then the UAE. The Saudi market, however, is the most restrictive from her experience. Both participants 2 and 8 expressed their support for the privatization policy, alongside questions of when the law will be revisited for implementation.

Another group of policy actors that contribute to the policymaking processes in Kuwait are international organizations. After five years of managing a field office in Kuwait, participant 3 shared how international organizations establish a field presence to help countries accomplish their development goals as defined in their national agendas. He shared the example of how the UN's presence exists in most countries of the Arab region.

These offices have programs tailored specifically to the country and region that our field offices deliver to. Kuwait has consulted with these organizations on aspects of privatization as it relates to the national development agenda. 
Documents reviewed at the international organizations' headquarters in Europe, reflect UNDP's multiple initiatives of consulting with the Kuwaiti government sectors on developing the national economy. One of the most notable contributions was in 2005 , in which UNDP developed the Kuwait tourism strategy in cooperation with the World Trade Organization (WTO). However, this study has still not been implemented. Various reasons were noted, including how the decision-makers who were delegated to implement this strategy lacked political will. Policy entrepreneurs that advocated for this strategy commenced their public post. The incoming cabinet members were occupied with government agendas that prioritized other policy issue areas. This aligns with Kingdon's (1984) theory of how a policy gains dominance on a national agenda when the three streams of politics, problem, and policy overlap, opening a window of opportunity for policy entrepreneurs to push their policy proposal. This will be further discussed in the next sections.

\section{Environment}

After briefly discussing the history of Kuwait and its political structure, participant 7 shared from his experience with leading a public authority of how political and social factors strengthen the government's presence in the country. The government's control of Kuwait's major revenue sources has strengthened its economic power. As a result, participant 7 explained that bureaucracy began to increase over time, until the government became and still is the exclusive distributor of primary public services. $\mathrm{He}$ shared his feelings of how this exclusive control has led to market failures and increasing 
expenditures, vis-à-vis employment funds, raising the need for a privatization reform.

Participant 10, a director at one of Kuwait's ministries, provided a similar explanation.

As long as the State maintains its position of being the exclusive provider of basic services to citizens, then the prices will continue to be subsidized thereby increasing the national budget deficit. Financing services such as electricity production and distribution, transportation, telecommunications, and others increases government expenditures negatively impacting the national economy.

Responses gathered from research participants indicate that privatization is not just a priority in Kuwait. It is a priority in the whole Gulf region. It is an economic wave popular in both developed and developing contexts that seek to strengthen the role of the private sector. Findings from the documents reviewed reveal that changes in Kuwait's national economy began in the 1980s, when the oil prices dropped. Nicholas confirmed that "privatization talks" started at that time.

Privatization became a heated topic because the government's burden was increasing as it is literally in charge of everything in the country. It is devoting all of its resources, manpower, and strategic focus to providing services and maintaining the legislative environment. There are minimal efforts left to expand government institutions and compete in global markets.

Over the past five years, the national budget deficit increased to 4.6 billion Kuwaiti dinars, equivalent to approximately 15 billion dollars (National Bank of Kuwait, 2016). According to the bank's semi-annual economic report, "the National Assembly recently approved the budget for the fiscal year 2016/17 (FY16/17) with an official deficit projection of KD 8.7 billion, or $26 \%$ of GDP." This budget deficit is largely attributed to lower oil prices, in addition to an increase in salaries that constitute one of the largest segments of the total budget. The salaries segment is even greater than expenditures for goods and services, transportation and equipment, and projects and maintenance (CSB, 2016) budget allocations. Kuwait's population is approximately 4.4 
million (CSB, 2014). Expatriates comprise about $30 \%$ of the total workforce (CSB, 2015). Participant 14, a former member of parliament, expressed his concern of how a large portion of the expatriates' salaries is likely to be spent abroad, rather than in local markets. He explained how this is a loss in economic stimulus, which negatively impacts Kuwait's economic development and growth process.

\section{Events}

One of the main events that prioritized privatization on the political agenda in Kuwait is the stock market crash in 2009. Participant 15 experienced this effect while directing a large government sector in the country. Moreover, participant 15 explained how he had to lay-off a number of employees due to the lack of public funds. During that time, privatization was re-introduced on the national agenda with a proposal raised to the parliament for voting. Participant 17 elaborated on how the economy of a country is shaped by events that take place in the political and legislative arenas. She shared her viewpoint of how Kuwait is still in a global economic crisis.

The geo-politics of the Middle East and North African (MENA) region is affecting our economic development process locally. International markets in far-east China and Japan have not fully recovered from the global financial crisis. They are diverting more towards industrial growth now.

Participant 8 concurred that Kuwait has always been struggling with two critical elements that shape the country: the legal structure and the political environment.

\section{Policy Formulation}

Responses to the research question of the existing policy issues in Kuwait that indicated the need for privatization initiatives varied based on the respondent's position, 
job sector, and how s/he perceives the policy will address issues in the country. A majority of the research participants identified similar issue areas, all of which have been clustered into themes and subthemes as displayed in Figure 2.

Figure 2

Thematic Analysis: Policy Formulation
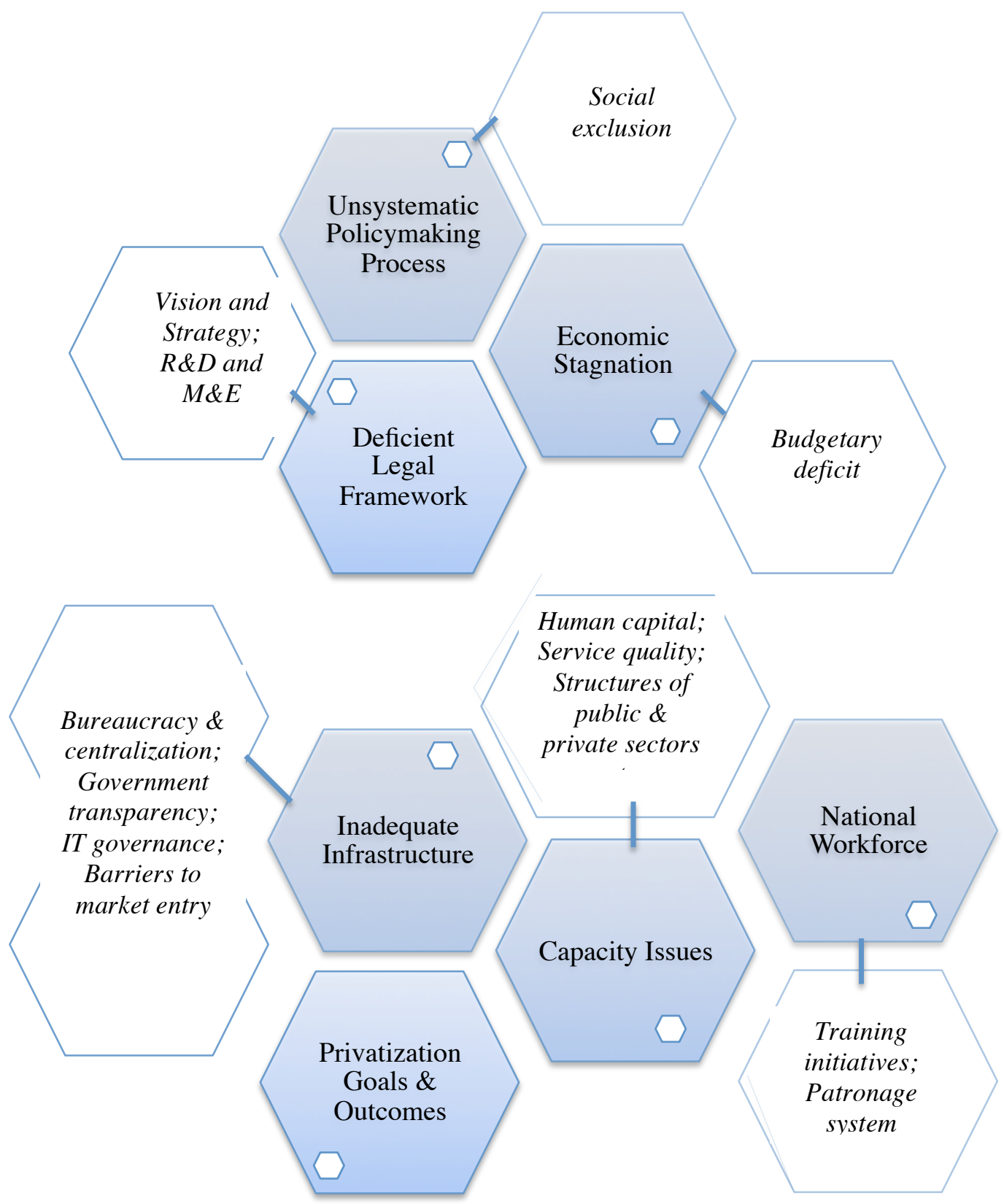


\section{Unsystematic Policymaking Process}

After serving for more than 15 years in various executive posts of government sectors, participant 9 expressed his frustration of the unsystematic policymaking process.

Some of the public policies on the government agenda are neither prioritized, nor based on current needs and issue areas. Those that are need-driven are neither comprehensive, nor sector-specific. A big part of my job was to develop strategic action plans for these policies. I remember discussions of how privatization would strengthen this system. We have yet to see. The biggest problem, from where I stand, is that the consistent operational methods used in public sectors are all the same. It is like all sectors are equal.

Participant 6 hinted at the unsystematic nature of policymaking by sharing the example of how his sector's duties and levels of authority changed based on conditions in the market place. After the stock market crash, the government bought the assets from indebted individuals and used that capital to establish the public authority that participant 6 has directed for the past 20 years. This authority then began to sell stakes of these companies in the marketplace. Participant 6 explained how this is unsystematic, given that others would theoretically perceive such activities as privatization initiatives. However, it was never considered privatization, as this authority never had ownership of any of these assets. In light of the country's fiscal situation and budget deficit, participant 6 suggested developing a plan to fund the government's privatization initiatives, using the returns of previous years.

From participant 12's responses, it seems that whenever the country enacts a new law or development program, it establishes a public entity to supervise the new policy or program. Participant 12 shared that each establishment is costing the country money and imposes on citizens and private sectors further logistical and time-consuming requirements. 
This process is halting the progress towards development. The problem in Kuwait is the lack of firm decisions, the many layers of unnecessary bureaucracy, and the different levels of political corruption.

Another significant factor contributing to the unsystematic policymaking is social exclusion. Both participants 24 and 25 argued the need for women and youth to participate in the country's policymaking processes, as equal as men in the Arab societies. In hope that the privatization policy will rectify this situation once implemented, participant 24 explained how youth in Kuwait are very entrepreneurial and expect their voices to be heard.

A review of ILO's (2015) MENA regional studies reflects a trend of unemployment and underemployment especially high among youth. This presents an issue of high concern in Kuwait, given that youth comprise approximately $60 \%$ of the Kuwaiti population (CSB, 2015). They present a large burden on the government, as employment opportunities must be expanded to accommodate this growing population. According to Ramady (2014), the Kuwaiti government attempted to resolve this by implementing a quota for private sectors of the minimum number of national labor that private sectors must employ. Participant 21 explained how this presents a problem.

Kuwaiti employees are more costly than foreign workers, especially for a private sector that is already struggling financially. From my experience, there are a lot of unqualified Kuwaiti employees when compared to the many options of foreign employees.

Participant 25 further discussed how the low representation of women leads to policy processes that are inefficient and inconclusive. According to the United Nation's Sustainable Development Goals (UN, 2015), there is a need to enhance female representation in Kuwait to ensure gender equality across public sectors of the country. 


\section{Deficient Legal Framework}

MP interviewees shared their perceptions of the legal framework. A former MP discussed, "during my time in office, I came across plenty of structural flaws in the laws that dictate social justice, which is why I think that the privatization law will reinstate balance from this angle." Participant 10 introduced additional problem areas in Kuwait that indicated the need for the privatization law. Working as a legislator, he explained how the legal frameworks in Kuwait are deficient.

The laws are vague and not comprehensive. There is a huge deficit in supportive legislature; many aspects of the law are left for individual interpretations. This really is the root of most development problems, including privatization policy.

Participant 17 added that the standard operating procedures (SOPs) are outdated for laws that have been enacted several years ago. There is a lack of research and development $(R \& D)$ and monitoring and evaluation $(M \& E)$ initiatives that would help achieve the country's vision for economic development. She explained this to be the reason why she is continuously advised to recruit contractors for government projects to fill these gaps in the Kuwaiti market.

\section{Economic Stagnation}

Interviewees representing financial industries stressed the issue of inflated salaries occupying a large portion of the country's budget. Participant 1 explained that the public sectors in Kuwait absorb a majority of the national workforce.

This creates a financial burden and budgetary restraints especially in recent years where labor unions of oil and education were on strike requesting salary increases. 
According to the annual reports of the Central Statistical Bureau (2016), salaries are the largest component of the national budget. The increasing public expenditure, combined with decreasing quality of public services, contributes to the country's economic stagnation from participant 7's experience.

Participant 8 felt confident that private sectors in Kuwait would actually consider participating in some privatization initiatives when announced.

It seems to be one of the better alternatives given the current economic market in Kuwait. About 50 companies have already pulled out of the stock market are now traded in a secondary market. The prices of company stocks are not reflecting the actual company-led, business activities. At the same time, the fees applied for staying in the stock market are very high, so it would probably be more advantageous financially for capable companies to enter the privatization bidding process.

Documents reviewed in the next sections of this research reflect the country's low economic development ranking when compared to global rankings. Participant 5 shared some additional reasons, as he perceives them, including the exploitation and misuse of natural resources and wealth.

The state's development programs are ineffective and definitely not comprehensive - either they are too focused on a particular industry, are developed only in response to particular problems or issues areas, or they fail to acknowledge the presence of private sectors. Some programs even overlook the growing number of small businesses.

\section{Capacity Issues}

According to participant 1, the most pressing five problems that Kuwaiti citizens face are relatively lower education standards, poor quality and insufficient healthcare services, unaffordable housing, labor market imbalances, and low quality of most public services provided. He referred to recent KFAED survey results that indicate citizens' 
discontent with the quality of medical services. Healthcare expenditures occupy a great portion of the public budget, however the quality is relatively poor in the region (CSB, 2016). As per KFAED survey results, many citizens would rather pay for medical bills at private hospitals than have to resort to free, public healthcare.

Focus groups of community members expressed their discontent with the poor conditions of working facilities. As one of the female participants, an administrator in one of the ministries shared, "before my division was moved to a newer building, we had to drive 40 minutes to what looked like a warehouse of a facility." Participant 16 stressed how the surroundings affect employees' productivity, which impacts an organization's outputs. This is why a major part of his private company's starting capital went for construction costs.

Participant 27 discussed further capacity issues that indicated the need for privatization initiatives in Kuwait.

The quality of public services in Kuwait, compared to international standards, is deteriorating. A majority of the country's national workforce is in government jobs. As the Kuwaiti population continues to grow, more money is allocated from the total budget to provide for this increasing number of people. More obstacles to growth and development are encountered, as a result.

Indeed, studies conducted by the Arab Planning Institute and Central Statistical Bureau (2015) indicate that $76 \%$ of employees work in public sector jobs, while only $21 \%$ have private sector jobs. 


\section{Inadequate Infrastructure}

When asked about the policy issue of government transparency, participant 21 shared her perspective of how self-interested actors, partisan preferences, and political biases can really weaken the infrastructure of the political arena if not evaluated.

There is a lack of government transparency. Some citizens cannot trust the work performance by public sector employees, which is why they prefer private sector services even if they have to fund what is accessible and free.

Alrumaihi (1994:2) discusses how the Kuwaiti public, "has a number of political priorities in mind; these problems, and especially the issue of balancing the budget and restructuring the economy, demand some action on the part of the government and the assembly; yet these and a score of other issues are still pending." The graduate students focus group participants shared their feelings of distrust in government as a result of this delay in implementing development programs in the country, although expenditures to fund proposals of these programs continue to escalate. A majority of the students felt dissatisfied with both the government and the National Assembly.

Furthermore, participant 18 explained from his experience that it is not beneficial to introduce strong performing private sectors to weak performing public sectors, as this can negatively impact the privatization goal of strengthening the public sector. $\mathrm{He}$ suggested to first revamp the infrastructure of the public sector that will be privatized and then introduce private sector market forces. Participant 20 presented the issue of government's continuous intervention in the state's activities.

The government's increasing bureaucracy and legislative regulations is preventing the private sector from developing naturally. The government cannot play all the roles of being the owner and the director. The only way to improve this is to restructure the legislative framework and incentive private investors of the high demands that already exist in the market. It is expected that this 
privatization policy is the supportive legislation needed to enhance economic environment of this nature.

Participant 23 shared the abundance of valuable economic assets in Kuwait that are yet to be utilized. She presented the example of the country's oceanfront that is lined with empty and deserted land. Participant 23's perceives that the privatization policy will benefit entrepreneurs that find opportunities in these neglected resources, with the support of the government. A trip to the free trade and port zones in Kuwait shows dumpsites and deserted land that, if developed, can provide access to the coastlines that participant 23 made references to.

Further aspects that attribute to the problem of inadequate infrastructure are Information Technology (IT) Governance. After spending 10 years at a ministry in the country, participant 14 was appointed director of a public authority to develop the IT infrastructure. He explained how IT governance in Kuwait is outdated and inconclusive, with databases that are inaccessible not only to the public and to private investors, but more importantly to government personnel within the same networks.

We have an issue with firewalls and information exchanges. The government passed the e-government law, following in the paths of Dubai's e-government; however, the law has still not been implemented. Still, technology is not effectively incorporated in public sectors of the country.

Entrepreneurs within the focus groups discussed their perceptions of how we are still in an economic crisis. Some of the reasons they stated include high barriers to market entry, low quality of services, low competition in the marketplace, and slow economic development. One of the participants explained how, "there are just too many requirements to enlist a new business; the time to approve a law and obtain a new license 
to establish a business is too long." Participant 4 shared his perspective of minimal implementation progress, despite the many development laws that have been enacted.

To be frank, some decision-makers like myself, are sometimes demotivated to plan and strategize as long as the infrastructure is weak and the bureaucracy is high.

\section{National Workforce}

Participant 28 shared some of the most common problems that resonate across public sectors in Kuwait, such as the lack of training opportunities and low public service motivation. While some focus group participants attributed the weakness of the national workforce to the existence of unqualified individuals in demanding public posts, others explained how this is due to the lack of training and empowerment initiatives offered, the lack of explicit job descriptions, and weak supervision mechanisms.

One of the community members in the istiqbal gathering discussed the patronage system that dominates a majority of the public sector in the country. She stated, "my department has very weak leadership; the promotion systems and rewards-and-benefits incentives are inequitably applied in our workforce." Listening to this remark, another participant in the same focus group expressed a major problem in the country being the growing number of self-interested politicians in office. Within the diwaniya gathering, one of the participants shared his experience working in different posts in the public sector.

We lack uniform payment schedules; the government must realize that citizens vary in income distribution, residency status, and years of service; they need to work with directors of each sector and restructure the fees and payment schedules before they implement any privatization initiatives. 
There was mixed feedback from focus groups when identifying issues concerning the national workforce in Kuwait. One of the females in the istiqbal focus group described how unsystematic work is in the public sector.

There is no workplace supervision; I rarely see my department manager; I think he is a professional at running the department from his office.

The participant seated next to her disagreed.

I think the ministry I work at is very efficient at implementing laws and following the standard operating procedures (SOPs). We have an organized hierarchy of demands, and semi-annual evaluation meetings. However, I must share my fear of how all of this would change once the privatization policy is actually implemented.

There were further discussions of policy issues in the national workforce and hope for the privatization policy to provide solutions. One of the respondents in the diwaniya shared his view of how there is no equality during the implementation of laws.

I think that we have all experienced a situation in which one of the managers in a high-ranking position in the workplace overrides certain regulations at times.

This is not a systematic way of work, which is why I choose to work in the private sector. I know this also exists in private companies, but at least there is enforced supervision and accountability.

Participant 6 discussed his personal experience of a company buyout, posteconomic crisis, which was accompanied with cheap labor that "got the job done." Not only were the work deliverables lacking the level of quality pre-crisis, but also maintaining accountability became more difficult.

\section{Privatization Policy's Goals and Expected Outcomes}

When asked about privatization's goals and expected outcomes when approving this legislation, a majority of the interviewees from both public and private sectors agreed that the main goal is to diversify the sources of funding beyond oil revenues, and increase 
the quality of services delivered to nationals. In view of the policy issues faced in the country, interviewees explained how privatization was one of the proposed solutions. However, the responses indicate that there is not much social awareness or working knowledge of this method as a reform strategy. Participant 20 explained how there is not much knowledge of how to implement privatization in Kuwait.

In my opinion, the government should step down from its absolute control of most assets in the country. For example, the government exclusively owns all production services related to social security, oil, water, and electricity. There is a "crowding out" effect. The public sectors are crowding out the private sectors, making it impossible for private sectors to perform adequately. This is increasing unemployment, as private sectors have the freedom of recruiting 'cheap labor'.

A majority of the research respondents agree that privatization is a "good"

solution to current policy issues faced in the country, but only if it is implemented effectively and equitably. Some of the interviewees that are more involved in formulating country policies proposed other reform initiatives that the government can adopt in lieu of privatization. For example, participant 29 discussed how a corporate tax system could be used to sustain the economy.

We now have a stagnant private sector development process. Most of the small businesses are in the food industry because this license is the fastest to being approved, compared to those in monopolized industries. In fact, with the booming social media scene, we find people shifting to home businesses so they do not even have to deal with government bureaucracy at all.

Participant 26 has participated in the privatization discussions and policy planning for the past seven years. He shared his thoughts of the legislators' expectations when approving this policy.

Privatization is an opportunity for the country to move towards a knowledge economy. The goal of privatization, as we see it, is to change the government's role from an owner to a regulator. 
Graduate student respondents discussed the issue area of democratic policymaking and opportunities that contribute to the country's development process. One of the participants suggested that, "if we think about it, we are contributing to the development process on a daily basis by just going to work and accomplishing our dayto-day duties." Another participant expanded on this view of the roles his fellow colleagues possess, "our roles are critical; we have a duty to apply what we learned at the university to the workplace so the greater society can benefit from the services we provide them, regardless of where we each end up working; we will all serve the same community at the end of the day."

\section{Policy Implementation}

Interviewees discussed the obstacles facing the privatization policy's implementation based on their experiences with the law itself and the public sector's policymaking dynamics. The themes that emerged from participants' responses to the obstacles facing the policy's implementation were clustered into the meaning units displayed in Figure 3.

Figure 3

Thematic Analysis: Policy Implementation

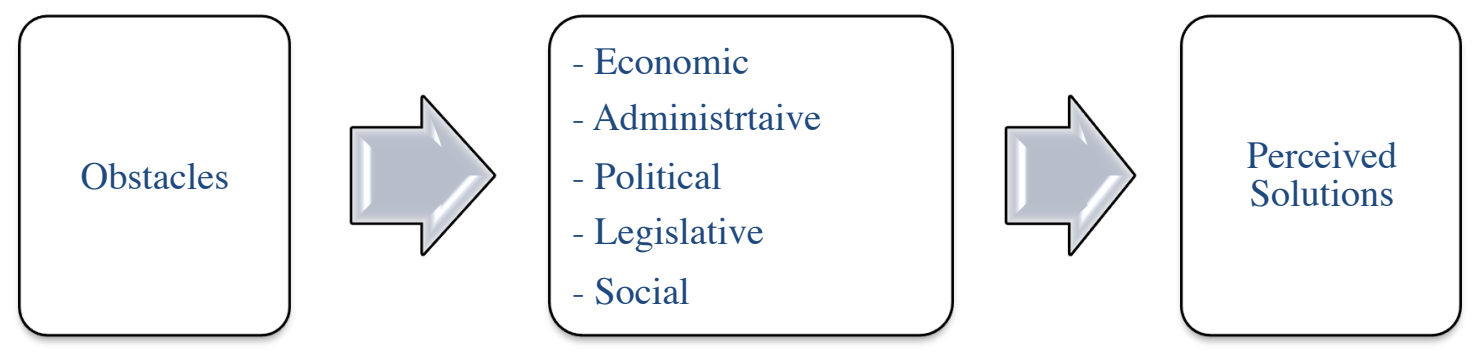


Participant 17 suggested some factors, including inconclusive legislation, poor leadership, inconsistent decision-making process, capacity issues, and unsupportive public policies in the country. Participant 7 noted additional reasons such as social factors, weak infrastructure of existing private markets, an unsystematic employment structure, and a political climate that changes with new government posts and parties' majority in parliament.

\section{Obstacles}

\section{Economic}

Participant 29 mentioned that law $37 / 10$ is deficient. One of the provisions in the law levies $35 \%$ on private investors (Article 13.1). Participant 29 mentioned how requesting an investor to fund the joint stock company at a minimum of $35 \%$ will demotivate investors.

Participant 16 stressed his disapproval of the government's implementation of a quota for national employment. He expressed how, "naturally, new privatized projects start on a smaller expense scale, sometimes even outsourcing to cut costs, and then increase this scale gradually." When these companies generate profits, they revisit their employment structures. As such, participant 16 suggested that the government should enforce such quotas after privatized projects develop over time. Participant 10 presented a different perspective with regards to costs and employment of nationals.

Ifeel that law 37/10 has really accounted for the rights of workers. Workers have the option to remain in their position, protected for five years, after which the private sector can decide whether to renew employment contracts or replace. Also, the government has agreed to provide financial benefits to members of the workforce that choose to not continue working in their sector after it has been privatized. 
Nevertheless, she discussed how the government's possession of a golden share in the privatized asset could be problematic. Participant 10 elaborated that private sectors may feel resistant to enter this relationship, feeling that contributing its hard-earned profit should give them the upper hand in decision-making. In the context of asset valuations and production costs, participant 20 mentioned that individual asset valuations based on the actual book value does not exist from his experience leading a public authority. The usual method of operations is to equate all asset expenses as annual expenses for the sector. Participant 20 explained how this unclear distinction in reporting individual book values can present a problem when this sector is proposed for privatization.

\section{Administrative and Political}

While discussing the administrative and political obstacles facing implementation, participant 4 expressed frustration that the notion of a "free market" does not exist in Kuwait.

A merit system of employment does not exist and there is a lot of foreign labor in both private and public sectors of the country. To decrease this chaos of a political and economic scene, the privatization law was passed but most people would agree that it would mean selling the country to capitalists.

Fear of the private sector hiking up prices is yet another concern that was reiterated by focus group participants opposing this reform. On this same note, participant 15 explained that restricting the private sector from determining the management and operations for the privatized asset de-motivates them from approaching the public sector as prospective partners. 
Article five of law 37/10 states that the Prime Minister chairs the SCP, which consists of five Ministers and three independent members. However, the Ministerial posts in the country change every four years, as per the constitution (1962). Also, the Emir has the power to reinstate the Parliament in the case that a critical event arises requiring a new elections process to take place. In this context, participant 1 explained how this structure naturally stalls the implementation process. He states, "SCP board members keep changing, and the independent members are required to present the previously agreed upon work plan for approvals from the new members." According to Article 6, the Council has to be in agreement of, "the issuance of its decisions, the committees it forms from among its members or outside of them, and its financial and administrative system." In the case that ongoing projects do not yield a majority vote with the new board members, participant 1 deduced that some projects would face a likelihood of not being renewed and would thus result in a waste of the country's resources and SCP's efforts.

Participant 3 concluded the interview explaining how privatization's

implementation is possible, if certain aspects are met:

This reform can be a solution for all problems perceived on the national and international level, but first support must be built socially and not just legislatively. Work processes cannot be centralized if the country's privatization goal is to increase foreign direct investments.

\section{Legislative}

Almost all of the interviewees agreed that the legislative framework is insufficient. According to participant 7, the problem does not lie in the lack of laws.

The real problem is the vagueness of existing and new laws, and the lack of implementation. Many laws are shelved. Many strategy and action plans continue to collect dust. 
Officials managing the country's reserves discussed how foreign investors are not incentivized to invest in Kuwait given the country's current business climate and political environment. During the interviews, they explained that foreign investors are uncertain of their rights and expected profits. Some of the concerns noted include the absence of egovernment in the country, changing regulations, increased government intervention, and the time lapse between obtaining a license and starting a business that risks the loss of business opportunities.

\section{Social}

In reference to the national workforce, participant 17 noted the structural imbalances in the labor market and social demographics that developed over time as a result of previous development programs. She attributed the decline of economic growth in 2015 to the unskilled labor force and lack of specialization that creates losses in the marketplace.

Recruitment of employees in the public sectors is based on "guaranteeing jobs for all." Employees should be recruited based on a sector's need. In doing that, consideration should be made for education requirements in the more technical sectors that will be privatized, so as to enhance the process of meeting predetermined goals in that respective sector.

Diwaniya members mainly discussed the features of centralized performance in the public sector of Kuwait versus decentralized private sector operations. One of the members attributed the delay in implementation to the divided government and ineffective leadership. Another member in the same diwaniya explained how bureaucracy slows, sometimes even hinders, progress. 
Focus group participants shared their perspectives of some social obstacles that face this policy's implementation. Three of the participants in the istiqbal agreed to the need to restructure the public sector first and establish a common ground between the organizational performances of sectors in the same industry for goods and services.

There will always be opposition from public sector employees and managers that are not law-abiding to working hours and ethical duties. When their divisions are privatized and the work conduct is monitored as in private sectors, these employees will no longer be able to enjoy their relaxed work life.

\section{Perceived Solutions}

Biygautane et al. (2016:1) states that, "while market-based reforms might appear to be a solution to the growing fiscal constraints in the three Gulf states, considerable administrative, cultural, economic, and political barriers hinder their effective implementation." In this context, interviewees and focus group participants identified some requirements for the policy's success, as they perceive based on knowledge and experience.

\section{Economic}

When discussing the economic situation of the country, one of the focus group participants explained , "the only safe investments we can make today is either in real estate or the stock market; I hope that the privatization law can expand our investment options in some sectors of the country."

Participant 5 summarized some of the expected goals when approving this legislature, as he directly contributed to drafting the policy. He explained how the government sector usually bails out public sector enterprises that incur drastic losses. The 
state's treasury funds are often used to cover such losses so as to maintain economic continuity in the country. Participant 5 discussed how privatization is an attempt to introduce private capital as an alternative source of funding, in addition to crowding out the low-income generating public enterprises. Participant 19, another interviewee that directly participated in drafting the law, stated the government's intention of passing the legislation to eventually reduce price inflations across the public sectos.

Bringing in foreign investment will help create new jobs, as there are rarely any vacancies in the public sectors anymore. There is an over-capacity of workers and limited positions.

Participant 8 shared the need to establish Kuwait as an economic center first in order to implement privatization.

Compared to private sector work processes and extensive knowledge of the marketplace, the government lacks these tools, access, and experience. We have been in the industry since the earlier years of economic booms. The idea of privatization should have been implemented years ago.

He explained how Kuwait's current investment market has a key advantage and a disadvantage.

Kuwait is the only country in the GCC, in which investors can have individual portfolios in their own names at the investment company. There are fewer restrictions for local investors that are doing business with private Kuwaiti sectors. Simultaneously, the investment tools in Kuwait are limited. At our company, we managed to surpass the local market and tap into international markets, creating new tools and profit-generating methods for our clients.

Noting these differences, participant 12 asked an important question, "Kuwaiti private sectors lacks diversity, thus will the government focus on strengthening local businesses or resort to seeking foreign investors?" He explained the critical need of ensuring a strong private sector that is capable of leading this reform. 
Participant 24 discussed how the new generation of youth is educated and ambitious, but they lack the financial and legislative support. She raised an important question of, "how will the government support entrepreneurial youth in an unstructured private market that is dominated by monopolies that have been in the same family business for several years?" From her point of view, the government should focus on how to facilitate the participation of middle and lower class investors.

\section{Administrative}

In order for the policy's implementation to be successful on an administrative level, participant 23 presented certain elements that should be accounted for. These include the national workforce, the legal environment, and the government's distinctive role as a utility provider, vs. a cost subsidizing entity. The transfer process and transitioning between these two roles must be gradual. As participant 23 explained, "you do not want to kill the infant that you just gave birth to."

In the case of Kuwait, participant 9 identified three requirements to ensure the privatization policy's success. Based on his experience directing a government sector in the country, these needs include the capacity and commitment of the policy's implementers, performance management, and organizational performance.

Capacity refers to the availability of resources to carry out privatization initiatives, of which mainly should include the money, manpower, legal autonomy, and the knowledge of how to effectively implement this policy. Commitment is where the main problems exist. A high level of commitment is reached when the lower-level implementers, such as teachers, police officers, and social workers, share the same values and goals as the executive policymakers.

Participant 14 also discussed the aspect of performance management as the policy tools needed to measure goals. 
I would like to know how and what will be privatized first. We need to be included in each level of the decision-making process during implementation stages, rather than just being told what to do and how to transform our divisions per laws enacted and policy amendments circulated.

According to participant 10, existing government programs need to be reevaluated and revamped to current times and needs. He shared his experience of how different issues come into the spotlight at different points in time. In this context, participant 17 explained that research production alone is not effective.

The state should focus on all possible obstacles facing implementation - the ones that currently exist and the ones that are likely to develop as more foreign players enter the Kuwaiti marketplace.

\section{Political}

Reiterating what has been shared by a majority of the interviewees, participant 18 highlighted how the government and parliament lack a strategic vision and action plan. He feels that more than one political agenda is dominant and sometimes issues are prioritized based on political benefits.

I personally asked for amendments to be made by the Ministries Council, but my requests remain unanswered. It is difficult to implement the law as it is in its current condition.

\section{Legislative}

Approval of the privatization law stirred considerable opposition in Kuwaiti society. Participant 21 stated that, "unlike other laws that are usually adopted quietly with a majority in agreement, this law made a lot of noise in Kuwait." Participant 28 explained how a large number of lawyers, economists, and even politicians were strongly in opposition. Some members of the National Assembly shared their anti-privatization viewpoints, but that did not prevent the law's adoption and the Parliament's approval of 
the draft bill. Document reviews of the congressional committee reports reflect 33 members voted in favor of the draft law and 28 members rejected it. Arguments of all opponents to the privatization law, some of which comprised the interviewee sample, reason that approval of privatization will eventually transform the country's economy to a complete capitalist economy. Participant 21 expressed fears that, "the law will allow private capital owners to have greater control over the national economy." Interviewees from the Kuwait Oil and Petroleum industry claimed that, "the law comprises provisions that contradict chapters of the constitution that relate to the oil sector, especially in regards to revenue generation and ownership." Lawyers of local NGOs reaffirmed the existence of irregularities in the law's framework that conflict some articles of the constitution.

The success of privatization, as participant 30 outlined, will require the establishment of principles that determine the private sector's involvement, downsizing government, controlling the budget and government expenditures, strengthening evaluation and supervision mechanisms, focusing on local employment, and developing programs that align with the SDGs as the country needs and aspires.

\section{Social}

Participant 27 discussed how government programs are mostly focused on developing the economy. Topics covered include financing sectors, allocating the budget, and expanding development plans. Participant 27 shared how minimal attention is devoted to developing human capital, especially with population groups of women and youth. 
Not only are there limited focus, but also inexistent criteria for assessment and evaluation of the country's policies. From my experience, it is quite rare for plans approved in Kuwait to have a binding timetable and evaluation mechanisms for managing the performance and goals achieved. Therefore, who should we hold accountable - the MPs, the government, or the uninformed public? Maybe we should just not renew the contract with the sector that was handling the project and find a new contractor.

Participant 15 added the need to unify government's operations, given that many projects remain incomplete as the recent Jaber International Stadium. In this case, the project's construction was halted due to insufficient funding and contractor demands.

The Social Securities network (SSN) in Kuwait maintains social welfare to eligible individuals and groups of the society. This enables nationals to achieve better standards of living, while mitigating the negative effects of economic and social changes, as experienced in the Kuwaiti society (SSN, 2009). In this context, participant 25 discussed how reforms like privatization help support the country's development process by maintaining the state's efforts of SSN to underprivileged social groups.

It can be considered the first line of defense and social order to avoid the negative effects of this reform, of which would also impact the national workforce.

In sum, documents reviewed of the United Nations' stance with regards to this reform strategy, state that, "privatization is a demanding business process, that needs high quality technical inputs (...) and better quality governance; success depends on domestic institutional reforms, vis-a-vis reform of education, reform in capital market institutions, strengthening the rule of law and property rights, reduction of transaction costs, and proactive industrial, technological and trade policies" (UN,1999:9). 


\section{Policy Evaluation}

Research participants' responses to the question of whether evaluative criteria were considered when adopting the privatization legislation, were coded into the main themes in Figure 4.

Figure 4

Thematic Analysis: Policy Evaluation

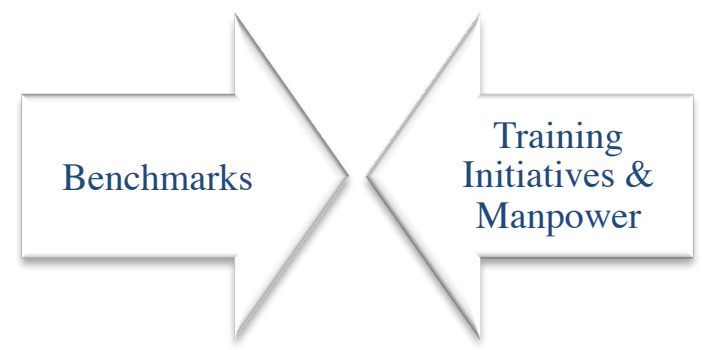

There was minimal feedback to this research question, which indicates the lack of such criteria for public policies in Kuwait.

\section{Benchmarks}

Participant 16 shared his view of how bureaucracy in Kuwait is much more stringent than in other GCC countries.

This makes it difficult to have any benchmarks at all. I know this personally as my duties involve my interactions with banks in the region, on a daily basis, to fulfill banking needs.

The financial banking structure in Kuwait is more systematic, according to the examples of loan and investment policies that Julian shared. However, interviewees representing the private sectors agreed that Kuwait is a very difficult market to enter as a foreign direct investor, even though there is vast demand for a diversified basket of goods 
and services. Participant 8 explained this is because private sectors in Kuwait are considered technically advanced in the Gulf region, although not diversified in sectors.

Participant 14 discussed how the SCP should consider benchmarks and models of successful privatization initiatives in Arab countries, such as Qatar, UAE, Jordan, and Lebanon. Only then - based on takeaways from these countries' experiences - a strategy can be developed.

Dubai is a successful experience because it has a clear strategy, strong leadership, and a structured workforce. It does not have sustainable resources like some of the other GCC countries, but it managed to prosper with in spite of that drawback.

A review of the GCC council's publications positions UAE as the leader of the economic development wave in the GCC region, as the country is dominated by serviceoriented industries. Participant 15 shared his experience of how it is difficult to benchmark Kuwait against other GCC countries, even though the country shares similar historical roots. He explained this is because Kuwait has a different political structure, decision-making processes, and social contexts.

Participant 21 shared her viewpoint of how privatization in Kuwait is long overdue. Within the region many countries have already implemented market reforms. Kuwait is actually among the few to fall behind in this reform movement.

It is usually better to implement privatization during times of prosperity. In times of economic stagnation, the last thing people want to do is pay for free services or job hunt. The last thing private sectors want to do is pay for a new portfolio of stocks and shares. 


\section{Training Initiatives and Manpower}

When asked about the training and rehabilitation initiatives that exist for personnel that will be directly involved in foreseeing privatization's implementation stages, participant 9 replied that employees are not ready to handle these workplace transitions. He explained how his employees are used to routine work processes and shorter working hours.

Although $M \& E$ is a big deal in my sector, it would be wrong to deny that that there is minimal supervision in some of the other public sectors. Also, recruitment standards for experience and knowledge are lower than in comparable private sectors.

Participant 28 and 29's responses indicate that it is very difficult to change the

political, economic, and social environment in Kuwait. Interviewees representing executive posts in the country are hopeful of the younger, more educated generations.

However, participant 28 mentioned how new market entrants are in favor of private sector jobs, more so than public ones.

After a few years of working in high-demand and long-hour jobs in the private sectors, you will see these employees transition to public sector jobs that comparably have less supervision, less job demands and thus lower stress levels, stability, a guaranteed payment schedule, more vacations, and annual bonuses. This is why private sector recruiters tend to recruit foreign workers over nationals because these workers will not have the option to transition to a public sector, as they are not nationals. So the amount of time and energy put into training these foreign workers stays longer within their corporate environments.

Participants from the diwaniya community group reiterated the same information

of how the Kuwaiti private market is dominated by monopolies. One of the respondents stated, "it is so bureaucratic for smaller businesses to enter and have a chance in the marketplace for offering similar goods and services; there is no healthy competition." Currently, private banking sectors have a minimum of $60 \%$ Kuwaiti quota (Ministry of 
Social Affairs and Labor, 2009). This minimum percentage of national labor, or Kuwaitization, depends on the private sector industry. Kuwaitization is a law issued by the Ministry of Social Affairs and Labor that enforces ratios for national employment in the private sector. In the case that a private company fails to apply these standards, the ministry would stop issuing the company work permits, legal transactions, and the release of ratio certificates (Salih, 2010). Some of the diwaniya members working in private sectors explained how there should not be a fixed quota. They shared their view of how a minimum Kuwaiti labor force must be a flexible number and not fixed.

In addition to training initiatives, monitoring and evaluation, and market forces that are required as evaluative mechanisms, participant 23 stressed the importance of research as a component that sets the stage for agenda setting. Representing the international nongovernmental organization (INGO) networks, she noted how their research efforts are mostly sought after during the earlier policy development stages.

As an internationally recognized organization, we are tasked with market assessments and feasibility studies for most countries and sectors. It would be beneficial for Kuwait if we were given access to oversee implementation stages, as well. However, the political environment of the GCC is very particular and so our contributions can only be as a consultative status in research and development $(R \& D)$.

Participant 24 elaborated on how INGOs also play a strong role as an evaluative and monitoring body. She discussed how her organization meets quarterly with the government to assess progress made against target goals and performance indicators. However, in the case of privatization policy in Kuwait that is yet to be implemented, no evaluative actions can be taken.

We try to raise social awareness through the activities we host in countries of the Gulf region. Unfortunately though, participation rates are low in the workshops 
and seminars hosted by our field offices. National workforces of Gulf countries generally lack the culture of motivation and incentives, unless attendance is mandatory by employees or the government as a prerequisite to public sector employment. Private sectors of those countries are a different entity that we do not interact with.

A review of past initiatives led by INGOs in Kuwait includes hosting roundtable discussions and focus groups with community members. Objectives of these initiatives have been identified as analyzing issue areas in the country and providing participants with an opportunity to interact and grow from this integrative process. Participant 25 stated, "my dream is to see intelligence developed and employed locally, rather than bringing in people internationally as a need arises."

\section{Political Decision-Making}

In the final research question, participants were asked about the decision-making processes in Kuwait. The emerging themes from their inputs are divided in Figure 5.

Figure 5

Thematic Analysis: Political Decision-Making

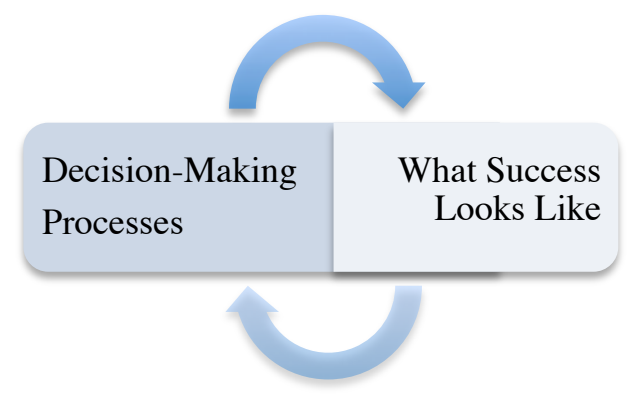

Responses varied between the general norms followed and the processes adopted for the privatization law in particular. 


\section{Decision-Making Processes}

In the case of the privatization policy in Kuwait, participant 4 discussed how the decision-making process was inefficient. He explained that decisions are made according to consensus, political bargaining, and purely economic benefits.

I stood in strong opposition to the draft law as it was being voted on in the national assembly. Yes, I agree that this reform strategy will help decrease the government's burden, but we need to start gradually and study the market first before making a political decision of a market-based reform.

Participant 13 shared his experience working at government sectors, in that

Kuwait lacks a strategic direction. He explained how there is a vision for the country, but no direction of how to accomplish it. Some important questions he raises are, "Which sectors to privatize first? What is specifically needed?" He stressed that consideration must be made regarding how this privatization law will help achieve what needs to be achieved in the country.

Analyzing interviewees' responses and community members' experiences and feedback indicates how the policymaking method leading up to a decision varies based on multiple factors. Participant 26 presented some methods he employs to improve the policy process in the sector he directs. These include a transformational leadership style, public sector motivation (PSM), efficient managerial practices, and total quality management (TQM) approaches.

In 1986, Development Law 60/86 was enacted that required the government to have an economic strategy plan and a long-term vision that can be accomplished in shorter-term action plans. Development projects that resulted from this law were not accomplished until 2005, after several amendments that requested detailed plans for 
development projects in the country. However, the government was still in charge of developing these projects. When asked about this law as it originated from his public authority, participant 10 indicated how the government was too burdened to execute large-scale projects that would transform the economy and fulfill the law's predetermined goals.

The government's role was not only to plan and execute these projects, it also had to raise social awareness and build public support. Again, too much burden. What is happening now is essentially what happened in the 80s all over again. It is a vicious cycle, but at least we have an enacted law this time around, although there is no expected time frame between the law's enactment and actual implementation. This is probably why it has already been six years now and still no implementation efforts made.

Participant 2 simplified the equation when he discussed that, "the private sector has the expertise, and the public sector has the money." This is the case in all of the GCC countries, given the similarities in the societies, economy, and political structures of the country. Saudi Arabia, however, presents a different case, as participant 17 explained, since people do have the money but lack variations in investment vehicles.

In my opinion, the national portfolio of a country should be made public so people and investors can equally be informed.

Participant 20 discussed how decision-making in Kuwait is strictly at the Ministerial and parliamentary levels. As a result of this process, participant 20 explained how the country "suffers" from an incomplete democracy, where the voting system is lacking critical elements that would make it completely democratic.

The public sector I direct operates on behalf of the government, making decisions as a public entity. Having said that, we do not play a direct role in the policy development arena. In cases where we are given the opportunity, I advise the board to opt out of participating, as it is not part of the investment authority's duties. 
Participant 14 elaborates on this point, sharing his experience of how decisionmaking power is directly related to the privileges a certain government body has. These privileges can exist in the form of financial assets and/or political authority. Participant 8 shared that most of the private banking sectors in Kuwait were not asked to contribute to privatization policy's decision-making process.

The law was formulated at the government, approved at the parliament level as per constitutional requirements for any law's enactment in the country, and then made public by the Council of Ministers.

Participant 19 mentioned how privatization can present some serious challenges, which is why a reform of this nature needs a proper legal structure. He raises some critical questions including, "Where are we today? What are the major components of the GDP? How can we implement privatization, and where do we go from here?"

Development, from participant 30's experience in the Middle East, is an equation that consists of two variables - infrastructure plus human capital. Participant 30 explains that the UN focuses on the human capital components of the development process, which include women and youth. This is mainly because the cultural context of Middle Eastern countries already has a strong male dominance. The UN and its subsidiary bodies strive towards equality and social inclusion in any development process.

Our involvement with the privatization policy in Kuwait is via a consultative status. We overlook aspects of implementing this law in ways that ensure sustainability and human development. We call for a political decision-making process that incorporates elements of governance, gender equality, south-south cooperation, and SDGs' enhancement.

Interviewees representing international organizations discussed the aspects of social exclusion not just of population subgroups, but within the government as well. 
Participant 25 shared her observation that not all of the government's counterparts are responsive.

There is a lack of accountability in the decision-making process. To resolve this, the regional presence of the UN office developed a consistent set of SOPs to unify work processes in the Kuwaiti government sectors. However, in the case of privatization policy, no reference was made to these SOPs.

The World Bank's involvement with the privatization policy was consultative. Documents reviewed indicate that they contributed their expertise and knowledge to sections of the law that discuss the implementation stages. Special focus was made to ensure economic diversification, growth, and development of all country sectors (World Bank, 1993). The World Bank (1993) reported on how private sectors can play more active roles in this process.

Focus group participants reiterated how bureaucracy and centralization are dominating the decision-making environment in the country. One of the female graduate respondents mentioned, “we don't even know what type of privatization has been approved; will we be able to buy and own the assets?" A private sector, female employee participating in the istiqbal focus group expanded on this comment saying, "we are unaware of what the law allows private sectors to do; the law is not clear for us to even begin considering making any pitch, whatsoever, from our end." One of the other participants added, "I personally think that there is a big issue with the level of government transparency."

\section{What Success Looks Like}

Participant 22 shared her view of how there is a lot of potential and expertise in the private sectors that the public sector can benefit from. As a director at one of the 
Ministerial levels in Kuwait, Participant 22 mentioned that she expressed these thoughts during meetings leading up to the draft law's voting session. Her colleagues agreed that one law could not encompass all sectors in Kuwait.

Some of the executives that were interviewed at the Ministries explained how attempts to expand the economy are difficult, as long as the parliament keeps using its political power to "stand in the way." From participant 7's experience leading a government sector in Kuwait, it is not easy to shift the economy from its financially prosperous state to a conservative one for developmental purposes.

Readjusting economic scales demands support from all levels of the government and the society, as well. Since the time of the law's enactment to current day, there still is limited ground for action. For example, if land is requested for development and expansion purposes, either the land is limited or channels are too bureaucratic and time-consuming.

One of the former MP interviewees shared the example of how one of the recent initiatives he proposed to policymakers was to increase the price of electricity. He explained that the parliament strongly opposed this proposal knowing that asking their constituents to pay more than they have ever before for the same consumptions levels would risk losing votes and public support. Furthermore, participant 3 shared his perspective that early planning is needed in the country on a continuous basis and not only when crises happen.

Change is inevitable. However, Kuwait is walking to the airport instead of driving; the plane will take off, regardless.

Participant 3 also referred to the aspect of the 'pace of change'. From his experience, Kuwait has potential to embark on this development path, in terms of capacity and resources. However, the government needs to speed up this process. 
Due attention must be made to factors that can hinder the development process, such as issues of unemployment, inexistent platforms, and the oversupply of manpower, regardless of the low levels of demand. Nevertheless, development is possible with a coherent strategy and action. All elements that are needed already exist; we just need the vehicles to mobilize efforts.

A review of news coverage shows that media plays a significant role in Kuwaiti society. Free press is protected by the constitution. However, participant 5 explained, "The Ministry of Information should ensure that an adequate balance is maintained between private and government media channels."

When asked about the existing venues for public's participation in the policymaking sphere, participant 17 shared her experience as the director of a public authority.

I was not focused on expanding the channels for citizens' participation. There are various venues as it is. Instead, I would focus on increasing the level of intellect and awareness in the society. That way, citizens can participate on behalf of a larger majority, rather restricted knowledge of their personal needs only. I focused mostly on policies that would strengthen education and training needs for both private and public sectors.

According to the focus group respondents, successful decision-making is the ability of governments to meet the needs of its citizens. One of the graduate student participants explained:

I think that all of our needs are met. The government is already ensuring that the main public services are offered to us, such as education, health, infrastructure, housing, food, water, and electricity.

This point of view was reiterated amongst a majority of participants, "the problem is not the lack of access to services; it is the quality of these services." Another participant in the same focus group strongly argued that, "the government really should not offer free services if it cannot guarantee good quality; I would rather pay but at least 
have service worth the value." However, a third participant in this discussion disagreed, “the important point is that citizens' needs are provided by the government in a percentage of approximately $80-90 \%$; the quality is not great but it will do." This remark was reiterated by a fourth respondent, saying "I really do not care about the quality as long as it is free."

Success, from the perspectives of these focus group members, lies in the restructuring of government and public policies. A male graduate student explained:

The problem is that the government appoints unqualified individuals in high decision-making positions in the country. How can we expect successful policy development and implementation if the people in charge are not knowledgeable enough?

A member of the istiqbal focus group shared her dissatisfaction with the way policies are formulated in the country, saying "we still need to ensure that all sectors in the country and all population subgroups are participating; sometimes its feels like our presence is insignificant during prosperous times and critical during severe economic or political events."

Women have made considerable progress in their education levels and political participation over the past recent years, however the cultural and workplace obstacles to gender equality remain (Shah and Alqudsi, 1990). The istiqbal focus group participants agreed that, generally, women are still dependent on men for career, education, and social choices. One of the respondents disagreed with the other's view of how females are underrepresented in policies developed nationally. She stated, "the law is on our side, but some women just do not want to accept it." The remaining majority of female students and community members argued the need to especially focus on the female population 
group in order to truly strengthen the policymaking process. In defense of the country's current political dynamics, one of the other participants shared her view that, "a majority of women in Kuwait are just generally not interested in politics." Counter-arguments of other members explained that, "the role of women in political office is limited because they are not given the opportunity." She continued to explain some of the reasons why opportunities are limited, "because females are very detail-oriented and committed to performing their duties ethically, whereas some of the male figures in office do not even have an agenda of motives to work; they are enjoying the power that the political system invests in them and feel reassured of remaining in their posts." Participant 10, also discussed this notion of how the culture determines the country's gender dynamics.

A successful policy like the privatization policy should include elements that acknowledge both perspectives of the society - females and males alike. We need provisions in the law that focus on a female quota or enhancing female employment in privatized sectors. We are used to MPs discussing policy issues from one perspective rather than a co-gender perspective. In the end, issue areas in the country affect the entire community.

\section{Research Findings}

Politics, as defined by Stone (2002:8) is, "the struggle over ideas seen from multiple perspectives, rather than objective facts." Data results gathered from participants' responses are molded into findings, as Patton (2002) describes, in order to provide a better understanding of the phenomena of policymaking in Kuwait. By blending the composite descriptions that were shared by individual research participants (Moustakas, 1994), the research findings below attempt to capture the commonalities and essence of the overall experiences with the privatization policy's development in Kuwait. 


\section{An International Perspective}

International organizations' perspectives are generally in support of the privatization movement in developing countries. A study of transitional economies conducted by the United Nations (1999:3), states that "the new paradigm of governance stresses decentralization; there is a growing realization that privatization is not the end of government participation but rather a new beginning." Privatization rebalances the role of the state. However, it remains "an intensely political process that involves conflict among key stakeholders" (9).

Failure of national governance is categorized as one of the global risks facing the Gulf region in general, which is amongst the top five global risks of highest concern in the world (WEF, 2016). The WEF describes this to be, "the inability to govern a nation of geopolitical importance due to a weak rule of law, corruption or political deadlock" (86). Results of the 2015 Global Risks Perception Survey calls for the need of public-private collaboration to develop actionable solutions that strengthen the country's resilience to the global risk of national governance failures - a risk that, if it occurs, can cause significant negative impact. The WEF (2016:27) concludes in its Executive Opinion Surveys that countries must begin supporting new models of public-private collaboration, in order to, "promote, finance, and deliver immediate assistance and alleviate long-term needs, with business collaborating closely with frontline responders on responsible investment to strengthen state and societal resilience."

Efficient governance is one in which corruption levels are low and transparency levels are high (Cassell, 2004). The rule of law is enforced so as to strengthen the progress of development and social sustainability. In this context, the indicators of 
'corruption' and 'transparency', along with other indicators, are included in Table 5 that follows. In this table, Kuwait is positioned within the context of GCC countries that have implemented a successful method of privatization. Singapore is included for comparison purposes of a developed country with a more diversified and stable economy ${ }^{2}$.

Themes and subthemes that evolved from the emergent and horizontalization strategies employed in the phenomenological data analysis method further informed the selection of comparable indicators in the table below. The objective is to identify the most resonating policy issues in Kuwait, as perceived by the interview and focus group participants, vs. the actual policy issues as measured by internationally recognized indicators in comparative indices. Points of convergences between both perspectives were used to inform the findings and recommendations resulting from this research.

Table 5

Country Rankings: Productivity and Growth

\begin{tabular}{llllll}
\hline & Kuwait & UAE & Qatar & $\begin{array}{l}\text { Saudi } \\
\text { Arabia }\end{array}$ & Singapore \\
\hline GDP (US\$ billions) & 120.7 & 345.5 & 185.4 & 653.2 & 292.7 \\
Population (millions) & 4.1 & 9.6 & 2.4 & 31.4 & 5.5 \\
GDP per capita (US\$) & 29,363 & 36,060 & $76,576.1$ & $20,812.6$ & $52,887.8$ \\
A. Diversion of public funds & 57 & 5 & 11 & 18 & 3 \\
B. Public trust in politicians & 73 & 2 & 6 & 12 & 1
\end{tabular}

\footnotetext{
2 Singapore has a relatively favorable business climate with an ease of investment, as reflected in the indicator rankings of Table 5. Participant 4 and 21 mentioned that a number of private companies in Kuwait have developed working relations with Singaporean businesses, over the past recent years. Further, a study conducted by the Oxford Business Group (2008) refers to the increasing trade flows between Kuwait and Singapore at a 34\% increase in exports during 2004 and 2006.
} 


\begin{tabular}{|c|c|c|c|c|}
\hline $\begin{array}{l}\text { C. Favoritism in decisions of } \\
\text { govt. officials }\end{array}$ & 85 & 4 & 6 & 18 \\
\hline D. Wastefulness of govt. spending & 90 & 2 & 1 & 12 \\
\hline E. Burden of govt. regulation & 108 & 3 & 5 & 28 \\
\hline $\begin{array}{l}\text { F. Transparency of govt. } \\
\text { policymaking }\end{array}$ & 103 & 14 & 15 & 38 \\
\hline $\begin{array}{l}\text { G. Strength of auditing and } \\
\text { reporting standards }\end{array}$ & 77 & 24 & 26 & 36 \\
\hline $\begin{array}{l}\text { H. Quality of overall } \\
\text { infrastructure }\end{array}$ & 62 & 4 & 27 & 30 \\
\hline I. Quality of the education system & 86 & 10 & 5 & 48 \\
\hline $\begin{array}{l}\text { J. Local availability of specialized } \\
\text { training services }\end{array}$ & 113 & 22 & 18 & 76 \\
\hline K. Extent of staff training & 80 & 16 & 8 & 57 \\
\hline L. Intensity of local competition & 59 & 9 & 17 & 37 \\
\hline M. Extent of market dominance & 95 & 10 & 11 & 29 \\
\hline $\begin{array}{l}\text { N. Effectiveness of anti- } \\
\text { monopoly policy }\end{array}$ & 115 & 19 & 15 & 32 \\
\hline $\begin{array}{l}\text { O. Number of procedures to start } \\
\text { a business }\end{array}$ & 126 & 54 & 94 & 126 \\
\hline $\begin{array}{l}\text { P. Number of days to start a } \\
\text { business }\end{array}$ & 120 & 48 & 53 & 98 \\
\hline $\begin{array}{l}\text { Q. Prevalence of foreign } \\
\text { ownership }\end{array}$ & 136 & 10 & 71 & 115 \\
\hline $\begin{array}{l}\text { R. Business impact of rules on } \\
\text { FDI }\end{array}$ & 131 & 14 & 69 & 118 \\
\hline $\begin{array}{l}\text { S. Female participation in labor } \\
\text { force, ratio to men }\end{array}$ & 117 & 123 & 116 & 135 \\
\hline
\end{tabular}




\begin{tabular}{lccccc} 
T. FDI and technology transfer & 116 & 3 & 7 & 36 & 2 \\
$\begin{array}{l}\text { U. State of cluster development } \\
\begin{array}{l}\text { V. Nature of competitive } \\
\text { advantage }\end{array}\end{array}$ & 48 & 2 & 10 & 23 & 12 \\
$\begin{array}{l}\text { W. Willingness to delegate } \\
\quad \text { authority }\end{array}$ & 38 & 13 & 7 & 29 & 21 \\
$\begin{array}{l}\text { X. Capacity for innovation } \\
\begin{array}{l}\text { Y. Quality of scientific research } \\
\text { institutions }\end{array}\end{array}$ & 104 & 15 & 19 & 72 & 20 \\
\hline
\end{tabular}

Sources: PACI (2016); CSB (2014); WEF (2016); WEF (2017); and International Monetary Fund (IMF)'s World Economic Outlook (WEO) 2016 Database.

Notes:

(i) Factors A through Y have been evaluated in terms of the relevant research questions for each factor. This draws on emerging themes from the data analyzed of participants' responses.

(ii) The factors are ranked for each country against the 138 economies included in the WEF assessments; the first economy is considered the most competitive in terms of growth and productivity.

Global competitiveness, per Schwab and Sala-I-Martin's (2016:4) definition is, "the set of institutions, policies, and factors that determine the level of productivity of an economy, which in turn sets the level of prosperity that the country can achieve.” Table 5 evaluates the competitiveness of Kuwait with respect to a select group of countries that have implemented privatization models of success. Schwab and Sala-I-Martin measure a country's economic growth and development in a Global Competitiveness Index (GCI) of 114 indicators, grouped into 12 pillars. Each of the 12 pillars has a different set of factors that are collectively and individually weighted. The 12 pillars are further categorized into 3 subindices. These subindices represent the 3 types of economies in the world: factordriven (stage 1), efficiency-drive (stage 2), or innovation-driven (stage 3) economies. Data to develop these indices were gathered from statistical datasets of internationally recognized organizations, including the UN, World Bank, and IMF. Innovation-driven 
economies are considered the highest level of development, relative to the prior two economies that are listed in the respective order.

Factors in Table 5, that relate to different GCI pillars, were selected based on relevance to: 1) the research questions, 2) participants' responses during data collection stages, and 3) the meaning units and themes that emerged during data analyses. According to the WEF's Executive Opinion Survey (2016), the most problematic factors for doing business in Kuwait are inefficient government bureaucracy, restrictive labor regulations, inadequately educated workforce, corruption, policy instability, inadequate supply of infrastructure, and insufficient capacity to innovate. Factors A through G comprise the first pillar of the Global Competitiveness Index, which are institutions. Factor $\mathrm{H}$ represents the second pillar of infrastructure. Factors I through K relate to the higher education and training pillar number five. The sixth pillar of goods market efficiency is represented by factors L to R. Factor S represents the seventh pillar of labor market efficiency, while factor T represents the eighth pillar of financial market development. The eleventh pillar of business sophistication consists of factors $\mathrm{U}$ to $\mathrm{W}$. Lastly, the twelfth pillar of innovation is represented by factors $\mathrm{X}$ and $\mathrm{Y}$.

Participant 19 explains how most of the public funds in Kuwait are spent on infrastructure. This is illustrated in Table 6, as rankings for "basic requirements" are not as low compared to rankings for "innovation and sophistication." According to participant 20 , "if a country does not have a 'diversion of public funds', then the economy will not grow." Participant 2 discussed that when the monitoring and evaluation mechanisms are weak, as in factor G, naturally the policies' development and implementation would be weak as well. Participant 1 explained, "the lack of trust in 
government gives birth to interest groups, as certain individuals become active enough to represent a larger group of like-minded individuals; this diverts people's hope and trust in government, to trust in the leaders of such interest groups." Moreover, the degree to which Kuwait is deploying its human capital potential is especially weak among youth and the bulk of the labor force, between 25 and 54 years of age.

Table 6

Global Competitiveness and Human Capital Index Rankings, 2016-2017

\begin{tabular}{|c|c|c|c|c|c|}
\hline & Kuwait & UAE & Qatar & $\begin{array}{l}\text { Saudi } \\
\text { Arabia }\end{array}$ & Singapore \\
\hline Overall & Yr 2016: 38 & Yr 2016: 16 & Yr 2016: 18 & Yr 2016: 29 & Yr 2016: 2 \\
\hline ranking of GCI & Yr 2012: 37 & Yr 2012: 24 & Yr 2012: 11 & Yr 2012: 18 & Yr 2012: 2 \\
\hline $\begin{array}{l}\text { Subindex } \\
\text { ranking "BR" }\end{array}$ & 36 & 11 & 5 & 32 & 1 \\
\hline $\begin{array}{l}\text { Subindex } \\
\text { ranking "EE" }\end{array}$ & 70 & 15 & 21 & 33 & 2 \\
\hline $\begin{array}{l}\text { Subindex } \\
\text { ranking "ISF" }\end{array}$ & 79 & 21 & 18 & 36 & 12 \\
\hline Score & 4.53 & 5.26 & 5.23 & 4.84 & 5.72 \\
\hline $\begin{array}{l}\text { Stage of } \\
\text { economic } \\
\text { development }\end{array}$ & $\begin{array}{l}\text { Transition } \\
\text { from stage } 1 \\
\text { to stage } 2\end{array}$ & $\begin{array}{l}\text { Stage 3: } \\
\text { Innovation- } \\
\text { driven }\end{array}$ & $\begin{array}{l}\text { Stage 3: } \\
\text { Innovation- } \\
\text { driven }\end{array}$ & $\begin{array}{l}\text { Transition } \\
\text { from stage } 2 \\
\text { to stage } 3\end{array}$ & $\begin{array}{l}\text { Stage 3: } \\
\text { Innovation- } \\
\text { driven }\end{array}$ \\
\hline $\begin{array}{l}\text { Overall } \\
\text { ranking of } \mathrm{HCI}\end{array}$ & 97 & 69 & 66 & 87 & 13 \\
\hline $\begin{array}{l}\text { HCI rankings } \\
\text { based on "age } \\
\text { groups" }\end{array}$ & $\begin{array}{l}\cdot 15-24 \text { yrs: } \\
115 \\
\cdot 25-54 \mathrm{yrs}: \\
108 \\
\cdot 55-64 \mathrm{yrs}: \\
99\end{array}$ & $\begin{array}{l}\cdot 15-24 \text { yrs: } \\
90 \\
\cdot 25-54 \text { yrs: } \\
\quad 68 \\
\cdot 55-64 \text { yrs: } \\
73\end{array}$ & $\begin{array}{l}\cdot 15-24 \text { yrs: } \\
72 \\
\cdot 25-54 \text { yrs: } \\
82 \\
\cdot 55-64 \text { yrs: } \\
71\end{array}$ & $\begin{aligned} & 15-24 \text { yrs: } \\
& 68 \\
\cdot & 25-54 \text { yrs: } \\
& 89 \\
\cdot & 55-64 \text { yrs: } \\
& 91\end{aligned}$ & $\begin{array}{l}-15-24 \text { yrs: } \\
25 \\
\cdot 25-54 \text { yrs: } \\
6 \\
\cdot 55-64 \text { yrs: } \\
39\end{array}$ \\
\hline
\end{tabular}


Notes:

(i) Subindex rankings: Basic Requirements (BR); Efficiency Enhancers (EE); Innovation and Sophistication Factors (ISF)

(ii) Ranking out of 138 economies, with the first economy being the most competitive in terms of growth and productivity.

(iii) Scores are measured on a scale of 1-to-7, with 7 being the most desirable outcome. These scores are a weighted average of the individual scores for each indicator entering the composition of the overall GCI.

(iv) See Appendix for further details of the Global Competitiveness Index framework (WEF, 2017).

(v) The Human Capital Index (HCI) ranks countries based on how well they are developing and deploying their human capital potential. Rankings are out of 130 countries (WEF, 2016). A further assessment of the learning and employment outcomes of individual age groups is listed on a scale of 0-to-100, with 0 being the worst and 100 being the best. As per WEF's assessments, the age group of 15-24 years represents youth, 25-54 years is the bulk of the labor force, and 55-64 years are the majority of senior members in the workforce. The full report includes the complete demographic profile of countries, with a distinction made for the five age groups, beginning at 0 years and ending at $65+$. For the purposes of this research, ages ranging from youth to senior members of the society are the only groups included, as data findings indicate that these groups are the primary contributors to the policymaking process as active or passive actors. Moreover, the retirement age in Kuwait varies between men and women and is determined based on marital status and years of service (CSC, 2008). The general age, as per the Public Institution for Social Security in Kuwait (2011), is between 40 and 65 years. The age group referenced for this research is between 15 to 64 years, noted in the table above.

From Tables 5 and 6, it can be argued that a country's economic development is

neither based on its GDP levels, nor its financial capacity. Instead, economic growth and development are a result of the level of international competitiveness and the level of social inclusion. This, in return, depends on the supportive nature of the country's internal structures with regards to the business climate, social environment, and political structures. For a country to reach higher levels of productivity and growth, both nationally and internationally, efforts and policy initiatives should be attributed to the weaker performing pillars. However, this is not to say that the stronger performing pillar should be overlooked or even assumed to remain strong continuously. Rather, public and private sectors should cooperatively approach the country's economic development plan of action in a strategically successful manner that capitalizes on the scarcity of resources and the potential of human capital. 
The country's vision moving forward is to economically reform Kuwait as a financial and commercial center for investments, development, and economic growth (MOP, 2010). According to congressional reports of the National Assembly (KNA, 2016), privatization should be the main focus for any economic reform efforts. Successful lessons learnt from neighboring countries can serve as benchmarks. The strategic objectives of economic reform efforts in the country, as outlined in the development programs for year 2035, focus on establishing long lasting economic structures that:

(1) Enhance local competition in the marketplace for goods and services;

(2) Create jobs for the national workforce;

(3) Shift the country's dependency from rentier economies to merit-based competition;

(4) Diversify the sources of national income.

The third objective would focus on shifting the country's economic dependence on one source of income that mostly benefits employees within the system and minimally benefits the society, to economies that produce real economic growth. Real economic growth integrates the workforce, increasing production and consumption trends. This results in the establishment of new projects to accommodate the new levels of social demand. Employment opportunities expand, thereafter, increasing the value of the national income multiplier and enhancing the national economy.

This concept of rentier capitalism, or, the economic practice of monopolizing access to any property so as to gain significant profit without contributing to the society (Marx, 1844), was a problem identified by research participants in this study. Lipset 
(1959) identifies economic development as comprehensive and continuous changes that are made possible by increases in the average real income and improvements in income distributions that favor the poor class, improve living standards, and restructure production channels. Thus, social inclusion during policymaking is a primary factor in a country's development process. Some of the other reasons why the public sector performs poorly in some developing countries is a result of large burdens on the public budget, lack of incentives on the part of management, little emphasis on profitability and efficiency, lack of appropriate accountability, and the absence of reliable information on performance (Mahmoud, 1992).

\section{Conclusion}

It was anticipated that research subjects benefited from their participation by having an opportunity to play an effective role in improving the policy development processes in their respective country. Goss and Leinbach (1996) discuss how providing participants with the opportunity to collaborate with researchers is empowering for some participants. Participants claimed that they benefited from the study in different ways. Focus group sessions provided participants with the opportunity to voice their thoughts, concerns, and ideas with regards to the research topics addressed. Kitzinger (1995) explains, "the interaction between participants enables them to ask questions of each other, as well as re-evaluate and reconsider their own understandings of their specific experiences." Furthermore, participating in this research proved to be an insightful experience for policymakers and administrators in that they were able to reflect on the

effective role they individually play in the policy development process. On a larger scale, 
the responses research participants shared helped identify dynamics of the policy development process in Kuwait. Problems facing implementation of the privatization policy and opportunities for process enhancement were openly discussed. The difficulty of implementing the privatization policy in Kuwait can be explained by a combination of the indicator rankings depicted in the tables above and data results gathered through this research. Data gathered and analyzed from the policymakers and community members is further elaborated in the next chapter. 


\section{CHAPTER FIVE}

\section{FINDINGS}

\section{Introduction}

Data collected reveal that the privatization law was enacted in response to the country's financial situation. Executive and legislative bodies in the country approved the law only after a thorough assessment of the country's ability to fund privatization programs. According to the IMF (2016), Kuwait is considered a high-income country by international standards. The World Bank, as well, classifies Kuwait, Saudi Arabia, and Oman as high-income countries. However, all six of the GCC countries are still in the developing economic status, regardless of income classifications (UN Conference for Trade and Development, 2016). This reiterates one of the GCC Council's (1981) objectives of unifying political and economic policymaking structures. It also reaffirms the development policies' diffusion processes in the region. Interviewees discussed the main goal of approving this legislation is to enhance economic growth both nationally and internationally.

As with most policy issues, support and opposition to the law continues to dominate the political sphere. On the one hand, some of the focus group participants opposed the law in fear of being dominated by natural monopolies, or as one of the participants called it "the money guzzling monopolists." They also fear job losses and how the dynamics of customer care and accountability would change accordingly. When asked, "Are you against privatization", participant 1 responded, "It depends on how it would work, who would have the chance to enter, and who will determine and make all 
the decisions." Theorists that are pro-privatization discuss how privatization introduces the element of market competition, which eventually reduces the overall price of goods and services (Savas and Savas, 2000). This reform has been widely regarded as being cost-effective, while improving quality and customer care (Al Gore, 1992). However, how realistic is this logic in an already monopolized market, or a limited vendors market? In other words, how effective is privatization in a market with very little competition? Some of the concerns shared by the university focus group participants are, "right now, we can pass on our discontent of government services to the MP that represents us; however, there would be no one to speak to if these services were privatized."

Article 108 of the Constitution states that, "a member of the Assembly represents the State in its entirety and safeguards the public interest." In this context, some focus group members feel that their voices are heard through their representative MPs; however, this would change if the public sector were privatized. Some of the other focus group members at the istiqbal gathering expressed their feelings of how the MPs they voted for are working to advance personal interests and political agendas. This highlights the element of political manipulation. On the other hand, opposition to the privatization law, as shared by some of the other research participants, is mainly a result of capacity issues, inadequate infrastructure, and the law's vagueness in clearly defining the rights of each private and public sectors' fair cooperation.

This chapter analyzes data findings in the context of the guiding hypotheses. References are made to literature reviewed of policymaking frameworks and theories of public management. 


\section{Policy Structure, Participants, and Key Determinants}

H1: Perceived problems, actual problems, political preferences, and economic benefits are factors and elements drove the agenda-setting process in the case of privatization policy in Kuwait.

Data findings indicate that perceived problems in Kuwait, as highlighted by research participants, were similar to the actual problems, as measured by internationally recognized indicators in the global comparative indices.

A policy's development course is determined by how it is structured, per the country's constitution. The constitution defines the political subsystems and power hierarchies. The constitution does not prohibit the creation of political parties. As a result of this freedom to aggregate, the society became more fragmented over time. This has slowed down the policy's development cycle, as interest group leaders feel strongly about exercising their political freedoms in an open democracy that allows them to confront and hold politicians accountable.

Data results highlight some of the key participants in Kuwait's policy development process. The Emir, Cabinet of Ministers, and the Parliament are the primary actors. The civil society plays a secondary policymaking role through their tribal, sectarian, and religious ties, or through affiliation with interest groups and political parties. Data shows that some of the MPs supported the policy in fear of not being reelected by constituents that were dissatisfied with the government's performance. Three of the interviewees discussed how government officials are often keen on gaining political recognition during their time in office, in order to secure their posts during reelections. Kingdon (1984) discussed this concept of policy entrepreneurs - actors who use their knowledge of the process to further their own policy ends. According to 
Kingdon (1984:165), "they wait in and around government with their solutions at hand, waiting for problems to float by to which they can attach their solutions, waiting for a development in the political stream they can use to their advantage."

The extensive network of tribal, sectarian, and interest groups in Kuwait depict the case of hyperpluralism. Nathan (1995) explains this as a case in which several groups are strong enough that the government is unable to function. In the case of privatization policy, interest groups did not play a significant role in the policy process. Further, academic and research institutions, as well as the country's private sector, were minimally consulted during the policy's development. Nevertheless, these civil and academic groups identified a majority of the law's shortcomings when interviewed. Interviewees highlighted the need to expand research and development (R\&D) initiatives prior to proposing any policy in the country.

The World Bank, International Monetary Fund, the United Nations'subsidiary bodies also had a notable role during privatization discussions. In general, these international organizations contribute atypically to the policy processes in the Gulf region. They attempt to influence policymaking through their international expertise, more than the utilization of financial instruments. To advance their policy agendas of sustainable development, these organizations seek alternative venues of cooperation such as consultative statuses.

Documents reviewed reflect the role of international organizations in the GCC region, as they work closely with local governments to provide UN Country Teams (UNCTs) with strategic guidance and policy advice. They provide coordinated and technical support through their established inter-agency Quality Support and Assurance 
(QSA) mechanisms, and oversight through their specialized performance management systems. In the case of privatization in Kuwait, the IMF, World Bank, and UNDP regional office were recruited as consultants for the government. Data findings highlight the role international organizations play in strengthening the policymaking process in Kuwait. International organizations do so through three main venues: (1) providing technical expertise in the form of workshops and training programs for the national workforce, (2) conducting needs-based assessments and studies of the market, (3) researching policy issue areas and sharing knowledge by organizing focus groups and roundtable discussions in the countries where a field presence exists. These organizations lack the power and ability to enforce their policy agendas in the GCC countries, however their advice is valued and impacts the process on a macro-level. Market studies and strategic assessments of the elements that comprise this policy's development were notable.

The political preferences of these policy actors were found to be drivers of the agenda-setting process in the case of privatization policy in Kuwait. In the past recent years, research participants have witnessed slower policy processes in Kuwait, due to the complex networks of actors. While some of these actors advocate on behalf of a majority of the public, others attempt to politically manipulate the structure in pursuit of selfinterests (Niskanen, 1971).

Data findings reflect that the population subgroups of women and youth are often marginalized in the policy development process. Focus group responses conveyed a low level of female participation in the country's policymaking process. Compared to the 1990s, women's political participation has increased with passage of the law that grants 
them voting rights in 2005 (UNDP, 2009). However, women in Kuwait continue to be socially excluded. Focus group participants explained this to be a result of the culture and traditions where men are often viewed as the dominant, decision-making figures in the society. This research has shown that a key input to the policymaking process is information. Jones and Baumgartner (2005) argue that information is not value neutral. Spicer (2010) discusses the concept of value pluralism existing in societies. Thus, if policymaking is an "unorganized, ambiguous process" (Feldman, 1989:5) that includes elements of social exclusion, this could increase the likelihood for political manipulation. This would, in return, question policymakers' keenness on preserving social equity and administrators' optimal level of decision-making discretion.

The element of economic benefit was also found as a driver in the agenda setting process. Further reasons that contributed to the rise and fall of the privatization topic on the government's agenda include changes in the environmental conditions and events. The plunge of oil prices attributed to the different points in time in which this topic has dominated the public sphere. According to Ramady (2014), Kuwait's economy is the least diversified in the GCC region, with a great dependency on hydrocarbon revenues. Consequently, during periods of high oil prices, the country experiences economic, social, and political stability. Recently, however, this has not been the case. Between 2011 and 2013, the hydrocarbon GDP growth percentage declined from $14.9 \%$ to $1.5 \%$ (HSBC, 2013). With the fall of oil prices in early 2016, privatization was reintroduced on the agenda of many GCC countries (Biygautane et al., 2016).

Data findings indicate that there was a push from politicians for economic expansion and diversification. Simultaneously, the public - representing both of the 
country's sectors - was pushing for greater openness and inclusiveness in the political process. In the absence of effective government management, it is challenging for any private sector to lead a prosperous national economy. The global economic crisis signified the need for strong evaluative mechanisms, explicit procedural actions, enforced accountability, and effective state operations in order for private sectors to thrive (Peters et al., 2011). Countries have expanded the most during economic booms, of which private sectors played a strong role in developed prosperous states (Farazmand, 1999). In this context, it can be concluded that a country relies upon both the private and public sectors' activities. However, defining a level of cooperation between both sectors is needed to distinguish between the type of assistance and support that is favorable and the levels of intervention that is unfavorable. Participant 13 explained during one of the interviews, "the current structure of private industries in Kuwait is not fit to lead the transformation process to a value-added economy that is based on labor and production; thus, implementing the privatization law is expected to help these private companies reach their target goals, which benefits the greater society, in return."

\section{Privatization Policy Development}

H2: Privatization of the public sector is generally viewed as an enhancement of the country's economic development process.

Data responses of the problems that the privatization policy addresses varied based on the respondent's perception of the policy's goals and outcomes. Findings indicate that there were two groups of responses. The first group perceived privatization as a government restructuring initiative, enacted in response to other persistent issues in the country. These issues are the unsystematic policymaking process, deficient legal 
framework, and inadequate infrastructure. The second group viewed the privatization policy as a step towards economic development. They shared their views of this policy addressing the problems of economic stagnation, capacity issues, and national workforce concerns.

Differences between the two groups of responses speak to two larger issues: 1) an uninformed public of the target goals related to such a restructuring initiative, and 2) the government's lack of communication of the country's needs and policy issue areas. This second issue is also found to be a hindrance to the policy's implementation, that is the country's lack of vision and action plan to supplement law 37/10. Consequently, if the government is still struggling to define this policy's parameters, then it is understandable that a majority of the public is uninformed. Regardless of the different views for the existing problem areas that drove the policy's formulation, there was a general consensus that privatization can enhance the country's economic development process. However, research participants noted the need for an adequate legal framework and supportive infrastructure, in order to ensure the policy's effectiveness.

Data findings indicate that the privatization policy seems to have been enacted without following the standard policy processes that transcend from policy formulation stages to law generation and implementation. Matters of concern were not expanded until after the bill was approved and revised based on the public's voice of critical issue areas. Even then, the bill remains vague and deficient in the ways discussed. According to an OECD study of resource productivity in eight of the world's highly industrialized countries, a more inclusive model of growth is needed to improve citizens' well being. This is especially important in a world economy with a fast-growing population (Gurria, 
2016). Humphries (2004) discusses how it can take many years to implement a policy and experience its benefits. Standards, procedures, and principles act like a tool kit of what must be followed in order to fulfill the target objectives. Therefore, one of the takeaways from the data analyzed is to focus on developing policies based on needs and consumption trends. Consequently, more than one law can help in defining a comprehensive approach to implementing a policy.

Findings infer that the policy was developed in response to an actual problem, as defined by a certain number of individuals. This problem is primarily economic stagnation. In the case of privatization policy, the economic conditions of the country paired with privatization initiatives in peripheral regions, attracted the attention of policy entrepreneurs that prioritized the issue and ultimately passed law 37/10. Biygautane et al. (2016) reaffirms that the dramatic plunge of oil prices in the later half of 2014 led oil dependent states of the Gulf to, yet again, discuss implementation of market-based reforms such as privatization and public-private partnerships (PPPs). The risk of an energy price shock is an issue of particular concern in countries of the GCC (WEF, 2016). An Executive Opinion Survey conducted by the WEF in 2015, reflected how the low prices are already leading to a decline in exports, revenue generation, and public finances. IMF survey results (2015) reveal how energy price shock is undermining financial planning, raising a crucial need for economic diversification.

Oil is the leading revenue generator in the Gulf region. Therefore, a plunge in oil prices inevitably leads to a fiscal crisis especially in Kuwait where the nation's wealth depends on oil and petroleum revenues (IMF, 2014). Oil wealth is what transformed Kuwait from a desert emirate to a modern city-state (El-Katiri et al., 2011). This 
economic dependency determined the country's political structure in terms of distribution of power and control of this resource that is nonrenewable (Tetreault, 1991).

Consequently, fluctuations in the price of oil can severely impact the national economy, as this resource is the country's primary revenue base. Results from documents reviewed of international organizations reflect economic trends that directly relate the plunge in oil prices with peaks in privatization talks at the government level. Privatization was first discussed in the 1980s, when the government was experiencing an economic crisis (Farid and Sirriyeh, 1986; Aldujayli, 1986). In fact, Bennell (1997) discusses how in the 1980s, the World Bank and IMF started advising countries in Africa on implementing structural adjustment programs, as attempts to reform state-owned enterprises. This reinforces both factors of the plunge in oil prices and rentierism as drivers of privatization talks in Kuwait.

In the case of Kuwait, the economy was suffering due to plummeting oil prices in the 1980s. Privatization talks peaked again in 2006 - the second point in time where oil prices were plummeting (IMF, 2003). It was not until 2010 that the law was enacted partly due to the legislative support of the 2010 National Assembly and the global economic crises. The SCP was formed, as per the law, but no implementation efforts were made. The economy began to stabilize thereafter, until 2015 when oil prices dropped drastically worldwide. This, yet again, raised concerns for the law's status and delay in implementation, as currently being experienced in Kuwait.

After the end of the oil boom in the 1980s and 1990s, particularly the Arab states with few resources, struggled with budget crises. With the exception of the Gulf states, most Arab countries sooner or later had to resort to the IMF, thereby being exposed to a 
neo-liberal agenda. Beck (2014:2) explains, "although most structural adjustment programs that the IMF imposed on the Arab states were diluted and only half-heartedly implemented, the IMF still contributed to the fact that the reform agenda, which originally contained strong political aspects, gradually mutated into an economic program of liberalization."

\section{Delay in Implementation}

H3: Obstacles facing implementation of the privatization policy in Kuwait include: Policymakers' problem definition, capacity issues, and lack of legislative support.

Policy issues in Kuwait, as perceived by the interviewees and focus group participants versus the actual policy issues, as measured by internationally recognized indicators in comparative indices, were compared in the first section of this chapter. Findings indicate that indeed the perceived issues and the actual policy issues are similar. Therefore, there is no inconsistency in problem definition as suggested in the guiding hypothesis. Instead, the delay in privatization policy's implementation in Kuwait is attributed to four main reasons. Two of these reasons - capacity issues and lack of legislative support - were hypothesized, while two other reasons were identified during data analysis. All four reasons were coded into the following clusters of meaning: (1) limitations in the law itself, (2) inadequacies in the country's political structure, (3) no supplemental plan of action approved to implement the law, and (4) unsystematic policymaking, in general, and particularly in the case of privatization policy.

\section{Limitations in the privatization law}

An analysis of all data collected and reviewed summarizes limitations in the law itself on four thematic fronts. 
First, there are some critical contradictions between the privatization method approved and individual provisions of law 37/10, regarding the state's rights and the private sectors' privileges. Document reviews of the privatization law, bylaws, NGO reports, along with the state's constitution reveal discrepancies between provisions of law $37 / 10$ and the constitution regarding the state's ownership and asset control. The law itself is vague in elaborating which method of privatization has been approved. Even within the provision of Article 1 that states, "transferring partial or full ownership of the asset to the private sector," it does not specify the type of ownership. Berg and Berg (1997) discuss how private ownership of public's assets can exist in the forms of stock sharing, IPO, divestiture, spinning off, amongst other forms as per agreed partnerships and contracting. Hartley and Parker (1991:11) argue that, "privatization embraces denationalization or selling-off state-owned assets, deregulation (liberalization), competitive tendering, as well as the introduction of private ownership and market arrangements in the ex-socialist states."

Furthermore, the privatization method stated in the law's preamble is the transfer of ownership for a public enterprise, wholly or partly, in accordance with provisions of law 37/10. These provisions refer to the, "the processes of transferring public projects into joint stock companies, protecting the rights of national employees, controlling prices, transactions, and revenues arising from the privatization process" (explanatory memorandum, law 37/10). However, these provisions grant the government decisionmaking privileges that are not common in similar privatization approaches as defined in the literature and through history. For example, Article 2 in Chapter 1 of Law 37/10 states, "companies established within provisions of this law, are obligated to abide by the 
prices and the service systems as may be decided and approved by the regulatory authorities after a periodical review thereof, and prices shall not be increased unless by approval of these authorities; these companies shall periodically provide the competent regulatory authorities will all information enabling them to assume their regulatory role." As seen, the government intends to transfer ownership to the respective private sector, however it still would be authorized to exercise the privileges it previously had as a full owner. Essentially, if the government dictates the final decisions and prices of goods/services, then what is the incentive for the private sector? Entrepreneurs and private sector representatives of the research sample expressed confusion on this point.

It seems that major shortfalls in the law can be summarized into the following: (1) the method of privatization approved contradicts the remaining provisions encompassed in the law thereafter, and (2) the privileges granted to the government reflect the divestiture method more than the 'sale of asset' or 'transfer of ownership' privatization methods.

This concept of ownership and control is further acknowledged by Bishop, Kay, and Mayer (1995), as they explain how changes in ownership are directly associated with changes in control exerted by the state and a transfer of control to private investors. The aspects of control and ownership have overlapped extensively in law 37/10. Both aspects are separate, although not mutually exclusive, making it important to identify points of convergence and divergence. One possible approach is to redefine this method to, “ownership partly and within certain restrictions," given the government's constitutional rights of participating in final decision processes that concern public assets. These restrictions, therefore, must be clearly stated in the law's individual provisions. Another 
approach is to revisit the privatization method approved and have it as a 'divestiture' method instead. If this privatization method were to be enforced in Kuwait, the government would still maintain ownership of the asset and all its privileges as stated in law 37/10; however, management would be transferred to the private sector. The method of transferring ownership is theoretically defined as the transfer of a majority ownership of state-owned enterprises to the private sector by the sale of ongoing concerns or assets following liquidation (Kikeri, Nellis, and Shirley, 1994). Instead, the divestiture privatization method grants the State rights over national wealth and certain public services, as per the constitution. These limitations in the law, paired with the undefined responsibilities/privileges of each private and public entities entering the 'fair' agreement is also a reason for the policy's paralysis.

Second, there are further limitations in the law that could increase the government's administrative and financial burden if not clarified. Some of the provisions in law 37/10 define privileges and actions that require actors in the privatization process to, "return to the privatization law for clarification," or, "act within limits of the privatization law" (Article 2.1). However, given that the current law is inconclusive and the SCP has yet to release standards and procedures (S\&Ps) that make law 37/10 legally binding at the state level, this law cannot be implemented on its own. Therefore, even after choosing between the divestiture or asset sale approaches discussed, supplemental S\&Ps are still required. Additionally, some of the general provisions that refer to the manner in which privatization would take place, state for example, "within the applicable laws" (Article 2.2), and, "in accordance to the law" (Article 3); however, there is no clear indication of which law(s) are referenced. Clarification is needed to guard against the 
likelihood of misinterpretations during implementation stages. In the case of privatization initiatives during Clinton's administration in the United States, a detailed Conflict of Interests Act during the sales of government-owned uranium enrichment and helium plants would have helped protect the rights of public and private partners (Savas, 2000). Savas explains how the failure of public officials in clearly specifying the complete dimensions of a service purchased from or by contractors, "inevitably leads to misunderstandings and disputes" (13). This concern of monopolists dictating the price levels was reiterated by a majority of the research participants. Perhaps enacting a Conflict of Interests Act can protect public funds from manipulation and oversee that the public interest is being served.

Moreover, Article 12 calls for the establishment of, "a Kuwaiti joint stock company to which tangible and intangible assets, and liabilities of the public enterprise scheduled for privatization, shall be transferred." When asked who will establish this joint stock company, reference was made to Article 14 of the Law that vaguely states, "The governmental body in charge of setting up the company shall determine its capital and carry out the distribution of all shares (...).” Therefore, a government sector is in charge of establishment; however, no indication is made of which sector this will be and how duties shall be divided. Also, in the percentage distributions of the joint stock company, it remains unclear the basis on which the exact numerations shall be set.

Furthermore, the maximum allowed time frame between the establishment of the joint stock company and the transfer of this company to the selected private sector, remains undefined. This is especially important given the evolving political and economic climate in Kuwait with new parliamentary elections and cabinet member 
appointees every four years, per the constitution. How will these changes in public posts impact both continuing and new contracts of privatization? These unclear provisions could raise the likelihood for certain 'factors and elements' to exploit or politically manipulate the policy's implementation process.

Third, the law is deficient as it neglects small and mid-sized businesses in the Kuwaiti marketplace by making no reference to them. Focus group participants in the diwaniya and istiqbal gatherings stated that the private sector in Kuwait is saturated with monopolistic individuals that have abundant capital and political privileges. Therefore, if the goal of privatization is to strengthen the private sectors' role and enhance cooperation between private and public sectors of the country, then how likely can this goal be achieved if the law does not consider smaller businesses? When asked the research question of how to ensure successful implementation of the law in order to achieve the desirable outcomes, a majority of the respondents from these two groups agreed that, "it would be beneficial for some of the law's provisions to discuss the level of support our comparably smaller enterprises can expect to achieve; will selection of our proposals be prioritized over the monopolizing companies." It is anticipated that removal of this red tape will help smaller businesses participate. Assaad and Roudi-Fahimi (2007) note that the population in Arab countries over the recent years has become much younger and educated. The increasing levels of unemployment have sparked their entrepreneurial spirit to start small and mid-size businesses. In this context, selection criteria are needed to identify the basis upon which private sectors shall be chosen. It must be included as part of law 37/10 to ensure a uniform process of selection, considering the turnover rate of public posts in Kuwait (Tetreault, 2001). 
Some suggested criteria for selecting the local private sectors could include the company's capital, track record, strategic vision, financial forecasts, and plan of action. Having uniform selection criteria to supplement the law could respond to some of the research participants' claims of patronage systems dominating the public sector in the country (Lynn, 2001). This group of respondents justified their choice of private sector employment as an attempt of being part of a merit system of government (Davis, 2012). Data responses gathered indicate that economic growth generated from privatization initiatives should be based on productivity, social equity, and merit. This would not only incentivize private sectors to participate locally, but also could help the national economy transition from rentier economies to merit-based economies. Achy (2012) explains how such economies drive competition and economic performance through productive investment.

Fourth, the law minimally discusses one of the most critical components - the entities that will be conducting the valuations for assets to be privatized. The law mentions that two international consultants will decide which sectors the respective public enterprise will cooperate with (Article 11). However, prior to embarking on the decision process, how will these consultants be chosen in the first place? Interviewee respondents shared their concerns about the, "two specialized independent consulting organizations (that) shall be entrusted with the valuation of tangible and intangible assets, and liabilities of every public enterprise for privatization" (Article 11). Data findings reveal that it is insufficient to merely mention that "at least one of which (has) international experience" and that the "process (of selection) takes publicity and competition into account" (Article 11). As such, criteria that specify the process for 
selecting consultants could be based on their experience in asset valuations within the GCC region, familiarity with the social, economic, and political settings of the region, track record of international performance, affiliations and global recognitions, funding sources, and the organizations' shareholders. The last criterion is a verification measure to rule out any potential biases in consultants' inputs to the SCP. It can be concluded from the documents reviewed that the state's role is now expanded post-enactment of the privatization law. The state is responsible for maintaining a strong legislative and administrative environment, ensuring justice, overseeing healthy competition, providing support for small-sized strategic projects, restricting the rise of monopolies, protecting low income individuals and families, and enhancing the employment opportunities for nationals.

\section{Inadequacies in the country's political structure}

It is not only the law that is limited. Both focus group and interviewee participants noted inadequacies in the country's political structure, as they made references to how politically empowered bodies in the country are charged with similar duties and privileges. According to Article 7 of law 37/10, the Council shall, "lay down the general policy of the privatization processes (and) prepare a schedule for the public enterprises planned by the Council to be privatized." The valuation shall be, "approved by the Council after submitting it to the State Audit Bureau," after which the Council shall, "announce the final establishment of the joint stock company for every public enterprise" (Article 11). As indicated, the SCP is the only entity that the law has granted the authority to determine and implement the privatization activities. However, different public entities 
can still establish contracting agreements with private bodies for consultations, trainings, and other purposes. This can introduce a new risk of having a political gridlock, making it difficult to pass laws that satisfy people's needs (Neuman and McKnight, 1997). Clinton's (1992) attempt to reform the healthcare system so all American families can have access to healthcare, was stopped for four years due to political gridlock on healthcare. This could be of a high-impact, if it occurs in Kuwait, given that the country's scarce resources and relatively limited number of private and public sectors due to the country's size and population. In this case, policymakers may face capacity issues that would hinder privatization policy's implementation. From the data analyzed of the country's political structure, it could be more effective for the state to unify all efforts that involve cooperation of the public sector with private entities, with one representative body in the county. In view of privatization policy's enactment, this body would be the Supreme Council of Privatization.

\section{Lack of a plan of action to guide the law's implementation stages}

Data findings indicate that many provisions of law 37/10 require action plans, such as those pertaining to duties that are strictly government and duties for the designated private sector. This issue is especially significant as it relates to employment structures post-privatization (e.g. wages, benefits, task delegation). Some of the questions raised by focus group participants include, "Who will provide the capital? What will be the cost structures?" Further critical questions are whether the government will subsidize some of the costs, post-privatization, to ensure affordability for all nationals. 
The constitution states that the government shall offer education and guarantee healthcare for all (Articles 11, 13, 14). Also, all of the natural wealth and resources are the state's property, whereby the state shall preserve and properly utilize these resources (Article 21). Therefore, if wealth generated from public services wholly belongs to the State, then how is it possible to privatize state-owned assets and require the cooperating private sector to contribute all revenues to the government? Further, if the government guarantees primary education and healthcare services to all citizens at no cost, then would privatizing management of those public services be acceptable? If so, how can the government proceed with selecting the private vendor(s) and delegating tasks between each sector? Moreover, on the human capacity front, how will the professional capacity of the national workforce be developed? These questions stirred confusion amongst interviewees when asked, and therefore should be clearly identified in the law.

\section{Unsystematic policymaking}

Participant 14 and18 shared their views of how unnecessary it is for the government to establish a new authority/entity to manage the implementation process every time a new law is enacted in the country. From their point of view, this process not only thickens the bureaucracy for citizens and private sectors, but also is inefficient and hinders the development process.

The membership of five Ministers in the SCP board could lead to inefficient work processes, unproductivity, and small-scale accomplishments, rather than longer-time economic benefits. This structure of board members could also hinder policymaking, as all privatized projects must be approved and organized by the SCP. However, Ministerial 
seats in the country must change every four years with the parliamentary cycle (constitution, 1962). Therefore, the time post for countrywide project planners and implementers is too pre-mature for actual change to happen. To avoid circumstances of having to reverse the privatization tide (Warner, 2008), membership of the SCP board could be re-evaluated taking into consideration the country's evolving political cycles.

It is necessary to not only have a systematic policymaking process, but also an inclusive one. Focus group respondents expressed how the public's voice should be heard louder given that they are the recipients of privatized services. Members of the national workforce are the ones engaged in the process and affected by the operational changes that would accompany this reform. The private sector, along with the public sector, are also the decision-makers whose decisions of implementing this reform would determine the business, political, and social climate of the country. As seen in the case of KIA, there is a need to raise awareness for each relevant body's role in the privatization process the public, employees, private sectors, and government sectors. Implementing a policy is as significant as formulating a policy and evaluating it, thereafter, for modification and improvement.

\section{Evaluative Criteria}

H4: There is a lack of evaluative criteria for public policies in Kuwait.

Data findings indicate: 1) minimal research and development initiatives prior to the policy's formulation, 2) a lack of monitoring and evaluation criteria defined in law 37/10, and 3) no training and rehabilitation programs provided to develop a more skilled workforce that can transition with the developing economy. Coglianese (2012) states the 
significance of indicators to track a policy's cycle. In the case of Kuwait, however, the country lacks adequate the infrastructure for live statistical data of public sector growth. Furthermore, evaluations are needed to, "assess the substantive outcomes of the (privatization) policy, and any relevant process outcomes based on administrative, democratic, or technocratic values" (Coglianese, 2012:7).

Documents reviewed indicate that benchmarking is a common performance measure used in different government initiatives. According to a World Bank (2010:2) report of GCC countries and the economy, "one unusual aspect of the Gulf is the dichotomy between political development, where institutions remain quite traditional, and economic ambitions, which can be benchmarked against the most sophisticated economies in the world." A comparison of the GCC countries' political and economic statuses, as measured by the global competitiveness indices of government performance and productivity, present Kuwait in a mid-ranking of 38 out of 138 global economies (WEF, 2016). UAE and Qatar seem to be in the lead, with GCI rankings of 16 and 18 , respectively. In an effort to drive similar economic growth, Kuwait re-kindled privatization discussions of what reflects a bandwagon effect. Ehteshami (2003:64) explains this situation as, "a bandwagon effect (that) arises as the Gulf emirates emulate one another, each adopting some of the features of the others' participatory mechanisms." Although Kuwait was the first GCC country to introduce this reform, the UAE and Saudi Arabia were among the first to implement privatization initiatives of stock sharing. As Saudi Aramco currently discusses privatization policy, along with the UAE's devolution of state-owned enterprises, there is more pressure on Kuwait to conform to regionally accepted standards of such privatization initiatives. This rentier effect, that Berry and 
Berry (2007) introduce, discusses the likelihood of states adopting similar policies due to their geographic proximity and regional diffusion of policies. Bordering states share economic aspects and similar social problems, such as oil and democracy. Mooney and Lee (1995) explain how this leads to the adoption of similar policy actions. These policy actions can be successful if implemented effectively with adequate evaluative criteria.

Research participants conveyed the weak evaluative initiatives taken for past policies in the country. Initiatives targeted at measuring performance and monitoring progress made must be strengthened. This especially applies to the case of privatization policy, both during and post-implementation.

\section{Decision-Making Model}

H5: Policymaking in Kuwait resembles a garbage can decision-making model.

In the case of privatization policy in Kuwait, findings from the data analyzed reveal the garbage can decision-making model applied for the policy's enactment. The aggregative method of decision-making, in which a group brainstorms policy alternatives to reach the most optimal decision (Frederickson \& Smith, 1997), is not very common in the political decision-making arena of Kuwait. Within the context of Kuwait, the garbage can model is seen frequently in many past policy decisions. Stone (2002) explains this strategy where the desirable ends determine the means. This ambiguous decision-making process is neither sequential, nor consequential. For example, was the privatization policy made based on a certain image of the public sector, rather than looking at what the reality was? When asked how decisions were made, most of the responses were, "based on the need of the time, because there are many problems on the agenda and privatization was 
seen as a solution to address more than one problem." However, Zahariadis (2014:42) explains that, "information overload often paralyzes the process or compartmentalizes attention, forcing policymakers at the top to address policy issues that are often different from those experienced at the street level." Hood (2011) discusses how policymakers are more likely to focus on policy issues they are able to solve, so as to be praised for rightful acts rather than failed initiatives.

Data collected through this research indicate that policy decisions are made based on multiple factors that include partisan preferences and self-interested policymakers. Minimal attention is devoted to the quality of the policy and social inclusion. The methods of deciding on a policy vary. Some legislatures focus on devising policies that improve the quality of living. Others base policy selections by weighing costs against benefits (Sharpe, 1998). Self-interested politicians would propose policies that benefit their constituencies. In any case of political decision-making, Birkland (2015:6) explains, "policy is interpreted and implemented by public and private actors who have different interpretations of problems, solutions, and their own motivations."

When asking interviewees what the different venues were for citizens to politically participate, responses included, "through their representative MPs, feedback to their direct supervisors, media channels as Kuwait has a free press, and Citizens Service Centers established in each municipality by the Ministry of Interior." One of the policy issues a focus group participant shared was that citizens' voices are not being reflected in the privatization law as currently approved. In spite of the different venues for citizens' political participation, it is undetermined whether their weak participation is due to the 
limited effect of current channels, or if politicians are not representing constituents.

Participant 17 shared somewhat of a different perspective.

I have not experienced citizens fearing being transparent or opinionated against the government. Instead, people in Kuwait are very confident in voicing their thoughts and needs. The problem is that what they share is not listened to, just heard. Some of these concerns are not listened to, because citizens are generally uninformed of all the details - which reflect upon the government's transparency and the representative MP's attempts at keeping his/her constituents informed.

\section{Summary of Findings}

Kingdon (1984) views the policy process as agenda setting, formulation, implementation, and evaluation. Dynamics of the recent privatization policy in Kuwait indicate that six years into the passage of this law, there are no implementation efforts visible. An investigation of the policy triggers vs. inhibitors, from the perspectives of research participants, helped explain the delay in the policy's implementation. The legal, economic, political, and social challenges facing the implementation of privatization shape the policy environment in Kuwait. Legal challenges relate to the entry of foreign firms and whether jobs will be threatened. Economic challenges refer to the inexistence of a macro-strategy action plan, whether private investors are demotivated, and whether the public sector is incapable of accommodating this reform strategy. The political challenges include how to handle private monopolies, whether capital exists, and if public goods and services will still be affordable for the lower-income groups. Lastly, the social challenges focus on whether people are aware of public sector problems that currently exist and if people are willing to adapt to the environment post-privatization.

Analysis of the data collected reflects that among the factors negatively impacting public sector's performance are increasing government bureaucracy and intervention, in 
addition to the lack of accountability and supervision mechanisms. Further, there are minimal training opportunities for public sector employees, which contributes to the low level of productivity. A consideration of the needs addressed by labor unions is also important. Additionally, at least four interviewees agreed on the need to restructure the public sector first before proposing privatization. Private sectors may not be capable take over the much larger and disorganized public sector given the differences in work processes, organizational charts, and job descriptions.

A review of the policy issues and implementation obstacles highlight part of the criteria for this reform's success, which includes technical feasibility, reform acceptability, budgetary capacities, and public acquiescence. Lipsky (1980) discusses how effective implementation of any policy requires the participation of policymakers across different government levels, support of decision-making authorities, and social demand. One of the biggest obstacles, based on research participants' responses, is the lack of a top-down approach to implementation (Van Horn, 1975; Mazmanian and Sabatier, 1983). Stone (2002:8) defines politics as, "the struggle over ideas seen from multiple perspectives, rather than objective facts." Policy formulation, from Stone's perspective, is therefore achieved through political discourse that results in shared meanings and collective action. In order to achieve successful implementation of policies on a larger scale, it is widely agreed that policies must be both effective and responsive. In other words, the policy action must lead to desired outcomes and serve as an agreement between the bureaucracy's decisions and the public's preferences. The political discourse process involves multiple players, hence different views and plural values (Spicer, 2010). If such views are not accounted for during a policy's formulation 
stage, this could result in a process that is less efficient especially given the unsystematic and inconclusive policymaking structures. This research has shown this as the case of privatization policy in Kuwait.

Data reviewed reflects that there were some amendments made to the law by congressional committees formed post-law's enactment (explanatory memorandum, law 37/10). This memorandum makes minor references to some issue areas and concerns as developed from neighboring countries' privatization experiences, such as privatization processes, workers' rights, penalties, and asset valuations. Although follow-up initiatives were made, data reviewed reflect the law and its explanatory memorandum remain unclear. This could result in legal disputes when parties involved attempt to decipher privatization agreements - cases of which would increase the government's burden. After reviewing all the documents and responses of research participants, one of the suggested approaches is to redefine the privatization method in a way that would resemble the divestiture method. Given the constitutional restrictions of national wealth generated from public services, public asset ownership, control, education, and health rights, it is difficult to implement a privatization method that does not violate any one of these firm restrictions.

An economy that accommodates privatization would be shifting its focus from the redistribution of wealth to the production of wealth, whereby each worker is viewed as a significant contributing factor to the national economy. As such, privatization reform should not be viewed as a process, rather a need. This reform requires root and procedural changes, not just administrative and organizational. Then only, will the State be ready to cope with the different policy issues pre-exiting and as they arise. Moreover, 
the need for privatization is not to be perceived as an alternative to public services, rather an investment in people, primarily, and an investment in stocks and funds for future generations. Article 13 of law 37/10 calls for 50\% of the government's revenue generated from privatized sectors to be reserved for the next generation fund. This economic shift of focus would also build the present-day national budget. Essentially, the privatization law expands the State's role beyond providing infrastructure and basic services, to fostering a friendly business environment and managing the equitable distribution of wealth within the society. Continuous monitoring and evaluation would help ensure that such goals are met.

Privatization as a reform strategy targets higher quality, while maintaining a costeffectiveness. These two goals appeared to be on the forefront of pro-privatization lobbyists' agendas in Kuwait. Although quality and cost-effectiveness remain the ultimate targets for this reform, other factors have evolved during the new public management reforms of the $20^{\text {th }}$ century. These include public service motivation, expanding the market for the same basket of goods and services, and unifying the operations of public and private sectors in the country. The final result, as shared by research participants in support of the policy, is that privatization initiatives attempt to rebalance the role of the state. According to the UN's (1999:9) report on developed countries, this reform, "marks a new beginning for government participation, not the end; however, it is an intensely political process, involving conflict among key stakeholders." To reiterate Birkland's (2010:2) claim of how policymaking is about problem solving, data analyzed through this research shows that the privatization policy in Kuwait was a solution to different issues faced over the course of recent years. The Kuwaiti 
government has proposed privatization as a reform strategy to improve the public sector, however this partly depends on whether the country has the capacity and structures to facilitate implementation. Interviewees from both the public and private sectors agreed that any change impacting the political, social, economic, or environmental factors of the country would have to be in a gradual and transitional manner. This research not only investigated the policy processes in the case of this policy in Kuwait, but also the reasons underlying privatization as a perceived solution. Analyzing privatization law 37/10 provided a better understanding of the political decision-making processes in the constitutional monarchy setting of Kuwait. 


\section{CHAPTER SIX}

\section{DISCUSSION AND CONCLUSIONS}

\section{Introduction}

This chapter is divided into two main sections. The first section analyzes data findings in the context of privatization and policy development literature reviewed. The second section discusses recommendations based on data analyzed from the interviews, focus groups, and documents reviewed. Recommendations are suggested for strengthening the policy development process in Kuwait, in addition to succeeding in the implementation of the privatization policy across the country's public sector.

Implications for future research are presented.

\section{Discussion}

\section{The Privatization Policy Case in Kuwait}

Data results indicate that there are many hindrances to implementing law 37/10. According to the interviewees, the law has legal shortfalls that make it difficult for actors on both sides to fully acknowledge their rights and privileges in the privatization process. Responses revolved around the legislation being incoherent and inconclusive. Participant 4 discussed how, "there is no time frame indicated between establishing the joint stock company and thereafter transferring this company to the chosen private sector - this could halt the entire process, as people are more proactive to deadlines." Some of the other reasons for the poor performing political system, that the research participants shared, include the lack of action plans for policies enacted, bureaucracy matters, and capacity issues. The government, as well, lacks the mechanisms to properly evaluate 
which services to privatize and the optimal stock valuations that would still maintain the public's equitable access, employees' rights, and the government's goal of revenue generation. It is likely that not all sectors can accommodate this reform strategy. Some sectors will need to be restructured, while others will require a different method of reinventing government.

Another economic obstacle hindering implementation of the privatization policy is the existing monopolies that dominate the private Kuwaiti market. Participant 18 concludes, from his experience, that a market with more than one vendor for the same goods and services is characterized as healthy competition that drives prices down to benefit the buyer. However, he presented the Kuwaiti marketplace to be a different case.

A monopolistic market where the competition is limited or nonexistent, as in the case of Kuwait with water and electricity for example, the government must enforce a price ceiling to prevent a monopoly that makes these services unaffordable. The government can also subsidize these particular costs or provide compensation for lower income families whose financial statuses are registered as such at the SSN. Such compensation may also incentivize citizens to consume less, in which the government can later on consider providing compensation benefits to this group of people.

As seen in this example, positive spillover effects can be generated if the marketbased reform is implemented effectively. This study discusses yet another significant element of policymaking - social inclusion. A majority of the respondents agreed that population subgroups should have an equal opportunity in the decision-making processes, regardless of social class and entrepreneurial track record. A special emphasis should be made for women and youth. This is a critical component during the policy's formulation stage. For example, town hall meetings could provide these population subgroups with a platform to voice their thoughts and concerns. People need to feel that they are valuable 
contributors to the country's development process. Only then will they be able to play a more active role. Data analyses signify the roles government officials and parliamentarians possess as the main determinants of any policy enacted nationally. Whereby, civil society groups and NGOs play a lesser role.

Responses of the more traditional community members reflect a resistance to innovation and reforms that would change the pace of their conservative lifestyles. Rokeach (1970) agrees that the more central the threatened value, the more resistant the culture is to change. Both the traditional and non-traditional focus group responses reflect an erosion of citizens' trust in government. In this context, establishing bonds and channels for open communication with the society is especially essential, prior to implementing the privatization policy. This would help reduce social resistance to the reform policy.

Despite the goals of privatization, this market-based reform cannot be implemented across all of the country's public sector. There are constitutional exclusions to privatizing certain sectors in which the state's role is irreplaceable. Thus, although one of privatization's main goals in Western-based reforms is to strengthen private sector's role in the economy by expanding their ownership base, this goal is not possible nor desirable in the case of constitutional monarchies. It is stipulated in Article 20 of the constitution (1962) that, "all natural resources and wealth generated from these resources, are state-owned and the responsibility of the state to preserve and ensure proper use especially in the fields of state security and the national economy." Interviews with the Ministry of Planning noted further restricted sectors of defense and security, as supervised by the Ministry of Defense and the Ministry of Interior. The GSSCPD 
reiterated how other countries in the Gulf have also restricted privatizing certain public services, such as education and health.

The social landscape of policymaking in Kuwait is partly defined by the representative parliament and the differentiated civil society (Alrumaihi, 1994). Cohen and Arato (1992) discuss the concept of a differentiated civil society as a society that is part of a private economy, which disapproves being completely controlled by public entities. They discuss the concept of, "the utopian horizon of civil society is based on preserving the boundaries between the different subsystems and the lifeworld (...) communicative coordination of action, in place of imposing this organizational principle on all of society" (Cohen and Arato, 1992:456). A democratic society focuses on issues of freedom, justice, and equality (Waldo, 1948). In this context, democratic changes tied to privatization initiatives would emerge on three main fronts, as discussed from the data analyzed: ownership, organizational, and operational.

\section{Political Decision-Making in Kuwait}

Data analyzed in this research reveals that six years into passage of the law, no implementation efforts are witnessed. Instead of the interviewees' expressions of a majority support for the privatization law, given their direct involvement with the law's formulation, interviewees reiterated limitations in the law. It was found, from the research conducted, that these interviewees are mostly charged with implementing the policy. Their contributions during the formulation stage were limited to either a vote of support, or lack thereof. The final policy decision made depicts a centralized effort by the government, voted at the parliament, and passed on for enactment. 
One of the interviews remarked, "we need to build the infrastructure and train the people to manage this reform, these are all needs that should have been outlined as part of the written law." In a study conducted by Olshfski and Cunningham (2008), the different decision making models applied by governors that were replaced in office were compared to the successful management style of Governor Alexander Lamar of Tennessee (19791987).

Many governors manage another way. They maintain a highly controlled management system, with little independent decision authority granted to their cabinet appointees. In that control model, the governor and the appointed staff initiate policy changes (...) in a centralized, control-mode governance system, the cabinet member has a large implementation role, but a limited policy-making role. (6)

Whereas, Governor Alexander's style involved pushing political decision-making to the lowest feasible level, to ensure the effectiveness and feasibility of policies. Good policy and good governance emerges from good management and a decentralized policymaking process, where administrators are also involved in policymaking roles at the higher government levels. This ensures a comprehensive policy that responds to both inter-organizational capacity needs and social demands, as shared by respondents that represent some of the privatized organizations.

The case of privatization policy in Kuwait sets forth an example of the controversy when observing the divide between politics and administration. Theorists express opposing views of whether a politics-administration dichotomy should exist and responsibilities be clearly divided (Wilson, 1887; Weber, 1922; Goodnow, 1900), versus whether theoretical expressions of a dichotomy should be phased out given that such a divide is impossible to observe (Gulick and Urwick, 1937; Waldo, 1948; Appleby, 1945; 
Miller, 2012). Denhardt and Denhardt (2000) are in favor of a new public service that values administrative discretion. The privatization policy in Kuwait was approved by the Emir and enacted by the government in a set of bylaws that, according to government officials that wrote the bill, were sufficient to engage in the policy's implementation stages. However, data gathered verifies that the policy is not yet implemented since its enactment in 2010. Participants in this study pursue both roles of policymakers and administrators in their respective organizations. They have contributed to the law's formulation, as policymakers, and will pursue the role of administrators when the policy's implementation stage commences. Some of the recurring responses from research participants of the hindrances in the law's implementation, include:

- The uninformed selection of committee members that contributed to the policy's formulation;

- The insufficient market studies conducted prior to drafting the policy's bylaws, resulting in unfeasible outputs;

- Some of the policymakers' lack of knowledge and experience in administering a policy's implementation process.

Theorists in defense of the politics-administration dichotomy attempt to increase accountability in government and minimize the likelihood for corruption arising from self-interested politicians that take advantage of their administrative discretion (White, 1926). The goal is to create a sound ruling process that is efficient, orderly, and responsive to society's needs. However, is limiting discretion a solution that would indeed restrict the self-interested behavior of policy formulators and implementers? 
Establishing adequate monitoring and evaluation mechanisms requires the appointment of unbiased individuals that can supervise activities of policymakers. However, there is also the possibility for a decision-maker in such a supervisory position to be self-interested. As such, it is difficult to completely rule out preferences from interfering in the political decision making process. Although, acknowledging this concept is important in order to consider alternatives for more effective policy formulation and efficient implementation. For example, when interviewees were asked whether reference was made to benchmarks during adoption of the privatization policy in Kuwait, most responded "no." The use of benchmarks for countries similar in social, economic, and political environments, can help ensure a more effective policymaking process. In the case of policymaking in the European Union, De la Porte et al. (2001:291) discuss how social benchmarking is, "only successful when the public is involved in scrutinizing the policy areas which political leaders choose for benchmarking, the decision makers' identification of best practices in the other Member States, and the efforts made to improve national performance."

As covered in previous chapters, actors in the political decision-making process can behave rationally, irrationally, or incrementally. Rational choice institutionalists, like Downs (1967) and Niskanen (1971), acknowledge that corruption can exist in policy processes around the world. Self-interested politicians can behave in ways that maximize their personal gains. There are two positions to this argument. Some theorists advocate the need for bureaucracy to be more democratic by having a representative bureaucracy (Kingsley, 1944; Allison, 1971). From their viewpoint, this helps maintain accountability in the policymaking systems. Other theorists call for restricting discretion, and instead 
increasing external controls to lessen bureaucrats' freedom of acting autonomously (Lowi, 1979; Finer, 1941).

This is not to refute the argument that the politics-administration dichotomy does not exist. Indeed, politics is administration and administration is political (Waldo, 1948). However, data analyzed for the case of privatization policy in Kuwait illustrates how government officials who strictly pursue the role of politics in the dichotomy, developed the work product of a policy that lacks feasibility. Although the dichotomy does not exist explicitly, the structure of policymaking in Kuwait requires government officials that enact a policy to be well informed of the administrative needs during implementation stages and beyond. Bosso (1994) explains how the decision process followed by an administrator resembles that of a policymaker, in which experience, background, and personality matter.

Since the idea of limiting a policymaker's discretion is likely to be of minimal impact, the focus should shift to increasing accountability measures across all levels of government. Weber (1922) depicts the government as a bureaucratic pyramid, in which accountability is especially critical at the pyramid's apex. He explains how each bureaucrat is held accountable to the next higher rank in the pyramid. The apex would be accountable to the public, which in return enhances the public's role in shaping the country's policies and voicing their needs.

Decision-theory suggests that understanding the various decision-making mechanisms requires one to consider the actors involved, the discretion granted, and the self-motives (Shafritz et al., 2011). Public administrators discussed some of the most common decision-making strategies such as incrementalism, self-maximization, bounded 
rationality, aggregative method, and garbage can models (Lindblom, 1979; Simon, 1946; Frederickson \& Smith, 1997; Stone, 2002). Some determinants of an individual's political power include the bases for choices made, rational vs. irrational; the leadership style exercised, transactional vs. transformational; and the management style imposed, Weber's (1922) bureaucracy vs. Bevir's (2010) democratic governance.

\section{Social Integration}

A study of the privatization policy in Kuwait reflected how not all stakeholders were included in the policymaking process. Articles of the 1962 Constitution made clear references to "the citizen", without making a distinction between the male and the female. Data findings indicate that women in Kuwait continue to be marginalized in both the decision-making processes and in the composition of country policies. Despite data findings that indicate females' high participation in the labor force and education sectors in equal percentages as males (CSB, 2015; PACI, 2016), their numbers are drastically lower in the social and political arenas. Even within the labor force, research participants shared how seldom are Kuwait women given the opportunity to hold decision-making positions across employment sectors. Interviewees confirmed the low numbers of females in the country's judicial sectors, ministerial and undersecretary positions, and as board members in executive government posts.

Kuwait, as a global nation, is an active member of several international organizations that include the United Nations, World Bank, and subsidiary organizations. According to the United Nations' 2030 Agenda for Sustainable Development, almost 
seven of the sustainable development goals (SDGs) target inclusive societies, peaceful development processes, stronger communities, and equal opportunities.

SDG 4: Ensure inclusive and equitable quality education and promote lifelong learning opportunities for all.

SDG 5: Achieve gender equality and empower all women and girls.

SDG 8: Promote sustained, inclusive and sustainable economic growth, full and productive employment and decent work for all.

SDG 10: Reduce inequality within and among countries.

SDG 11: Make cities and human settlements inclusive, safe, resilient and sustainable.

SDG 16: Promote peaceful and inclusive societies for sustainable development, provide access to justice for all and build effective, accountable and inclusive institutions at all levels.

(UN, 2015)

Therefore, political decision-making in Kuwait must: 1) encompass the female perspective, 2) increase female representation in the social and political spheres, and 3) include women as active participants in the decision-making processes. This research has shown how some public policies in the country lack inclusivity. Therefore, to increase the quality of public policies, the country must focus on political integration of all population groups - women and youth included.

\section{Kingdon's Multiple Streams Analysis}

Kingdon (1984) summarizes the policy system into three streams: problems, policies, and politics. Although each stream is conceptually independent, a policy dominates the government's agenda when the three streams overlap. Policy entrepreneurs determine this overlapping process as they strategically raise awareness for key issue areas at certain points in time (Jones, 1994; Zahariadis, 2014). In doing so, 'policy windows of opportunity' are created where the three streams couple and an official policy proposal is made. In the case of privatization policy in Kuwait, it seems that the politics 
stream was the most dominant amongst the other two streams. Kingdon explains the politics stream as comprised of the national mood, campaigns of pressure groups, and the administrative or legislative turnover. When research participants were asked about the agenda-setting dynamics of the privatization policy, a majority of the feedback referred to elements within the politics stream. The combination of the 'national mood' and 'turnover in government' greatly impacted the agenda-setting stage. A majority of the focus group respondents were generally dissatisfied with the quality of public services. They expressed willingness to pay for private services although similar services are offered publically, free of charge. Content analyses of the documents reviewed indicate that privatization discussions peaked at different points in time, over the past years. Support for the policy varied over time, considering the turnover of government officials in office. The turnover of government posts would provide a window of opportunity for policy entrepreneurs, that support privatization, to push their policy agendas.

Elements in the surrounding environment, such as successful privatization initiatives in the UAE and Saudi Arabia, generated interest at the executive level of government for this reform movement. From the data analyzed, policymakers supported public-private cooperation in an attempt to decrease the government's budget expenditures. Thus, within the context of Kingdon's MSA, the politics stream, plus elements from the problem stream - particularly social factors, economic factors, and the different levels of policy integration - heightened the privatization issue on the public agenda.

Furthermore, March and Romelaer (1976) explain how attention is a function of the number of issues that compete for the policymaker's attention, the opportunities, the 
policymaker's biases, and their formal position in the organization/government. Data analysis reflects the reason why the policy gained momentum and was enacted in 2010, rather than in 1997 during the earlier discussions. This is a result of two factors that Olshfski and Cunningham (2008) discuss - density and integration. Olshfski and Cunningham (2008:30) explain that, "when defining a problem, the more complex the situation, the less likely a rational choice approach is useful for understanding the decision process, and the more likely the social constructionist approach will account for what is observed." Privatization in Kuwait became a high-density issue in 2010 due to the impact of certain factors, such as stakeholder size, issue's intensity, cultural values, and non-linear decision-making structures in the country.

\section{Governance in Kuwait at the $21^{\text {st }}$ century}

As Wilson (1887:15) concluded, "it is getting harder to run a constitution than to frame one." Reformers continue to view variants of cost-effectiveness as keys to better government (Savas, 1987). However, this research argued that better government is based on much more than merely cost-effectiveness. Achieving democratic constitutionalism requires the existence of various factors and elements that change in accordance to the political cycle and relevant needs. Implementing the privatization policy changes the understanding of governance from the classical era to the modern $21^{\text {st }}$ century policymaking structures. Governance of the $21^{\text {st }}$ century, as Frederickson (2005) explains, shifts the role of government from serving to managing networks.

Alrumaihi (1994) discusses how, "democratization will not benefit the majority unless the opposition parties and opinion leaders abandon their old style of radical 
confrontation with the government and adopt a policy of coexistence." These root causes align with Osborne and Gaebler's (1992) concept of reinventing government to acknowledge the differences in sociopolitical interests and the need to ensure social inclusion. Also, changing the incentive structures, the culture, and ensuring accountability, can strengthen the power structure. As for Kuwait, data reveal that reinventing government by implementing new managerial reforms is decided at the executive levels of government, overlooking population subgroups of precisely women and youth.

Public choice theory refers to how actors behave in different institutional settings, given different incentive structures (Boston, 1991). Data and literature analyzed infer that the type of politics exercised largely depends on the decision-making pattern(s) applied. In terms of public policy making in the developing world, some of the most common decision-making strategies employed are incrementalism, self-maximization, and bounded rationality (Lindblom, 1979; Simon, 1946). The aggregative method of decision-making (Frederickson \& Smith, 1997) is the least common in Kuwait's political decision-making processes. Within the context of Kuwait, a hybrid between the aggregative method between selective decision-makers, in addition to the garbage can model, is identifiable in most of the past policy decisions made. With the privatization policy, in particular, the garbage can decision-making model was the most dominant. Stone (2002) explains the strategy where the desirable ends determine the means. This ambiguous decision-making process is neither sequential, nor consequential. For example, was the privatization policy made based on a certain image of the public sector, rather than evaluating what the reality was? This question sheds light on the issue of the 
"welfare queen," in which the policy was initially proposed based on a certain image of what the desired public sector would be. Data findings reveal that aspects of actual capacity, needs, and realistic goals were not discussed during the policy's development cycle.

In the case of Kuwait, Zhao (2014:202) discusses how, "increased political participation in some of the Gulf States has led to a balancing act between the customary consensus-building approach to decision making and a desire for more vigorous policy debates on key issues." Khodr (2014:276) elaborates that, "it has also been recognized that the government type and nature of the political system, as well as the nature of societal composition, influence the policy process and choices, and determine the participants." In this context, policy outcomes are more likely to be influenced by members with procedural expertise. Zahariadis (2014) summarizes the problem-solution sequence and the politics of choice most affected by, 1) the degree of fragmentation in the politics and policy streams, and 2) the type of policy window. He acknowledges that, "policymakers operate under significant time constraints; time constraints limit the range and number of alternatives to which attention is given" (38). Under conditions of ambiguity, as data indicate is the case with privatization policy in Kuwait, Feldman (1989) explains how information is produced but not applied in decision processes. As a result, some decisions are opaque and made as the process unfolds (Sharkansky, 2002). This situation stands in stark contrast to decision-making models in business firms where the goal is clear and explicit. As Cohen, March, and Olsen (1972:1) state, "organized anarchies can be described better as a collection of ideas than as a coherent structure." 
According to Cohen, March, and Olsen (1972:8), most decisions in the garbage can model, "are made not by problem resolution but by flight (when problems leave the choice arena) or oversight (by action before the activation of problems)." Further, Zahariadis (2003) contends that Kingdon's policy development cycle demonstrates how policies are made in search of a rationale. Given the short duration for the opening of an opportunity window in the politics stream, policymakers have become more focused on providing solutions in a timely manner. The garbage can model, introduced by Cohen, March, and Olsen, served as an inspiration of Kingdon's multiple streams framework (MSF) for policy development (Bendor, Moe, and Shott, 2001). Kingdon's multiple streams framework is still the most common when, "explaining national, supranational, and subnational policies in a variety of cross-national settings" (Zahariadis, 2014:34). Building on the fifth research question's hypothesis of how decision-making in Kuwait resembles a garbage can model, data analysis not only proves this hypothesis but also draws empirical conclusions to Kingdon's multiple streams framework.

\section{Democracy and Policy Development}

There are three key arguments in the field of public administration and organizational theory that relate to topics of this research. These arguments are briefly discussed below.

\section{Centralization Vs. Decentralization}

Waldo (1948) notes how centralization and decision-making are key issues in politics. When discussing the welfare state, Waldo explains how the goal of government should be to executively lead in a responsive and representative manner. Although 
policymaking in the Gulf region is similar in issue areas and socioeconomic contexts, it can also vary based on a country's factors and elements. In Kuwait, research participants were mostly in agreement that policy development and implementation is centralized and bureaucratic. All decision-making efforts take place at the executive level, between Ministers and MPs. In the UAE and Qatar, the process is more decentralized in comparison. Simultaneously, UAE and Qatar rank higher than Kuwait in terms of productivity and economic growth, as measured by the Global Competitiveness Index. However, this is not sufficient ground to determine whether the level of policymaking centrality directly impacts the pace of economic growth. The private sectors of both Qatar and the UAE play a significant and active role in strategizing, implementing, and financing the countries' development processes. Their roles include hosting training programs, empowering citizens, and launching advocacy and awareness campaigns. The transition of governments in the Gulf from a centralized to a decentralized approach to governance could facilitate citizens' participative roles in government. Data from documents reviewed indicate that some of the GCC countries devote attention to regional policy diffusion and implementation of successful lessons learnt from developed countries.

\section{Bureaucracy Vs. Democracy}

Focus group participants, particularly the female graduate students and istiqbal members, advocated the need for enhanced female representation and gender equality. They stressed how females are underrepresented in the professional workplace and in the political arena. Their voices are overpowered by men's voice in the society. A majority of 
these focus group respondents agreed that equal female opportunity is a critical component of any democratic policymaking process. Data findings indicate that the lack of such opportunities is a major policy issue in Kuwait. Norris and Inglehart (2001:126) explain how, "a fundamental problem facing the global process of democratization is the continued lack of gender equality in political leadership.” In 2000, women's political representation in office within the Gulf countries constituted approximately five percent of elected representatives. This percentage was enhanced at very modest rates producing minimal impacts in the governments' decision-making processes (Kapiszewski, 2006). The UN's report on gender equality and development (2000) recognizes the need for enhancing women's equitable rights in the fields of work, healthcare, education, and the public sphere.

\section{Social Inclusion}

Although Dye (1987) argues that the elite mass shape public policies while the public is less interested, data analyzed through this research argues otherwise. The situation of people being passive contributors in the policy process is not reflected in the case of Kuwait. Participants of the diwaniya and istiqbal focus groups were very knowledgeable of the political arena. According to one of the diwaniya participants who leads an interest group in Kuwait, "people know what they want and need, however when it comes to selecting their representative MP, culture and party affiliation guide their decisions." Public opinion is an important element of the democratic system, as long as people have the tools and willingness to participate (Lindblom and Cohen, 1979). Binder (2004) notes how this can result in interest group formation and the development of new 
political agendas, should the public's voice not be heard. Waldo (1948) advocates for a science of administration that acknowledges the public's interests and a political system that enforces democratic values. Davis (2012) argues the main reason for the Arab revolution is the need for public participation and more efficient political processes. Consequently, the public's participation should take place during both policy formulation and implementation stages (Khodr, 2014).

\section{Privatization as a Step towards Economic Development}

A majority of the interviewees agreed that the main reason behind privatization's lack of implementation is the law's limitations and lack of comprehension. Prior to establishing evaluative mechanisms for the policy, consideration must first be given to the tools that would facilitate effective implementation. A successful policy design would, 1) integrate perspectives of stakeholders who will be implementing the policy, and 2) account for all possible obstacles, such as social resistance to this reform (Olshfki and Cunningham, 2008:77).

Policy stalemate, or a legislative gridlock, occurs in situations where it is difficult to pass laws that meet the public's needs. Binder (2004) devotes some of these reasons to the institution's structure, the country's constitutional design, and the number of actors in opposition to the policy process. She concludes that a divided government impacts legislative performance. Data analyzed for the case of privatization policy in Kuwait reveals that the political decision-making structure is dependent on the majority of parties in parliament. Although privatization was discussed in the early 1980s, the law was not enacted until 2010 during a parliamentary session in which a majority of voters were pro- 
privatization. This reiterates Kingdon's explanation that in order for a policy to arrive on the legislative agenda, a coupling must occur of all three streams along with a policy window of opportunity. The turnover of policymakers in office, alongside the increasing budgetary gap set the tone for privatization policy's momentum. Privatization reform has generally resulted in a complete transformation of government's outputs and work processes - economically, socially, and politically (Megginson et al., 1994). This research concludes that executive policymakers and lower-level implementers should consider modest approaches to implementation in order to keep the public positively engaged.

To enhance the effective implementation of privatization, certain provisions within the current policy must be revisited for amendment or further elaboration. For example, the criteria for selecting SCP members are still vague. If privatized sectors are to be selected primarily by the SCP, then it is expected that SCP members be representative of major public entities in the country. Moreover, it is the government's duty to maintain a policy process that is efficient, effective, and responsive to the society's needs. After all, “ a public administration which fails to work for changes which try to redress the deprivation of minorities will likely be eventually used to repress those minorities" (Frederickson, 2010:7).

Research participants identified the policy issues of the lack of employee training, increasing bureaucracy, government intervention, political manipulation, weak R\&D, and weak performance measurement. However, these policy issues are pre-existing before the privatization debate. Privatization is the government's proposed solution to the root problems of economic stagnation and citizen dissatisfaction. Although Kuwait can 
accommodate this reform policy, as expressed by the World Bank (1993), it must be accompanied by a strategy that assesses all relevant factors and elements. This strategy should address the key aspects of, (1) how to reach consensus in the multi-player industry of what to privatize and how, (2) how to restructure sectors to accommodate the marketbased reform, and (3) how to prioritize these sectors once restructured. Furthermore, when selecting which private sectors the government should contract with, Lowery (1998) warns against preference error, monopolies, and political manipulation.

The government's enforcement of a price ceiling can either be advantageous or disadvantageous. On the one hand, the public's perspective is that a price ceiling attempts to minimize monopolies from rising. On the other hand, the private sector's perspective is that it demotivates them and limits their ability to generate greater revenues from demand-driven projects. Private sectors explained how revenues generated would eventually contribute to the national budget surplus. This is also one of the state's privatization goals (MOP, 2010). When discussing how the government should proceed with implementing the privatization policy, or any forthcoming policy for that matter, it is relevant to note Alrumaihi's (1994) response.

While the general concepts come from the West, the machinery of implementation must be developed to reflect the tradition, history, and general social environment of each country (...) If democracy is an active peaceful engagement of debate through channels safeguarded by a constitution accepted and adhered to by all, then Kuwait is a democratic society with a democratic government (although it is not a full-fledged democracy, when compared to the idea of a Western-style democracy). Important factors (such as a majority of an Islamic society) limit the growth of full-fledged Western democracy in Kuwait (...) A form of democracy that is incompatible with a society can cause real harm, even leading to civil war (as in recent developments with the Arab Spring) $(2,5)$. 
Researchers that made references to the political structures of the Gulf region discussed how the constitution does not support the development of absolute democratic societies, in ways that would resemble democracies of Western nations (Aldujayli, 1986). A review of the policymaking processes in Kuwait reaffirms this point; however, data analyses explain why the opportunities of democracy are limited in the Gulf. The political structure of a country is based on its history of governance, culture, and society. A complete democracy would require changing the culture and traditions in the country. World experiences of privatization's implementation show how this reform transformed people's lifestyles of depending on zero-cost public services. As such, this reform has yielded minimal legislative and public support from this group of individuals in Kuwait. However, transformational policies of this nature are also attempts at maintaining a transparent government that accounts for social inclusion and value pluralism.

Ostrom (1974) discusses some strategies that ensure the effectiveness and responsiveness of public policies in any given political context. He calls for decentralization, distribution of authority with accountability measures that eliminate power abuse, and replacing efficiency as the primary goal with democratic administration instead. Tiebout (1956) further elaborates supporting the establishment of multiorganizational arrangements that accommodate citizens' mobility. Policymaking faces challenges in the multiplayer industries of how to deal with the accountabilitydiscretion nexus. External political influences make it difficult to hold policymakers accountable. Herring (1936) argues that the role of bureaucrats strengthens, as they are obliged to ethically define the 'public interest' in order to fulfill it. Data findings indicate 
that in order to advance in any effective policy development process, a policymaker must be able to build successful working relations with interest groups.

Policymaking should be representative (Allison, 1971), participative (Frederickson, 1989), and decentralized (Ostrom, 1973). To successfully implement the privatization policy in Kuwait, building inter- and intra-organizational capacity able to withstand this reform's implementation process is essential. Theorists such as Heinrich \& Lynn (2000) and Frederickson (2005) discuss the new methods of providing services in the public sector, by focusing on intra-organizational relations and the adaptation of an organization's workforce towards redefined values of governance and performance. Moreover, to ensure the success of privatization, the attitudes of employees towards implementing this reform strategy must first be identified and analyzed. Human relations theorists (e.g., Mayo, 1926; McGregor, 1957) signify the role that employees play in any organization. Consequently, an analysis of employees' attitudes would help determine their level of support when adapting to the anticipated transformations.

Mahmoud (1992:40) expresses how, "privatization can produce important net gains to society when the costs of public operation outweigh the benefits." In order for this reform strategy to be successful, this research has identified key elements that must exist. These include the public's support, comprehensive legislation, and clear tasks delegation between the private and public cooperating sectors. Support could be built through educational programs and awareness campaigns that highlight privatization's benefits to the public and respond to citizens' primary concerns. Selection of the private sector could be one that the public is already favorable of its work processes, management structure, strong organizational performance, and financial stability. 
In the case of Kuwait's privatization policy, Prager and Desai (1996:185) explain, "contracting out, if implemented thoughtfully and on the basis of the appropriate models and relevant data (that appropriately interpret private sector-public sector costeffectiveness comparison), can yield short-run savings as well as longer-term improvements." This involves addressing the empirical and political issues that are relevant. Ultimately, the Kuwaiti government has the financial resources to explore development strategies (CSB, 2016), however this research has shown that a strategic vision for application is required to achieve the goal of fiscal stimulus. Olshfki and Cunningham (2008) reiterated the idea of seeking advice from peers in neighboring States as a successful strategy for policymakers. Lessons learnt from cases of privatization's success in similar sociopolitical contexts of peripheral Gulf countries, could enhance the policy's implementation process in Kuwait.

Ostrom (1971) critiqued Wilson's (1887) claim of the need for central power, arguing instead that organizational arrangements can help stimulate healthy competition. Through the application of western-based policy frameworks, this research explored differences between policymaking processes of developed countries and the processes in transitional economies such as Kuwait. From the lens of research participants, differences were highlighted to bridge the East-West gap in policy analysis and provide useful takeaways that future research can further elaborate. Although existing literature discusses the topic of privatization, this research explored new venues for this policy's development in contexts of the Gulf. Data findings have inferred the strategic recommendations, below, for effective policymaking and successful privatization implementation. 


\section{Recommendations}

Proposing privatization as a public sector reform strategy depends primarily on the need and the country's capacity to facilitate the implementation stages. This research has demonstrated the need and the lack of such capacity. The reality of public sector reforms is that successful initiatives in one country may not yield similar benefits in another, if not approached strategically. In the case of Kuwait, data findings conclude that there is not one best form of privatization in the country. Each sector has a different dynamic due to constitutional restrictions of ownership and control of national wealth. Research participants representing financial sectors agreed that privatization in the form of public offerings is the most suitable for their industry. Research participants representing the health and education sectors agreed that divestiture is the best method since the government must maintain ownership of these assets, per the constitution. There is a need for the government to clearly define the target objectives, goals, and quality standards it aims to achieve (e.g. quality of services, target budget). Policy recommendations are discussed for a more effective and responsive policymaking process. These recommendations are based on the thematic issues that developed from the data analysis: 1) systematic policymaking, 2) legal framework, 3) economic development, 4) infrastructure and capacity issues, 5) the national workforce, and 6) political decision-making.

\section{Recommendations for a systematic policymaking process:}

1. One of the most important pillars of Al Gore's National Performance Review was incorporating the public's feedback and the national workforce, during political 
decision-making processes (Kamensky, 1996). Data collected reveal that Kuwait lacks a citizen satisfaction survey that contributes to the country's economic development plan. Surveys of this nature do not exist at the executive ministerial levels. Small-scale efforts that assess citizens' needs and concerns are either NGOsourced or individual efforts. However, these two entities are limited in their capacity to conduct a national survey. Therefore, establishing a balance between efficient government operations and a responsive policymaking process that incorporates the public's feedback is a significant step towards achieving democratic policy processes.

2. Policymaking is a continuing process and should not be seen as an exit from governance. Therefore, in the case of privatization policy in Kuwait, it is important to focus on managerial work processes that strengthen the technicalities behind public service delivery to citizens. It could also be beneficial to refer to the successful experiences of neighboring countries with this reform.

3. Policy evaluation, as well, is an ongoing process. Implementation and evaluation need to be articulated clearly during the policy formulation stage.

4. For a public policy to be effective and implementable, the gaps between academics' research knowledge, practitioners' practical knowledge, and citizens' experiential knowledge, must be aligned. Such alignment will inform decision-makers in how to generate policies that are more inclusive and efficient when responding to social needs and the country's capacity issues.

5. Privatization projects should be implemented in a systematic and gradual manner. This ensures the fulfillment of needs for underepresented population subgroups, efficient use of resources, and the continuity of public sector initiavites. 
6. A step-by-step action plan for implementation should be devised by the SCP. The MOF and KIA could supply the SCP with a list of government entities to privatize as a joint stock company. They can also advise the SCP of restrictions and work processes, pertinent to the list of prospective sectors to privatize. As suggested by research participants, some of the public organizations must be restructured prior to policy's implementation. These relevant sectors would be restructed based on global

organizational standards (e.g. ILO's standards), in order to accommodate political and social transformations. This restructuing process is expected to drive private sectors' demand for stock purchases.

\section{Recommendations for the absence of a legal framework:}

1. In view of the inconsistencies between the constitution and law 37/10, a second explanatory memorandum is needed to specify the action plan for the identified sectors. Some industries have constitutional restrictions, such as health and education. Law 37/10 also excluded oil and natural gas productions. Explanatory memoranda should be developed in a tailored manner, specific to each sector. Privatization methods implemented should be industry-specific, to both observe the constitutional restrictions while clearly defining the duties of each cooperating sector to maximize the reform's results. For example, participant 20 and 29 discussed during the interview process how, "privatizing transportation is very different than privatizing prisons." Furthermore, interviewees representing financial sectors shared their disapproval of how the minimum percentage for investor holdings in the joint stock company is fixed. The follow-up memorandum to law 37/10 could justify these fixed 
percentages or even revisit the time frame for stock valuations, to build private sector support.

2. According to Birkland (2010:266), "a policy can be thought of as a set of laws, rules, practices, and norms (...) that shape the ways in which government and interest groups address these problems." In this context, the Supreme Council for Privatization can consider proposing the second memorandum for law 37/10, that:

a. Clearly states justifications for the privatization policy;

b. Incorporates perspectives of the lowest-level policy implementers;

c. Incorporates feedback from the society;

d. Clearly lists the performance measures and policy tools for accomplishing the privatization goals.

First, however, research should be conducted of all factors and elements that have influenced the policy's agenda-setting in Kuwait.

3. Data findings indicate that the government lacks the mechanisms to properly evaluate which public services to privatize. There is a need to conduct a thorough study of the industries and market capacity to select these sectors and reduce the burden on the State's budget.

4. Further clarification is needed for the constitutional provision of "ensuring a balanced and fair' cooperation between the private and public sector, as to how it shall be deciphered in law 37/10. Once this balanced scale is developed, measures need to be established to ensure fairness of privatization processes. 


\section{Recommendations for economic development:}

1. Hydrocarbon wealth generated in the country is shared across the public sector; however, economic reform initiatives like privatization are particular as they involve the private sector as well. As such, the state should demonstrate a high spirit of cooperation with private sectors in the country. This not only diversifies revenue sources, but also stimulates healthy market competition that would incentivize foreign investors to participate in the local Kuwaiti market. As a result, economic development in the country can be further strengthened in the longer term.

2. According to law $37 / 10$, the privatization method approved is transferring ownership of a public enterprise to a joint stock company (Article 12). In this context, there are some stock sale techniques to consider that could boost the economic development process that this reform targets. First, the government must ensure a strategic distribution of the stocks. Stocks should be distributed equitably to all citizens, at an acceptable or even a symbolic value. Article 14 states that such distributions are conditional in that stocks cannot be traded for a specified time frame until the privatization efforts prove to be successful, after which the market would determine these stocks' prices. Second, a competent administration is needed especially during the policy's primary implementation stages. This can be achieved in one of two options: (1) offering a certain percentage of stocks - for sale or administration - in an auction of competent business people, or (2) the state's retention of a fixed percentage of stocks in order to guarantee its predominant administration over time. Interviewees discussed how the second option might demotivate private sectors as it raises the 
likelihood for government intervention in market operations. However, this risk could be minimized with clear task delegation and a distinction of each sector's privileges.

\section{Recommendations for the inadequate infrastructure and capacity issues:}

1. Data findings reveal the need to strengthen performance management initiatives in the public sector. It is also suggested to enhance monitoring and evaluation measures for policies that have already been implemented, as they collectively impact the country's present-day infrastructure.

2. Elements of total quality management (TQM) could help guide the development of evaluative criteria for adoption in the Kuwaiti public sector.

3. There is a need for an inclusive and reliable database that is continuously updated. Data findings depict that the research leading up to policy proposals is weak. Policies are either proposed based on global movements or in response to timely issue areas. It is strongly suggested to incorporate e-government initiatives, as in the UAE.

4. Zahariadis (2014: 41) shares the example of, "the cases of spillover of privatization from the area of oil to telecommunications in Britain in the early 1980s and across different countries in later years." As such, feedback from previous programs helps when differentiating between successful and failed initiatives. Therefore, "successfully implementing a solution in one area may facilitate the adoption of the same solution in a seemingly unrelated area" (41).

5. Most government organizations in Kuwait adopt similar work processes, when in fact differences exist based on each organization's industry for goods and services. In this 
context, there is a need to develop a clear vision and strategy for each sector, within the realm of the country's economic development plan.

\section{Recommendations for the national workforce:}

1. When asked about the obstacles facing implementation of the privatization policy in Kuwait, one of the research participants discussed, "one of the drawbacks of the law is that although it mentions privatization in the form of asset sale, the law does not specify how privatization will impact the current work structure in the public sector."

One of the key reasons why countries around the world have adopted the privatization reform is because it, "reduces costs and improves quality" (Osborne and Gaebler, 1992), by employing cheap labor (O’Toole, 1997). This research shared how Kuwait's population is comprised of a large expatriate workforce. As a policy response, the government has implemented the Kuwaitization law (Hussain et al., 2007). This law enforces a minimum quota for national employees in the public Kuwaiti sector. Therefore, considering privatization's recent enactment, how will this law impact employment of nationals versus expatriates? How will it impact the pay structures of each and the recruitment processes? Mahmoud (1992:40) discusses one of privatization's obstacles, "It tends to arouse political opposition from employees who may lose their jobs (and) from politicians who fear the short-term unemployment consequences." Yarrow (1986:323) further elaborates, "It will be virtually impossible to privatize most government enterprises with out affecting adversely both the employees of the enterprise and some groups of consumers." Moreover, a recent study conducted by the CSC (2008) determined that most Kuwaiti nationals favor 
public sector jobs over the private sector due to payment benefits and work leaves. These benefits were legislatively approved many years ago, in an attempt of encouraging nationals to work in the country's public sector. Thus, how will implementing privatization impact these employees' expectations? Research respondents that questioned the policy raised all of these questions; therefore, it is suggested for the SCP and the GSSCPD to jointly address these concerns.

2. There is a need for a labor market strategy that encompasses the need for adequate training and development. This need can be fulfilled through any of the following suggested methods:

a. Enhancing the structures of the pre-established training centers in the country, to cater to current and prospective members of the national workforce;

b. Developing tailored training programs that are industry-based and needsspecific;

c. Incorporating standards and levels of action as documented by the ILO, imposing a minimum wage, and restricting an employer's will of unfair treatment of workers;

d. Establishing contracts and agreements to protect workers' rights from being exploited by prospective employees, especially since the stocks are eligible to be transferred after a certain period of time (law 37/10).

Training the national workforce is about instilling a new mindset for innovation and respect for qualification. Newman and Gaffney (2002) examine the ethical dynamics of public service reform and the need to reaffirm the core values of public administration in the face of competing business-driven practices. These steps can 
help achieve social justice, per Article 20 of the constitution, enhance privatization's goals of efficient and effective performance, and fulfill the state's target of a skilled workforce to strengthen the national economy.

3. Data findings conclude the need to develop an integrated rehabilitation program that equips prospective employees with skills and knowledge, tailored to the respective government sector for which they are recruited. This acknowledges that differences in work processes exist between each government entity.

4. The law discusses how government compensations would be given to workers that choose not, "to be transferred to the company to which the enterprise has devolved" (Article 20). In addition to these subsidies, the government could also consider compensating citizens that have lower consumption levels for particular public services. This would respond to some of the focus group participants that opposed the law in fear of price changes for public services, post-privatization.

5. There is a need for a policymaking framework that is characterized by a Human Rights Based Approach (HRBA). In a report on human capital, Schwab (2016) and Bean (2016) discuss the incorporation of HRBA in services delivery.

A nation's human capital endowment-the knowledge and skills embodied in individuals that enable them to create economic value-can be a more important determinant of its long-term success than virtually any other resource. This resource must be invested in and leveraged efficiently in order for it to generate returns-for the individuals involved as well as an economy as a whole. Because human capital is critical not only to the productivity of society but also the functioning of its political, social and civic institutions, understanding its current state and capacity is valuable to a wide variety of stakeholders (WEF, 2016:1). 


\section{Recommendations to enhance political decision-making:}

1. Data findings indicate that there is a push from respondents towards greater openness and inclusiveness in the political process. The case of privatization in Kuwait indicated how not all stakeholders were included in the policy's development process. Particularly, youth and women were marginalized. As such, political representation and social inclusion must be strengthened in the Kuwaiti political arena. Further advocacy is needed for these population subgroups. Aspects of value pluralism should be accounted for in the policymaking process.

2. The garbage can decision-making model has been predominant in the executive decision-making levels of Kuwait. There is a need to replace this model with a more integrative approach to policymaking.

3. Investigation is needed of which sectors to restructure for privatization's implementation, without incurring major financial and human capital losses. Mayo’s (1930) Hawthorne experiments conclude that interactional variables play an important role in motivating people. Therefore, administrative staff should acknowledge the differences between each employee's needs and productivity. Taylor (1912) discusses that the progressive development of workers varies based on their individual strengths and weaknesses. His theory of scientific management could be applied to public service delivery to explain how high-quality services are not entirely a result of a greater allocation of funds. Instead, improved services are also a result of scientifically managing workers based on each person's strengths and specialties, and the strategic use of limited resources. 
4. Machievelli (1950:20) argues that, "if we understand and plan the political actions we take in pursuit of our goals, we are better prepared to seize the political opportunities that arise in the normal course of political life." Data findings infer the need for better situational analyses and improved understandings of problem areas facing the implementation of privatization policy in Kuwait. Some of these issues, as developed through the research analyses, include capacity issues and defining the public needs.

5. In response to focus group respondents' claims of the erosion of citizens' trust in government, it is important for policymakers to focus on integrating the community throughout the policy development process. It is also significant to strengthen the democratic governance frameworks by holding frequent town hall meetings and encouraging MPs to connect with their larger communities and interest groups. This can help build momentum for the privatization policy and increase its subsequent effectiveness. Additionally, policymakers could develop the habit of defining problems from citizens' perspectives, rather than based on timely issues faced in the country.

6. To enhance implementation stages of the privatization policy, research indicates that it is helpful for policymakers to incorporate some characteristics of a democratic governance network. Thomson and Perry (2006) explain this as building collaborative and trust relationships, sharing power by eliminating strict hierarchical divides, and reconciling individual and collective interests.

7. Data findings reveal that the Kuwaiti public sector is bureaucratic and centralized. This can oppress managers' individuality when leading creative initiatives in the workplace. Public service motivation (PSM) levels are lower in Kuwait than in the 
UAE and Qatar (WEF, 2016). As a result, structures that define the amount of managerial discretion and autonomy for lower-level implementers should be revisited accordingly (Terry, 1998).

8. Lastly, there is a crucial need to establish the monitoring and supervision mechanisms previously discussed. This would help restrain self-interested politicians from politically manipulating the agenda-setting stage of policymaking.

In the end, public policies are often developed to aid the implementation of government programs (Dye, 1987). Privatization, as a reform movement, helped develop the economy in different sociopolitical contexts. In the case of Kuwait, "privatization aims to maintain the equilibrium between the public and private sector under the framework of fair cooperation between them for the purpose of achieving economic development, increasing production, encouraging the role of Private sector in the national economy, raising living standard and achieving prosperity" (Explanatory memorandum of Law 37/10).

\section{Strategic Policymaking}

According to Smith (1999), policymaking is the process of deciding who gets what, when, and how. Politics is the broader political discourse within which a policy is made (Zahariadis, 2014). This discourse includes ideas as seen from multiple perspectives, rather than objective facts (Stone, 2002). In the case of policymaking in Kuwait, the main struggle appears to be in the "how" that Smith describes. This research concludes that the "what" is based on needs of the time, as defined by the different factors and elements. The "when" is based on the sequence of events, human capacity, 
and financial and legislative support. However, the "how" is lagging for each stage of the policy cycle - how to formulate a comprehensive policy, how to implement it successfully, and how to evaluate it thereafter.

Prior to proposing any policy or government initiative, thorough research must be conducted. The public's opinion must be accounted for without neglecting any population subgroup. Therefore, investments in R\&D are of great significance. During this stage, policymakers must maintain open communication and high levels of transparency. Elements of a participative democracy and social inclusion are key. This will help build political support for reforms and strengthen social initiatives. Policy frameworks employed must be results-oriented and SMART. Proposals generated should outline the baseline, targets, indicators, and strategic action plans characterized by short and longterm goals.

The agenda setting and policy formulation stages are expected to be representative, equitable, and effective. Representativeness is enhanced when there is agreement between a bureaucrat's decisions and the community's preferences (Kingsley, 1944; Krislov, 1974). Equitability is achieved through the fair distribution of public services. Accounting for the different social and political values, during each stage of the policy development process, is critical. Effectiveness refers to the degree of which the policy leads to desired outcomes. It incorporates certain elements from Weber's idealtype bureaucracy (Wilson, 1989), such as specialization and clearly defined rules and procedures. It eliminates, however, the element of hierarchical control and instead calls for an active and participative citizenry (Frederickson, 1989). 
A policy's implementation stage must be efficient and integrative. Efficiency results when a rational choice is made after testing the relationships between preferences and courses of action (Simon, 1955). Research findings infer that efficient policy decisions involve the adequate use of resources, devolution of control, and democratic governance structures. An integrative policy process that involves different actors decreases the likelihood for political manipulation, while increasing accountability. Integrative policies include elements of social inclusion, value pluralism, and political participation.

Data revealed a lack of evaluative criteria for public policies in Kuwait. Evaluating the privatization policy's success, post-implementation, is possible through the adoption of performance measures. This process requires the assessment of actual progress made, against predetermined goals that are viewed as the baseline (Poister, 2003). Monitoring performance should be systematically conducted against a set of KPI's and objectives that various actors in the process can contribute towards. Hatry (1978:28) explains that, "unless you are keeping score, it is difficult to know whether you are winning or losing." Osborne and Gaebler (1992:146) expand on this view stating that, "what gets measured gets done."

In the case of privatization policy in Kuwait, each privatization initiative proposed should first: 1) identify existing issue areas, 2) explain how capacity will be built by mobilizing local resources, rather than foreign efforts, and 3) identify venues to advocate for social support and political awareness. In the final analysis, privatization should not be seen as a reform approach. Instead, it should be viewed as a restructuring process where root changes in the system are made gradually and strategically. To ensure the 
successful implementation of privatization initiatives, the economic development vision must be redefined, along with policymakers' leadership, management, and decisionmaking processes.

\section{Summary of Findings}

Figure 6 depicts the flow of action between the political subsystems, as they relate to the policy environment in Kuwait, the country's constitution, and the data analyzed.

Figure 6

\section{Policy Development Conceptual Framework}

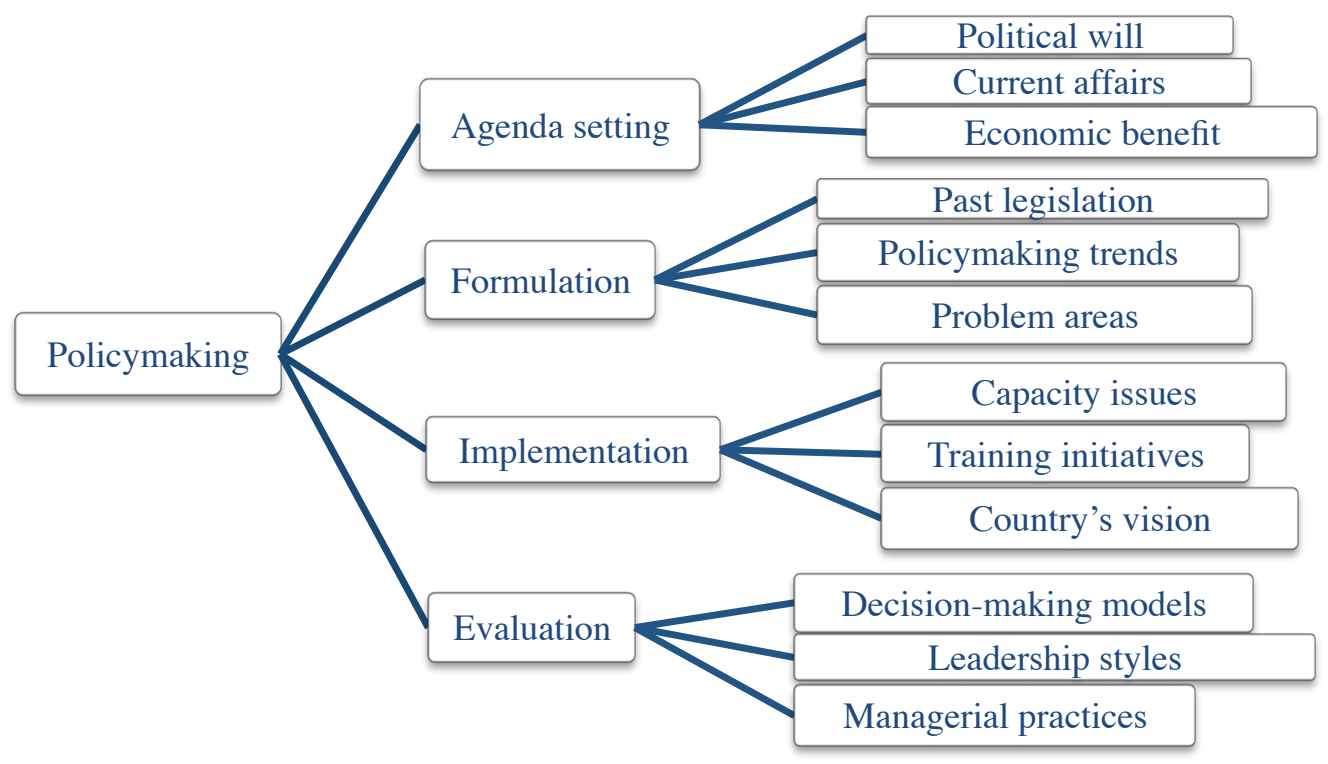

This model combines the main ideas in the research questions and hypotheses

that guided this study. The different activities involved at each stage of the policy process are distinguished in this diagram. The clusters of meanings developed from the data results and findings were discussed within the extant literature. The discussions below elaborate further on the themes that emerged from the data analyzed, within the context 
of Kingdon’s (1984) Multiple Streams Framework - problem, policy, and politics streams.

The country's global rankings along with the data analyzed from interviews, focus groups, and document reviews provide some key takeaways. For any process of policy development and economic advancement to be successful, all sectors in the country must cooperate. Some research participants' responses highlighted how the population subgroups of youth and women are often overlooked in the country's policymaking process. In the context of the privatization policy and reform movement, youth are especially important given their population composition (CSB, 2014). Data results indicate that the new generation of youth is particularly ambitious, educated, and entrepreneurial. Therefore, implementing a reform, such as privatization, requires the government's attention to this valuable resource of human capital. However, data results of Kuwait's Human Capital Index (HCI) rankings and reaffirmations of research participants' experiences, explain this case notwithstanding. As such, the country's longterm development agenda should not only focus on achieving higher levels of competitiveness, but also social inclusivity.

On a more macro-level, data analyzed reflect that a country's development process impacts all aspects of the society, culture, economy, and politics. This research explored how political decision-making in Kuwait differentiates from western-based theoretical frameworks. Policymaking requires vision, leadership, and management. Each stage of the policy process was explored with respect to privatization policy in the case of Kuwait. Data findings conclude that policies generated should be, 1) representative of the 
society's preferences, 2) equitable to all population subgroups, 3) effective in achieving desired outcomes, 4) efficient in the strategic use of resources, and 5) integrative.

Some theorists consider privatization as the government's innovative approach to running a country. However, this research concludes that if a market is not efficient, it cannot be innovative. In the end, economic development is a comprehensive process that is possible through the alignment of elements and factors across both private and public sectors. In order to experience actual economic growth, the government must consider reconciling the development process with international standards and work towards achieving these standards. Data findings conclude that a government that adopts a systematic and inclusive policymaking process will eventually foster a healthy ecopolitical environment. As a result, the country is more likely to achieve sustainable development goals, higher levels of productivity, and economic growth.

\section{Future Research}

After privatization has been implemented in Kuwait, future research can evaluate the success of this policy on fulfilling the country's priority goal of economic development. Research can compare the performance of certain sectors, pre- and postprivatization. Performance and growth data reported could also be used to compare a successful privatization model in Kuwait to a similar privatization model in the GCC region. The driving factors for success should be identified. After law 37/10 has been implemented, research should be conducted to evaluate the effect of privatized services, formerly free public services, on the lives of limited income individuals. Social and economic indicators could be assessed at different points in time. Future research can also 
evaluate the attitudes of national employees as they experience privatization initiatives in their workplaces. Research could also evaluate the effects of the privatization law on the real employment opportunities for nationals. The topic could be expanded further to evaluate the effects of policymaking post-Arab spring, with an emphasis on the social inclusion of youth and women.

\section{Conclusion}

Analysis focus group responses indicates that the population is informed and aware of its needs, which makes it difficult for the government to maintain exclusive ownership and control of public services that do not meet the standard levels of quality as experienced by citizens. Therefore, support for public-private cooperation exists; however, citizens remain fearful of how this policy will impact their professional and social lives. The inconclusiveness of the privatization policy not only hinders its implementation, but also decreases the likelihood for building support across different platforms. Sabatier (2007) explains how policy windows open for a short duration. Data results conclude that certain factors and elements must exist in order for a policy to succeed through its different development stages. These include social inclusion, comprehensive action plans, public support, political interest, a skillful civil service, and adequate evaluation mechanisms. Khodr (2014) discusses that a successful policy is one that is both responsive and effective.

Data analyses have shown that Western-based reforms of markets and government cannot be replicated in the Gulf region. The state-society relations that distinguish Gulf countries present an obstacle when implementing the privatization 
reform, as it redefines the state's authoritative role. This study portrays how culture and traditions often infuse the government's administrative approaches. The role of the ruling family in government is strong, as is the government's constitutional role in owning public assets and services. As the Arab Spring unraveled in neighboring countries of Tunisia, Egypt, and Libya, ruling families in the Gulf monarchies tightened their political grip even further. This was also the case in countries with transitional economies. Biygautane (2016:1) advocates for further theorization of this fundamental reform is needed, given that it can be perceived as, "a direct threat to the political legitimacy of the ruling elites." In this context, presenting the reform from the perspective of market operations, rather than ownership and control, can help build intra- and interorganizational support.

Kolderie (1986) elaborates that privatization need not be defined from a structural angle of who owns the enterprise. If the government's aim for privatization is to decrease its burden and increase cost-effectiveness, then the privatization concept should be redefined as, "how far the operations of an enterprise are brought within the discipline of market forces" (Beath, 1989:4). This research concludes the need for strong political will prior to policy formulation and especially during stages of implementation.

Not only is the reform's application in the Gulf region different from western experiences, but also the objectives of privatization vary. Some of the driving factors for privatization initiatives in the Westminster and American governments are costeffectiveness and redistribution of wealth to citizens (Miller, 1995). In the GCC region, Amico (2016) explains the governments' desire to retain high stakes in the privatized industries. In view of heightened privatization talks in the GCC region, a labor market 
strategy is needed to assess: 1) human capacity issues of cross-country employment of Gulf nationals, 2) immigration and accessibility of public services, and 3) regional fiscal policies and new financial structures in the region.

Research has shown that privatization, in the case of Kuwait, is not just a tool for economic reform. Rather, it is an attempt to restructure the national economy in its entirety. Politics and markets cannot be separated from each other. Lindblom (1977) presents the concept of politico-economic processes, in that both private and public sectors possess similar values of efficiency, liberty, equality, and popular control. Privatization is one of the main pillars in Kuwait's long-term vision for economic development, which targets:

1. Enhancing economic efficiency, economic stability, and the country's opportunities for expansion;

2. Increasing the government's productivity, based on cost-benefit analysis;

3. Rationalizing consumer behavior and investment;

4. Expanding the real employment-based growth rate.

A positive relationship exists between policymaking process and policy outcomes. While the policy procedures impact the policy's outcomes, the nature of the policy itself can also determine which policymaking procedures to apply.

Research participants discussed how the government should focus privatization efforts on strengthening the local market, rather than stimulating foreign investment. This further develops the Kuwaiti private companies to compete in the foreign market as shareholding companies. Also, it would address multiple goals that were shared by the 
different groups of research participants: the goals of economic growth (government sector's concern); achieving higher ranking in international growth indicators (nonprofits and international organizations' concern); generating market stimulus locally (private sectors' concern); building the future generations funds (university students' concern); enhancing job creation (public sector employees' concern); and preserving the country's national identity (general concern).

Findings of this research are likely to speak to broader issues of policy development and building support for reforms. Newman \& Gaffney (2002) reiterate the need to preserve the core values of public administration in the entrepreneurial policymaking practices. Privatization initiatives need not focus only on economic development. Privatization reform in Kuwait should also focus on achieving further humanitarian and resilience support, in addition to sustainability in all aspects of society beyond the economy. 


\section{REFERENCES}

Abed, G. T., \& Davoodi, H. R. (2003). Challenges of growth and globalization in the Middle East and North Africa. Washington D.C.: International Monetary Fund.

Abu-Hakima, Ahmad M. (1983). The modern history of Kuwait. Michigan, USA: International Book Centre.

Achoui, M. M. (2009). Human resource development in Gulf countries: an analysis of the trends and challenges facing Saudi Arabia. Human Resource Development International, $12(1), 35-46$.

Achy, Lahcen (2012). Rentier economy fueling unemployment and poor job quality in the Arab world. Carnegie Middle East Center, April 2012. Retrieved from http://carne gie-mec.org/2012/03/06/ar-pub-47449

Ahmad, Mohammed (1990). Possibility of privatization. Indian Journal of Public Administration, 36, 63-78.

Al-Dujayli, Mussab H. (1986). Political, strategic, and economic effects on Arab relations with the third world. In The Decline of Arab Oil Revenues, edited by Farid, Abdel Majid and Hussein Sirriyeh. London: Croom Helm. 113-129.

Alessa, Salman Y. (1981). The manpower problem in Kuwait. London: Kegan Paul International.

Alfuzai, Muna (2016). Diwaniya, no longer a male bastion. Kuwait Times. July 2014. Retrieved from http://news.kuwaittimes.net/diwaniya-longer-male-bastion/

Al-Hatim, Abdullah bin Khaled (1980). From here, Kuwait began. Kuwait: Dar Alqabas.

Alkoumi, Nabeel (2010). Privatization. Magazine of the Audit Bureau of the State of Kuwait, January, Issue 6.

Allison, Graham (1971). Essence of decision. Boston, USA: Little, Brown.

Almughamis, Turki (2016). Kuwait student government elections. Al Rai Newspaper. September 2016. Retrieved from http://www .alraimedia.com/ar/article/academic /2016/09/20/708723/nr/kuwait

Al-Nakib, F. (2014). Towards an urban alternative for Kuwait: Protests and public participation. Built Environment, 40(1), 101-117.

Alnajjar, G. (2000). The challenges facing Kuwaiti democracy. The Middle East Journal, 242-258. 
Alrashid, Abdul Aziz (1960). Tarikh Al-Kuwait (History of Kuwait). Beirut: Dar AlHayat Bookstore.

Alrayih, Abdulraheem (2011). Global Strategy for Privatization. Abu Dhabi Economic Journal. 2011 Issue.

Alrumaihi, Mohammed (1986). Beyond Oil. London: Al Saqi. 1994, Volume 1: Number 3. (1994). Kuwait: Oasis of Liberalism? Middle East Quarterly, September

Al-Saigh, Nasser and Buera, Abubaker (1990). Privatization in the Arab world:

Prerequisites for success. International Review of Administrative Sciences, 56, 126.

Alsalamah, J. M. (2004). Cultural roots of Kuwaiti maritime sailing: The history and the memories. Kuwait: Al-Rubayan.

Al-Saud, Bandar S. M. (1997). The GCC security convention: A legal and practical analysis. Glasgow Doctoral Dissertation.

Altamimi, Amer (2015). Economic development in Kuwait. Al Hayat Newspaper. Retrieved from http://www.alhayat.com/Opinion/Writers/7977626.

Alyahya, Muhammed (1993). Kuwait: Fall and rebirth. London: Kegan Paul International.

Amico, Alissa (2016). Is Privatization in the Future of GCC Countries? Retrieved from https://blogs.cfainstitute.org/investor/2016/03/21/is-privatization-in-the-future-of-gcccountries/

Ammons, D. N. (2002). Performance measurement and managerial thinking. Public Performance \& Management Review, 25(4), 344-347.

Anderson, James E. (2000). Public policymaking, 4th ed. Boston: Houghton Mifflin.

Anderson, James E. (2006). Public policymaking. Boston: Houghton Mifflin.

Anderson, L. (2011). Demystifying the Arab Spring: Parsing the differences between Tunisia, Egypt, and Libya. Foreign Affairs, 2-7.

Appleby, Paul (1945). Big Democracy. New York: A. A. Knopf

Assaad, R., \& Roudi-Fahimi, F. (2007). Youth in the Middle East and North Africa:

Demographic opportunity or challenge. Washington, DC: Population Reference Bureau. 
Baker, J. H. (1994). Policy challenges of UN peace operations. Parameters, 24(1), 13.

Barakat, Halim (1993). The Arab world: Society, culture, and state. Berkeley: University of California Press.

Barrett, Raymond (2006). Kuwait's political turmoil. Retrieved from https://www.opendemocracy.net/conflict-middle_east_politics/kuwait_3601.jsp

Barry, David; Cramton, Catherine; and Carroll, Stephen (1997). Navigating the garbage can: How agenda help managers cope with job realities. Academy of Management Executive, 11(2), 26-42.

Baumgartner, Frank R. and Jones, Bryan D. (1991). Agenda dynamics and policy subsystems. Journal of Politics, 53, 1044-1074.

of Chicago Press. (2002). Policy Dynamics. Chicago, USA: University

Bean, Sir Charles (2016). Independent review of UK economic statistics. HM Treasury, Cabinet Office, The Rt Hon Matt Hancock MP and The Rt Hon George Osborne MP.

Bennell, P. (1997). Privatization in sub-Saharan Africa: Progress and prospects during the 1990s. World Development, 25(11), 1785-1803.

Berg, A., \& Berg, E. (1997). Methods of privatization. Journal of international affairs, 357-390.

Berg. B. L. and Lune, H. (2012). Qualitative research methods for the social sciences, $8^{\text {th }}$ Edition. New Jersey, U.S.A.: Pearson Publications, Inc.

Berger, PL and Luckmann, T. (1967). The social construction of reality. Garden City, NY: Doubleday and Company.

Bernard (1994). Social research methods: Qualitative and quantitative approaches. Thousand Oaks, CA: Sage.

Berry, Frances \& Berry, William (2007). Innovation and diffusion models in policy research. In Theories of the policy process, edited by Sabatier, Paul. Boulder, CO: Westview Press. 223-260.

Bertelsmann Stiftung, BTI (2014). Kuwait Country Report. Gutersloh: Bertelsmann Stiftung.

Bevir, Mark (2010). Democratic governance. Princeton, NJ: Princeton University Press. 
Binder, S. A. (2004). Stalemate: Causes and consequences of legislative gridlock. Brookings Institution Press.

Birkland, Thomas A. (2010). An introduction to the policy process, $3^{\text {rd }}$ ed. Armonk, NY: M. E. Sharpe.

Bishop, M. and Kay, J. (1989). Privatization in the United Kingdom: Lessons from experience. World Development, 17 (5), 643-657.

Bishop, M., Kay, J., and Mayer, C. (1995). The regulatory challenge. Oxford University Press.

Biygautane, M., Gerber, P., \& Hodge, G. (2016). The evolution of administrative systems in Kuwait, Saudi Arabia, and Qatar: The challenge of implementing market based reforms. Digest of Middle East Studies.

Blake, Charles H. and Adolino, Jessica R. Comparing public policies: Issues and choices in six industrialized countries, $2^{\text {nd }}$ ed. Washington, D.C.: CQ Press.

Blomquist, William (1999). The policy process and large-N comparative studies. In Theories of the Policy Process, edited by Paul A. Sabatier, 201-232. 2nd ed. Boulder, CO: Westview Press.

Blumer, H. (1969). Symbolic interactionism. Englewood Cliffs, NJ: Prentice-Hall.

Blum, Jerome; Cameron, Rondo; and Barnes, Thomas G. (1970). The European World. Boston: Little, Brown, 1, 267-268.

Buchanan, James and Tullock, Gordon (1962). The calculus of consent. Ann Arbor, MI: University of Michigan Press.

Budhwar, P., \& Mellahi, K. (2007). Introduction: human resource management in the Middle East. The International Journal of Human Resource Management, 18(1), 2-10.

Burnard, P. (2006). A pragmatic approach to qualitative data analysis. In Research for evidence based practice, edited by Newell, R. \& Burnard, P., 97-107. Oxford: Blackwell Publishing.

Cairney, P. (2012). Understanding public policy. Basingstoke, UK: Palgrave.

Carpenter, D. P. (2001). The forging of bureaucratic autonomy: Reputations, networks, and policy innovation in executive agencies, 1862-1928. Princeton, NJ: Princeton University Press. 
Casey, Michael S. (2000). The history of Kuwait. Westport, Connecticut: Greenwood Publishing Group.

Cassell, M. (2004). Ambiguity and Choice in Public Policy: Political Decision Making in Modern Democracies. Perspectives on Politics, 2(03), 627-629.

Catlaw, T. J. (2007). Fabricating the people: Politics and administration in the biopolitical state. University of Alabama Press.

Central Statistical Bureau (2014). Population \& Housing. Data file, State of Kuwait. Table 17: 42.

Central Statistical Bureau (2015). Employment Statistics in Government Sectors. Data file, State of Kuwait. Section 3.

Central Statistical Bureau (2016). Income \& Expenditures. Data file, State of Kuwait. Table 23.

Chamber of Commerce and Industry (1990). Privatization: International Experiences and Economic Impact. Eastern Region, Saudi Arabia (1990/1410H).

Chow, A. (2014). Understanding policy change: multiple streams and national education curriculum policy in Hong Kong. Journal of Public Administration and Governance, $4(2), 49-64$.

Civil Service Commission (2008). Periodical of the Civil Service Commision in the State of Kuwait. July 2008, Volume 1.

Civil Service Commission (2016). History and Overview. Retrieved from http://www.csc.net.kw:8888/csc/ar/home.jsp

Clawson, P. (1997). Review of civil society in the Middle East. Middle East Quarterly, $4(1), 353$.

Clinton, B. (1992). The Clinton health care plan. New England journal of medicine, 327(11), 804-807.

Coglianese, C. (2012). Measuring regulatory performance evaluating the impact of regulation and regulatory policy. Expert Paper 1, Organization for Economic Cooperation and Development.

Cohen, J. L., \& Arato, A. (1992). Political theory and civil society. Cambridge, MA: MIT Press. 
Cohen, M. D., March, J. G., \& Olsen, J. P. (1972). A garbage can model of organizational choice. Administrative science quarterly, 17(1), 1-25.

Coleman, S., Brudney, J. L., \& Kellough, J. E. (1998). Bureaucracy as a representative institution: Toward a reconciliation of bureaucratic government and democratic theory. American Journal of Political Science, 717-744.

Compston, H. (2009). Policy networks and policy change: putting policy network theory to the test. Springer. New York: Palgrave Macmillan.

Creswell, J. W. (1998). Qualitative inquiry and research design: Choosing among five traditions. Thousand Oaks, CA: Sage.

(2007). Qualitative inquiry and research design: Choosing among five traditions. $2^{\text {nd }}$ ed. Thousand Oaks, CA: Sage Publications.

Crystal, Jill (1995). Oil and politics in the Gulf: Rulers and merchants in Kuwait and Qatar, Vol. 24. Cambridge University Press.

Dahl, Robert A. (1947). The science of public administration: Three problems. Public Administration Review, 7(1), 1-11.

Davis, John (2012). The GCC countries and the Arab Spring, between outreach, patronage and repression. London and New York: Routledge.

De la Porte, C., Pochet, P., \& Room, B. G. (2001). Social benchmarking, policy-making and new governance in the EU. Journal of European Social Policy, 11(4), 291-307.

Denhardt, Robert and Denhardt, Janet (2000). The new public service: Serving rather than steering. Public Administration Review, 60(6), 549-559.

M.E. Sharpe, Inc.

(2007). The new public service: Serving, not steering. New York, U.S.A.:

Denzin, Norman and Lincoln, Yvonna (2005). Handbook of Qualitative Research. $3^{\text {rd }}$ ed. Thousand Oaks, CA: Sage Publications.

Dolowitz, D. P., and Marsh, D. (2000). Learning from abroad: The role of policy transfer in contemporary policy-making. Governance, 13(1), 5-23.

Downs, Anthony (1957). An economic theory of political action in a democracy. The Journal of Political Economy, 135-150.

Downs, Anthony (1967). Inside bureaucracy. Boston, USA: Little, Brown. 
Durant, Robert (1998). Agenda Setting, the Third Wave, and the Administrative State. Administration and Society, 30(3), 211-247.

Durant, Robert F., and Diehl, Paul F. (1989). Agendas, alternatives, and public policy: Lessons from the U.S. foreign policy arena. Journal of Public Policy, 9, 179-205.

Dye, Thomas R. (1965). Malapportionment and public policy in the states. Journal of Politics, 27(3), 586-601.

Hall. (1987). Understanding public policy. Upper Saddle River, NJ: Prentice

Easton, David. (1953). The political system: An inquiry into the state of political science. New York: Alfred A. Knopf, Inc.

Ehteshami, Anoushiravan (2003). Reform from above: The politics of participation in the oil monarchies. Royal Institute of International Affairs, 79 (1), 53-75.

Elbadawi, Ibrahim and Kubursi, Atif (2014). Kuwaiti democracy: Illusive or resilient? American University of Beirut, 1, 2014. Retrieved from https://www .aub.edu.lb/ fas/ife/PublishingImages/IFE\%20Report-web.pdf

El-Katiri, L., Fattouh, B., \& Segal, P. (2011). Anatomy of an oil-based welfare state: Rent distribution in Kuwait. LSE Global Governance, 13.

Elmore, Richard (1982). Backward mapping: Implementation research and policy decisions. In Studying implementation: Methodological and administrative issues, edited by Walter L. Williams. Chatham, N.J.: Chatham Publishing.

Englander, M. (2012). Data collection in descriptive phenomenological human scientific research. Journal of Phenomenological Psychology, 43, 13-35.

Epstein, W. N. (2012). Contract theory and the failures of public-private contracting. Cardozo L. Rev., 34, 2211.

Farah, Tawfic E. (1979). Inculcating supportive attitudes in an emerging state: The case of Kuwait. Journal of South Asian and Middle Eastern Studies, 2(4), 56.

Farazmand, A. (1999). Globalization and public administration. Public administration review, 59(6), 509-522.

Farid, Abdel Majid and Hussein Sirriyeh (1986). The Decline of Arab Oil Revenues. London: Croom Helm. 
Fattahavo, Nawara (2011). From Kuwait Times: Diwaniyas define Kuwaiti social life. $A l$ Arabiya News. Retrieved from http://www .alarabiya.net/articles/2011/09/11/166328.html

Fayol, H. (1916). General principles of management. Classics of organization theory, 2, 15 .

Finer, Herman (1941). Administrative responsibility in democratic government. Public Administration Review, 14, 335-350.

Feldman, Martha S. (1989). Order without design: Information production and policymaking. Stanford, CA: Stanford University Press.

Frederickson, H. G. (1996). Comparing the reinventing government movement with the new public administration. Public Administration Review, 56, 263-270.

Frederickson, H. G. (2005). Whatever Happened to Public Administration: Governance, Governance, Everywhere. In The Oxford Handbook of Public Management, edited by Ferle et al. New York, U.S.A.: Oxford University Press.

Frederickson, H. G. (2010). Social equity and public administration: origins, developments, and applications. Armonk, NY: ME Sharpe.

Frederickson, H. G. and Smith, K. (2011). Public administration theory primer. $2^{\text {nd }}$ ed. Colorado, U.S.A.: Westview Press.

GCC Charter (1981). Charter of the Gulf Cooperation Council. Ministries Council: State of Kuwait.

General Secretariat for Development Planning (2011). Qatar National Development Strategy, 2011-2016. Doha: General Secretariat for Development Planning.

Ghabra, Shafeeq (1993). Kuwait: Elections and issues of democratisation in a Middle Eastern state. International Journal of Islamic and Arabic Studies, 1.

Giorgi, A. (1985). Phenomenology and psychological research. Pittsburgh, PA: Duquesne University Press.

Goodnow, Frank J. 1900. Politics and Administration: A Study of Government . New York: Macmillan Company.

Goss, J.D. and Leinbach, T.R. (1996). Focus groups as alternative research practice. Area, 28(2), 115-23.

Gray, M. (2011). A Theory of late rentierism in the Arab States of the Gulf. Georgetown University Library. 
Guest, G., Bunce, A., and Johnson, L. (2006). How many interviews are enough: Experiment with data saturation and variability. Field Methods, 18, 59-82.

Gulick, L. (1937). Science, values and public administration. As cited in Gulick, L., and Urwick, L. (2004). Papers on the science of administration, 189-195. Routledge.

Gurria, Angel (2016). Resource Productivity in the G8 and the OECD. A report in the framework of the Kobe 3R action plan. Retrieved from https://www.oecd.org/env/waste/47944428.pdf

Harris, R. A. (1994). A summary critique of the fact/value dichotomy. Retrieved from http://greensprout.homelinux.com/OldSalt/MyOldSalt/www.virtualsalt.com/int/factvalue. pdf

Hatry, Harry P. (2006). Performance Measurement. Second Edition. Washington, D.C.: Urban Institute Press.

(1978). The Status of Productivity Measurement in the Public Sector. Public Administration Review, 38(1), 28-33.

Heinrich, Carolyn and Lynn, Laurence (2000). Governance \& performance: New perspectives. Washington, D.C.: Georgetown University Press.

Herb, Michael (2002). Emirs and parliaments in the Gulf. Journal of Democracy, 13 (4), 41-47. Retrieved from https://muse.jhu .edu/login?auth=0\&type= summary\&url=/journals/journal_of_democracy/v013/13.4herb.html

Hill, C. J., and Lynn Jr, L. E. (2004). Governance and public management: An introduction. Journal of Policy Analysis and Management, 3-11.

Hofferbert, Richard I. (1966). The Relation Between Public Policy and Some Structural and Environmental Variables in the American States. American Political Science Review, 60(1), 73-82.

Holstein, J. A., and Gubrium, J. F. (1994). Phenomenology, ethnomethodology, and interpretive practice. In Handbook of qualitative research, 262-272, edited by N. K. Denzin \& Y. S. Lincoln. Thousand Oaks, CA: Sage.

Homan, R. (1991) Ethics in Social Research. Harlow: Longman.

Hood, Christopher (2011). The Blame Game. Princeton, NJ: Princeton University Press. 
Howlett, M. (1991). Policy instruments, policy styles, and policy implementation: National approaches to theories of instrument choice. Policy Studies Journal, 19 (2): 121.

Howlett, M. \& Ramesh, M. (1995). Studying public policy: Policy cycles and policy subsystems. Toronto, Canada: Oxford University Press.

HSBC (2013). Interim Financial Statements. HSBC Bank Middle East Limited. Retrieved from https://www.hsbc.com.eg/1/PA_esf-ca-appcontent/content/pws/kw/pdf/interim-report-2013.pdf

Humphries, B. (2004). An unacceptable role for social work: Implementing immigration policy. British Journal of Social Work, 34(1), 93-107.

Hussain, M. M., Mohamed, E. K., Islam, M. M., \& Rahman, M. (2007). Banking policies and regulations: comparative study of Kuwait, UAE and Qatar. International Journal of Financial Services Management, 2(3), 214-234.

Husserl, Edmund (1931). Ideas: General introduction to pure phenomenology. UK: Routledge Classics.

(1970). Logical investigation. New York: Humanities Press.

International Labour Organization, ILO (2015). World Employment and Social Outlook: Trends 2015. Geneva: International Labour Office.

International Monetary Fund (2003). Kuwait Country Report. Number 04-186. June 20031, 1-79.

International Monetary Fund, IMF (2015). Low oil prices, conflict weigh on Middle East's prospects. IMF Survey Magazine: Countries \& Regions. IMF Survey, Retrieved from http://www.imf.org/external/pubs/ft/survey/so/2015/car102115a.htm

Issacharoff, S., Karlan, P. S., and Pildes, R. H. (2002). The law of democracy: legal structure of the political process. Foundation Pr.

Jennings, M. K. (1998). Political trust and the roots of devolution. Trust and governance, $1,218-44$.

Jones, Bryan D. (1994). Reconceiving decision-making in democratic politics: Attention, choice, and public policy. Chicago, IL: University of Chicago Press.

(2001). Politics and the architecture of choice: Bounded rationality and governance. Chicago: University of Chicago Press. 
Jones, L. P., and Wortzel, L. (1982). Public enterprise and manufactured exports in LDCs. Public enterprise in less-developed countries, 217, 242.

Kamensky, J. (1996). Role of the 'reinventing government' movement in federal management reform. Public Administration Review, 56 (3), 247-255.

Kane, M. \& Trochim, W. (2007). Concept Mapping for Planning and Evaluation. Thousand Oaks, CA: Sage Publications.

Kapiszewski, A. (2006). Elections and parliamentary activity in the GCC States: Broadening political participation in the Gulf Monarchies. Constitutional Reform and Political Participation in the Gulf, 4, 88.

Kaplan, R. S. and D.P. Norton (1992). The balanced scorecard: Measures that drive performance. Harvard Business Review, January-February issue, 71-79.

Katz, Daniel and Kahn, Robert (1966). The social psychology of organizations. New York: Wiley.

Kay, J. A., and Thompson, D. J. (1986). Privatisation: A policy in search of a rationale. The Economic Journal, 96(381), 18-32.

Kelly, J.B. (1968). Britain and the Persian Gulf, 1795-1880. Oxford, UK: Clarendon Press.

Kettl, D. F. (2002). The Global Public Management Revolution. 2nd Ed. Washington, D.C.: Brookings Institution Press.

Khodr, H. (2014). A preliminary comparative study of policy making in two GCC countries-Qatar and Kuwait. Politics \& Policy, 42(2), 271-310.

Khuri, Fuad (1990). Tents and pyramids: Games and ideology in Arab culture from backgammon to autocratic rule. London: Saqi Books.

Kingdon, John W. (1984). Agendas, alternatives, and public policies. New York: Addision Wesley Longman.

(1993). Politicians, self-Interest, and ideas. In Reconsidering the democratic public, edited by George E. Marcus and Russell L. Hanson, 73-89. University Park: Pennsylvania State University.

Kingsley, Donald (1944). Representative bureaucracy. Yellow Springs, OH: Antioch Press. 
Kikeri, S., Nellis, J., \& Shirley, M. (1994). Privatization: Lessons from market economies. The World Bank Research Observer, 9(2), 241-272.

Kitzinger, J. (1994). The methodology of focus groups: The importance of interaction between research participants. Sociology of Health. 16(1), 103-21.

Kostiner, Joseph (2009). Conflict and cooperation in the Gulf region. Weisbaden: Springer.

Kreuger R.A. (1988). Focus groups: a practical guide for applied research. London: Sage.

Krislov, S. (1974). Representative bureaucracy. Englewood Cliffs, NJ: Prentice Hall.

Kuwait Alyawm (2010). Privatization Law 37/2010. Official Gazette of the Government of the State of Kuwait. Publication No. 979-56. Kuwait: Ministry of Information.

Kuwait Constitution (1962). Constitution of the State of Kuwait.

Kuwait National Assembly, KNA (2016). Supplementary session of the Council: Addressing the cooperation between the two authorities for the benefit of citizens. Congressional Reports, April 2016.

Kuznar, L. A. (2008). Reclaiming a scientific anthropology. United Kingdom: Altamira Press.

Lasswell, Harold D. (1958). Politics: Who gets what, when, how. New York: Meridian Books.

Lasswell, Harold D., and Kaplan, Abraham (1950). Power and society: A framework for political inquiry. Vol. 2. New Haven, CT: Yale University Press.

Le Grand, J., \& Bartlett, W. (1993). Quasi-markets and social policy: the way forward?. In Quasi-markets and social policy (pp. 202-220). Palgrave Macmillan UK.

Lester, James and Stewart, Joseph (2000). Public Policy. Belmont, CA: Wadsworth.

Light, P. (1997). The tides of reform. Binghamton, New York: Vail-Ballou Press.

Lincoln, Y. S. and Guba, E. G. (1985). Naturalistic Inquiry. Newbury Park, CA: Sage Publications.

Lincoln, Y. S. and Guba, E. G. (1994). Competing paradigms in qualitative research. In Handbook of qualitative research, 105-117, edited by N. K. Denzin \& Y. S. Lincoln. Thousand Oaks, CA: Sage. 
Lindblom, Charles E. (1968). The policy-making process. Englewood Cliffs, NJ: Prentice Hall.

Lindblom, Charles E. (1979). The science of muddling through. Public Administration Review, 19, 79-88.

Lindblom, Charles E., \& Cohen, D. K. (1979). Usable knowledge: Social science and social problem solving. Yale University Press, 21.

Lipset, S. M. (1959). Some social requisites of democracy: Economic development and political legitimacy. American political science review, 53(01), 69-105.

Lipsky, Michael (1980). Street-Level Bureaucracy: The Dilemmas of the Individuals in Public Service. New York: Russell Sage Foundation.

Long, T., \& Johnson, M. (2000). Rigour, reliability and validity in qualitative research. Clinical effectiveness in nursing, 4(1), 30-37.

Lowi, Theodore (1979). The end of liberalism. New York, NY: Norton.

Lynn, L. (2001). The myth of the bureaucratic paradigm: What traditional public administration really stood for. Public Administration Review, 61(2), 144-160.

Lynn, L., Heinrich, C., and Hill, C. (2000). Studying Governance and Public Management: Why? How? In Governance and Performance: New Perspectives, edited by Carolyn Heinrich and Laurence Lynn. Washington, D.C.: Georgetown University Press.

Machiavelli, N. (1950). The prince, and the discourses. University of Chicago Press.

Mahmoud, Mohammed F. (1992). Privatization: A solution to problems of public enterprises. Economics \& Administration, 5, 33-49.

Mansfield, E. D., and Pevehouse, J. C. (2006). Democratization and international organizations. International Organization, 60(01), 137-167.

March, J. G. (1978). Bounded rationality, ambiguity, and the engineering of choice. The Bell Journal of Economics, 587-608.

March, J. G., \& Olsen, J. P. (1983). The new institutionalism: organizational factors in political life. American Political Science Review, 78(03), 734-749. 
March, J. G., \& Romelaer, P. J. (1976). Position and presence in the drift of decision. In Ambiguity and Choice in Organizations, edited by James G. March and Johan P. Olsen. Bergen, Norway: Universitetforlaget. 251-276.

Marsh, D. (1991). Privatization under Mrs. Thatcher: A review of the literature. Public Administration, 69(4), 459-480.

Marshall, C. \& Rossman, G. (2011). Designing Qualitative Research. Fifth Edition. United States of America: Sage Publications, Inc.

Marx, Karl (1844). The economic and philosophical manuscripts. Institute of MarxismLeninism in the Union of Soviet Socialist Republics. Martin Milligan of Progress Publishers. Retrieved from http://libarch.nmu.org.ua/bitstream/handle/GenofondUA/ 19146/ed7dad69d823638f1ddd13a9bb6e6f54.pdf?sequence=1\&isAllowed=y

Mathison, S. (1988). Why triangulate? Educational Researcher. 17 (2), 13-17.

Maykut, Pamela and Morehouse, Richard (1994). Beginning qualitative research: A philosophical and practical guide. UK: The Falmer Press.

Mayo, E. (1930). The Hawthorne Experiment. The Human Factor, 6.

Mazmanian, Daniel A., and Paul A. Sabatier (1983). Implementation and public policy. Glenview, IL: Scott Foresman.

McCool, Daniel (1995). Public policy theories, models, and concepts: An anthology. Englewood Cliffs, NJ: Prentice Hall.

Megginson, W. L., Nash, R. C., \& Randenborgh, M. (1994). The financial and operating performance of newly privatized firms: An international empirical analysis. The Journal of Finance, 49(2), 403-452.

Meijerink, S. (2005). Understanding policy stability and change: The interplay of advocacy coalitions and epistemic communities, windows of opportunity, and Dutch coastal flooding policy, 1945-2003 1. Journal of European Public Policy, 12(6), 10601077.

Mernissi, Fatima (1992). Islam and democracy: Fear of the modern world, trans. Mary Jo Lakeland. Mass.: Addison-Wesley.

Miller, Alan N. (1995). British privatization: Evaluating the results. Columbia Journal of World Business, 30(4), 82-98.

Miller, H. T. (2012). Governing narratives: symbolic politics and policy change. Alabama: University of Alabama Press. 
Miller, H. T., \& Fox, C. J. (2007). Postmodern public administration. ME Sharpe.

Miller, Judith (1984). In modern Kuwait, old ways still shape society. New York Times. June 1984. Retrieved from http://www.nytimes.com/1984/06/10/world/in-modernkuwait-old-ways-still-shape-society.html

Ministry of Finance (2016). Privatization Reports. Department of Public Accounts. Kuwait: Ministries Council.

Ministry of Planning (2010). His Highness Sheikh Sabah Al-Sabah's 2035 Vision for Kuwait. Diwan Al Amiri. Retrieved from http://www.da.gov.kw/ara/festival/vision_ his_highness.php

Mooney, Christopher, and Lee, Mei-Hsein (1995). Legislating morality in the American States: The case of pre-roe abortion regulation reform. American Journal of Political Science, 39, 599-627.

Morgan D.L. (1997) Focus groups as qualitative research. 2nd Edition. London: Sage.

Mitroff, I. (1998). Smart thinking for crazy times: the art of solving the right problem. San Francisco: Berrett-Koehler.

Moustakas, C. (1994). Phenomenological research methods. Thousand Oaks, CA: Sage.

Moynihan, D. P. (2006). Managing for results in state government: Evaluating a decade of reform. Public Administration Review, 66(1), 77-89.

Nakhleh, E. A. (1986). The Gulf Cooperation Council: Policies, Problems and Prospects. Westport, CT: Greenwood Press.

Nathan, R. P. (1995). Reinventing government: What does it mean? Public Administration Review, 55(2), 213-215.

National Assembly (2009). Parliamentary bylaws, Chapter 3. Legislative Affairs and Drafting laws. $8^{\text {th }}$ edition. State of Kuwait.

National Assembly (2010). Kuwait Development Plan. Financial \& Economic Affairs Committee. Kuwait Parliament. Law No.9.

National Bank of Kuwait, NBK (2016). Kuwait: Public Finance. Economic Update. NBK Economic Research. Retrieved from http://www.kuwait.nbk.com/InvestmentAnd Brokerage/ResearchandReports/\$Document/MonthlyBriefs/engb/MainCopy/\$UserFiles/ NBKPFBudget20160802E.pdf 
Nellis, J. R. (1986). Public Enterprises in Sub-Saharan Africa, World Bank, Discussion Paper 1, Washington D.C.

Neuman, W. R., McKnight, L., \& Solomon, R. J. (1997). The Gordian knot: political gridlock on the information highway. Cambridge, MA: MIT Press.

Newman, Meredith A. and Michael J. Gaffney (2002). A Clash of Values: Public Ethics and the Business of Government. International Review of Public Administration, 7(1), 17-27.

Niskanen, William (1971). Bureaucracy and representative government. Hawthorne, NY: Aldine de Gruyter.

Norris, P., \& Inglehart, R. (2001). Cultural obstacles to equal representation. Journal of democracy, 12(3), 126-140.

O'Leary, R. (1994). The bureaucratic politics paradox: The case of wetlands legislation in Nevada. Journal of Public Administration Research and Theory, 4(4), 443-467.

Olshfski, Dorothy \& Cunningham, Robert (2008). Agendas and Decisions. New York, NY: State University of New York.

Osborne, D. and Gaebler, T. (1992). Reinventing Government. Masachussetts, U.S.A.: Addison-Wesley Publishing Co.

Ostrom, Vincent (1973). The intellectual crisis in American public administration. Alabama, U.S.A.: University of Alabama Press.

O’Toole (1987). Doctrines and development: Separation of powers, the politicsadministration dichotomy, and the rise of the administrative state. Public Administration Review, 47(1), 17-25.

O'Toole Jr, L. J. (1997). Treating networks seriously: Practical and research-based agendas in public administration. Public administration review, 57(1), 45-52.

Oxford Business Group (2008). Trade Up. The Report. Kuwait City: Kuwait, 46.

Parsons, W. (1995). Public policy: An introduction to the theory and practice of policy analysis. Cheltenham, Northampton: Parsons.

Patton, M. Q. (1990). Qualitative evaluation and research methods, 2nd ed. Newbury Park, CA: Sage.

Patton, M. Q. (2002). Qualitative Research and Evaluation Methods. $3^{\text {rd }}$ Ed. Thousand Oaks, CA: Sage. 
Perkins, J. (2016). The New Confessions of an Economic Hit Man. Oakland, CA: BerrettKoehler Publishers.

Peshkin, Alan (1988). In search of subjectivity - one's own. Educational Researcher, 17(7), 17-21.

Peters, B. G., Pierre, J., \& Randma-Liiv, T. (2011). Global financial crisis, public administration and governance: Do new problems require new solutions? Public Organization Review, 11(1), 13-27.

Peters, Guy (1999). American public policy: Promise and performance. Chappaqua, NY: Chatham House/Seven Rivers.

Peterson, J. E. (2001). The nature of succession in the Gulf. Middle East Institute, 55 (4): 580-601.

Poister, Theodore H. (2003). Measuring Performance in Public and Nonprofit Organizations. San Francisco, CA: John Wiley \& Sons, Inc.

Pope, C.; Ziebland, S.; Mays, N. (1999). Analysing qualitative data. In Qualitative research in health care, edited by Pope, C and Mays, N. 2nd edition, 75-88. London: BMJ Books.

Prager, Jonas and Desai, Swati (1996). Privatizing local government operations: Lessons from federal contracting out methodology. Public Productivity and Management Review, 20(2), 185-203.

Public Authority for Civil Information, PACI (2016). Population Data File by Gender. State of Kuwait. Retrieved from http://stat.paci.gov.kw/englishreports/

Public Institution for Social Security (2011). Retirement and Pension Funds. The Public Institution for Social Security in the State of Kuwait. Retrieved from https://www.pifss.gov.kw/Ar_Retirement.cms

Ramady, M. A. (2010). The Saudi Arabian economy: Policies, achievements, and challenges. Springer Science \& Business Media.

Ramady, M. A. (2014). State of Kuwait: Risk Analysis. In Political, Economic and Financial Country Risk. Switzerland: Springer International Publishing. 95-115.

Ray, Emilio Sacistan (1980). Some consideration on the role of public enterprise, in Public and Private Enterprise in a Mixed Economy, edited by W. J. Baumol, 44-52. London: The Macmillan Press Ltd. 
Roberts, N. C. and King, P. J. (1991). Policy entrepreneurs: Their activity structure and function in the policy process. Journal of Public Administration Research and Theory, $1(2), 147-175$.

Rochefort, David and Cobb, Roger (1994). The politics of problem definition. Lawrence: University Press of Kansas.

Rokeach, Milton (1970). Beliefs, attitudes, and values: A theory of organization and change. San Francisco: Jossey-Bass.

Rosenbloom, David (2007). Reinventing administrative prescriptions: The case for democratic-constitutional impact statements and scorecards. Public Administration Review, 67 (1), 28-39.

Rossman, R. B., and Rallis, S. F. (1998). Learning in the field: An introduction to qualitative research. Thousand Oaks, CA: Sage.

Ross, Michael L. (2001). Does oil hinder democracy? World Politics, 53(3), 325-361.

Russett, B., and Sutterlin, J. S. (1991). The UN in a new world order. Foreign Affairs, 70(2), 69-83.

Russo, E. and Shoemaker, P. (1989). Decision traps. New York: Simon and Schuster.

Sabatier, Paul (2007). Theories of the policy process, $2^{\text {nd }}$ Ed. Colorado, USA: Westview Press.

Sabatier, Paul and Jerkins-Smith, Hank (1999). Policy change and learning: An advocacy coalition approach. Boulder, CO: Westview Press.

Salih, A. (2010). Localizing the private sector workforce in the Gulf Cooperation Council countries: a study of Kuwait. International Journal of Public Administration, 33(4), 169181.

Salih, K. E. O. (1992). Privatization in post-socialist countries. Public Administration Review, 52 (6), 573-574.

Salih, K. E. O. (2013). The roots and causes of the 2011 Arab uprisings. Arab Studies Quarterly.35(2), 184-206.

Savas, E. S. (1987). Privatization: The key to better government. Chatham, NJ: Chatham House.

Savas, E. S., \& Savas, E. S. (2000). Privatization and public-private partnerships. New York: Chatham House. 
Savn, E. S. (1992). Privatization in post-socialist countries. Public Administration Review, 52(6), 573-574.

Schwab, Klaus and Sala-i-Martin, Xavier (2016). Global competitiveness report: 2016 2017. Geneva, Switzerland: World Economic Forum.

Schwandt, T. A. (2000). Three epistemological stances for qualitative inquiry: Interpretivism, hermenutics, and social construction. In Handbook of qualitative research, 189- 213, edited by N. K. Denzin \& Y. S. Lincoln. Thousand Oaks, CA: Sage.

Schwartz, R. (1977). Are the OECD and UNCTAD codes legally binding? In Int'l L. Vol. 11,529 .

Seale, C. (2000). Analysing your data. In Doing qualitative research, edited by Silverman, D., 154-174. London: Sage Publications.

Selvik, Kjetil (2011). Elite rivalry in a semi-democracy: The Kuwaiti press scene. Middle Eastern Studies, 47 (3), 477-496.

Selznick, Philip (1948). Foundations of the theory of organization. American Sociological Review, 13(1), 25-35.

Shah, N. M. (2007). Migration to Kuwait: Trends, patterns and policies. In Conference on Migration and Refugee Movements in the Middle East and North Africa, October 2007. The American University. Cairo, Egypt.

Shah, N. M., \& Al-Qudsi, S. (1990). Female work roles in traditional oil economy: Kuwait. Research in Human capital and Development, 6(5), 213-246.

Sharpe, C. (1998). How to conduct a cost-benefit analysis. Alexandria, Virginia: ASTD.

Simmons, B. \& Elkins, Z. (2004). The Globalization of liberalization: Policy diffusion in the international political economy. American Political Science Review, 1, 171-189.

Simon, H. A. (1946). Administrative Behavior: A Study of Decision-making Processes in Administrative Organizations. New York, NY: Free Press.

(1955). A behavioral model of rational choice. The quarterly journal of economics, 69(1), 99-118.

Sinclair, P., and Håkansson, T. (2000). The Swahili city-state cultures: A comparative study of thirty city-state cultures. Copenhagen: Reitzels Forlag. 
Smith, Adam (1776). An inquiry into the nature and causes of the wealth of nations. George Stigler, ed. Illinois, U.S.A.: University of Chicago Press.

Smith, Mark (1999). Public opinion, elections and representation within a market economy. American Journal of Political Science, 43(3), 842-863.

Smith, T. B. (1973). The policy implementation process. Policy Sciences, 4(2), 197-209.

Social Security Network, SNN (2009). Social Security Guide in Kuwait. The Public Institution for Social Security. Retrieved from https://www.pifss.gov.kw/upload/pifss_E_guide_eng_212.pdf

Spencer, L.; Ritchie, J.; O'Connor, W. (2004). Analysis: Practices, principles and processes. In Qualitative research practice, edited by Ritchie J. Lewis, 199-218; 219262. London: Sage Publications.

Spicer, Michael W. (2010). In defense of politics in public administration: A value pluralist perspective. Tuscaloosa: University of Alabama Press.

Stone, Deborah (2002). Policy Paradox: The Art of Political Decision Making. New York, NY: Norton.

Sullivan, H. J. (1987). Privatization of public services: A growing threat to constitutional rights. Public Administration Review, 461-467.

Taylor, F. W . (1912). The principles of scientific management. New York and London: Harper and Brothers Publishers.

Terry, L. (1998). Administrative Leadership, Neo-Managerialism, and the Public Management Movement. Public Administration Review, 58(3), 194-198.

Tétreault, M. A. (1991). Autonomy, necessity, and the small state: ruling Kuwait in the twentieth century. International Organization, 45(04), 565-591.

(2001). A state of two minds: State cultures, women, and politics in Kuwait. International Journal of Middle East Studies, 33(2), 203-220.

Trofimov, Yaroslav (2009). Kuwait's Democracy Faces Turbulence. Wall Street Journal. April issue. Retrieved from http://www.wsj.com/articles/SB123911916184897231

Ulrichsen, Kristian Coates (2014). Politics and opposition in Kuwait: Continuity and change. Journal of Arabian Studies: Arabia, the Gulf, and the Red Sea, 4 (2), 214-230. 
United Nations (1999). Privatization and regulation in developing countries and economies in transition. Report of the Experts. New York: ST/ESA/PAD/SER.E/19.

A.RES.70.1 (2015). The 2030 Agenda for Sustainable Development. Resolutions (2016). Formulation and implementation of national policies. Resolutions A.HRC.RES.30.24

United Nations Conference on Trade and Development, UNCTAD (2016). Country Classifications. Development status groupings and composition [Data file]. Retrieved from http://unctadstat.unctad.org/EN/Classifications/DimCountries_DevelopmentStatus_ Hierarchy.pdf

United Nations Development Group (2011). Results-Based Management. UNDG Handbook. Geneva, Switzerland.

United Nations Development Programme (2009). Elected women sworn in for first time in Kuwaiti parliamentary history. UNDP. May 2009. Retrieved from http://www.undp. org/content/undp/en/home/presscenter/pressreleases/2009/05/31/four-elected-womensworn-in-for-first-time-in-kuwaiti-parliamentary-history.html

(2016). UNDP and the UN in the Arab States. Retrieved from

http://www.arabstates.undp.org/content/rbas/en/home/operations/undg-arab-states.html

United Nations Statistical Division, UNSD (2000). The World's Women 2000: Trends and Statistics. New York. Retrieved from http://unstats.un.org/unsd/demographic/ products/indwm/wwpub2000press.htm

Van Horn, Carl E. (1975). The policy implementation process: A conceptual framework. Administration and Society, 6, 445-488.

Van Manen, J. (1990). Researching lived experience: Human science for an action sensitive pedagogy. Albany: State University of New York Press.

Vroom, V. H. (1964). Work and motivation. New York: Wiley.

Wainhouse, D. W. (1973). International peacekeeping at the crossroads: national support, experience and prospects. Baltimore: Johns Hopkins University Press.

Waldo, D. (1948). The administrative state: A study of the political theory of American public administration. New. York, The Ronald Press Company. 
Walker, Jack L. (1969). The diffusion of innovation among the American States. American Political Science Review, 63 (3), 880-899. Retrieved from http://www.jstor. org/stable/1954434

Warner, M. E. (2008). Reversing privatization, rebalancing government reform: Markets, deliberation and planning. Policy and Society, 27(2), 163-174.

Weber, M. (1922). Bureaucracy. London: Kegan Paul.

Weible, Christopher (2007). Understanding the political context of california marine protected area policy. Journal of Public Administration Research and Theory, 17(1), 95117.

(2014). Introducing the scope and focus of policy process research and theory. In Theories of the policy process, edited by Paul A. Sabatier and Christopher M. Weible, 3-21. 3rd ed. Boulder, CO: Westview Press.

Weimer, David and Vining, Aidan (2004). Policy analysis: Concepts and practice, 4th ed. New York, NY: Pearson.

Weir, M. (1992), as cited in Zahariadis, N. (2003). Ambiguity and choice in public policy: Political decision making in modern democracies. Georgetown University Press.

White, L. (1926). The city manager. Connecticut: Greenwood Press.

White, L. (1954). As cited in Classics of Public Administration, $6^{\text {th }}$ edition, by Shafrtiz, J. and Hyde, A. (2007). Boston, MA, USA: Thomson Wadsworth.

Wilson, J. Q. (1989). Bureaucracy: What government agencies do and why they do it. New York, NY: Basic Books.

Wilson, W. (1887). The study of administration. Political science quarterly, 2(2), 197 222.

World Bank (1983). The Challenge of Development, World Development Report. Oxford: Oxford University Press. (1993). Kuwait: A Privatization Strategy, Volume 1 (9/1993), 1-14. (2010). Economic integration in the GCC. General format. Retrieved from http://siteresources.worldbank.org/INTMENA/Resources/GCCStudyweb.pdf.

World Bank (2016). Countries and economies: Kuwait Data File. Retrieved from http://data.worldbank.org/country/kuwait. 
World Economic Forum, WEF (2016). The most likely global risks 2016: A regional perspective. Global Risks Report, GRR. Geneva, Switzerland: $11^{\text {th }}$ Edition.

World Economic Forum, WEF (2017). The GCR 2016-2017: Insight. Global Competitiveness Report, GCR. Geneva, Switzerland.

World Economic Forum, WEF (2017). The HCR 2016: Insight. Human Capital Index, HCI. Geneva, Switzerland.

Zahariadis, N. (2014). Ambiguity and multiple streams. In Theories of the policy process, edited by Paul A. Sabatier and Christopher M. Weible, 25-57. 3rd ed. Boulder, CO: Westview Press.

Zahlan, Rosemary Said (1998). The making of the modern Gulf States: Kuwait, Bahrain, Qatar, the United Arab Emirates, and Oman. London: Unwin Hyman, Ltd.

Zhao, J. (Ed.). (2014). Organizational Innovation and IT Governance in Emerging Economies. IGI Global. 


\section{APPENDIX A \\ Policymaking in the GCC Region: \\ The Case of Privatization Policy in the State of Kuwait}

\section{Interview Script}

Demographics

1. Name

2. Age

3. Education

4. Job Title

5. Current sector/agency of employment

6. Employment years

\section{Agenda-setting}

1. What factors and elements drove the agenda-setting process in the case of privatization policy in Kuwait?

2. What type of data was considered when approving this legislation?

\section{Formulation}

3. What are the perceived policy issues that privatization is intended to address?

4. What existing problem areas in Kuwait indicate the need for privatization initiatives?

5. How is privatization seen as a solution?

6. What were the privatization goals and expected outcomes when approving this legislation?

\section{Implementation}

7. What are the obstacles facing implementation of the privatization policy in the case of Kuwait?

8. What factors and elements are hindering the implementation of this policy? 
9. How effective is this policy in responding to the defined problem areas?

\section{Evaluation}

10. To what extent did the policymakers consider evaluation criteria when adopting the privatization policy?

11. Are there benchmarks?

12. What training and rehabilitation initiatives exist for personnel that will be directly involved in foreseeing implementation stages?

\section{Decision-making}

13. To what extent does decision-making in Kuwait follow any of the theoretical frameworks?

14. How did the decision-making process unravel in the case of privatization policy?

15. How does success look like?

\section{Focus Group Script}

Demographics

1. Name

2. Age

3. Marital status

4. Years of residency in Kuwait

5. Voting district

6. Occupation and sector

Agenda-setting

1. What factors and elements drove the agenda-setting process in the case of privatization policy in Kuwait?

2. How do issues gain dominance on the public agenda? 


\section{Formulation}

3. What problems does the privatization policy address?

4. What existing problem areas in Kuwait indicate the need for privatization initiatives?

\section{Implementation}

5. What are the obstacles facing implementation of the privatization policy in the case of Kuwait?

6. What factors and elements are hindering the implementation of this policy?

7. How effective is this policy in responding to the defined problem areas?

\section{Evaluation}

8. What training and evaluation initiatives exist for personnel that will be directly involved in foreseeing implementation stages?

\section{Decision-making}

9. To what extent is decision-making in Kuwait systematic?

10. How does success look like? 


\section{APPENDIX B}

In 2005, the World Economic Forum published the Global Competitiveness Index (GCI), which builds on the work of Klaus Schwab in 1979 and Xavier Sala-I-Martin in 2005. Figure 7 below lists the twelve pillars that can be further expanded to a list of one hundred and fourteen indicators of productivity and prosperity. The twelve pillars are further categorized into three subindexes of: 1) basic requirements, 2) efficiency enhancers, and 3) innovation and sophistication factors.

Figure 7

\section{The Global Competitiveness Index Framework}

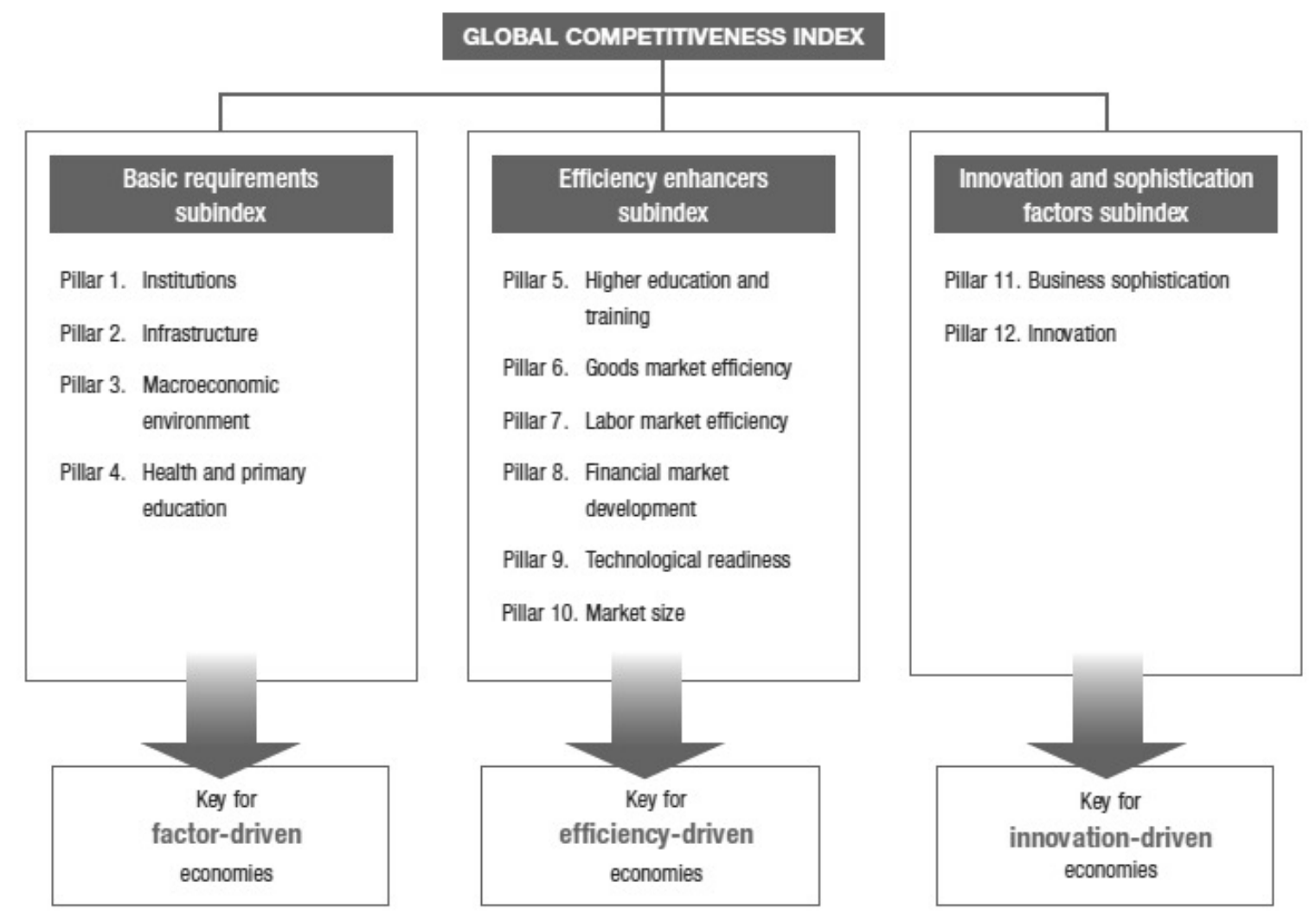

Source: The Global Competitiveness Report 2016-2017 of the World Economic Forum $(2016,5)$ 


\section{APPENDIX C}

\section{Economic Development Plan, State of Kuwait}

The economic development plan is the government's plan of action for the upcoming year. It is updated annually, with the primary objective of accomplishing the Emir's 2035 Vision for Kuwait. The secondary objectives are three: 1) human and social development, 2) economic development, and 3) administrative development. According to the Ministerial Law 11/2015, the General Secretariat of the Supreme Council for Planning and Development (GSSCPD) is the primary body that develops the final draft of the proposal. This final proposal is published every five years with annual reports released at the time of the budgetary cycle's closing date.

Site visits to the GSSCPD in Kuwait explained how the annual plan is collaborated. The GSSCPD requests all public bodies in the country to submit their individual development plans and budget proposals during a fixed time interval. Some of these projects are new proposals, while others are ongoing projects from the previous budget cycles. A high-level committee is formed at the MOP, comprised of members from the country's main agencies, such as the MOF and KIA. This committee reviews all the projects submitted in accordance to the country's financial capacities.

Project approvals from the MOP are then raised to the GSSCPD. The GSSCPD thereafter designs the annual economic development plan within the framework of the country's public policies. Since enactment of the law in 2010, privatization continues to resonate through the annual plans in terms of how the country can incorporate the private sector given the current policy structures in place. 
SHAHED ALTAMMAR

2009

2009

2012

2017
B.S., Business and Finance American University of Kuwait

Graduate Fellow, Foreign Affairs Georgetown University

M.A., Policy and Public Administration

University of Pennsylvania

Doctoral Candidate

Florida International University

\section{PRESENTATIONS}

Altammar, Shahed, (March, 2016). Human Action and Strategic Leadership. Presented at the Institute of Government at the University of Pennsylvania, Philadelphia, USA.

Altammar, Shahed, (March, 2015). Governance and Policy Development in the Wake of the Arab Spring. Presented at the American Society of Public Administration, Chicago, Illinois.

Altammar, Shahed, (May, 2014). Sustainable Development Goals and Human Rights in the Middle East. Presented at the Network of Institutes and Schools of Public Administration in Central and Eastern Europe, Budapest, Hungary.

Altammar, Shahed, (March, 2014). Building Partnerships: An Analysis of the French and US Experiences. Presented at the Ecole Nationale d'Administration, Miami, Florida.

Altammar, Shahed, (July, 2013). Capacity Development and Regional Integration. Presented at the meeting of board members of the Civil Service Commission in Kuwait, Kuwait City.

Altammar, Shahed, (June, 2013). Policy Approaches to Gender and Social Inclusion in Developing Countries. Presented at the Joint Congress of the International Association of Schools and Institutes of Administration (IASIA) and the International Institute of Administrative Sciences (IIAS), Bahrain, Kingdom of Bahrain. 